\author{
Monograph \\ urn:1sid:zoobank.org:pub:8DF89CFD-A549-4C69-8FBC-90EC8DEA9A66
}

\title{
New Ptiliidae (Coleoptera) from Sarawak in the spirit collection of the Natural History Museum, London
}

\author{
Michael DARBY \\ Department of Life Sciences, Natural History Museum, London, SW7 5BD UK. \\ Email: m.darby@nhm.ac.uk \\ urn:1sid:zoobank.org:author:FA87E30B-5023-4169-A47C-EB1EBC0A7EA1
}

\begin{abstract}
This paper is based on three collections of Ptiliidae from Sarawak totalling more than 2000 specimens made by staff and affiliates of the Natural History Museum, London, between March-July 1978. One new genus Niptella gen. nov with its type species Niptella gutta gen. et sp. nov. and 24 new species are described and figured: Sindosium collinsi sp. nov., Bambara hammondi sp. nov., Bambara subtortuosa sp. nov., Bambara tortuosa sp. nov., Erro brookei sp. nov., Cissidium globulum sp. nov., Cissidium longum sp. nov., Cissidium marshallae sp. nov., Cissidium pauxillum sp. nov., Cissidium subfoveolatum sp. nov., Cissidium triangulum sp. nov., Discheramocephalus nigritus sp. nov., Kuschelidium sarawakense sp. nov., Ptinella alisonae sp. nov., Acrotrichis acuta sp. nov., Acrotrichis belli sp. nov., Acrotrichis bidens sp. nov., Acrotrichis geiseri sp. nov., Acrotrichis globosa sp. nov., Acrotrichis hanskii sp. nov., Acrotrichis muluensis sp. nov., Acrotrichis plaga sp. nov., Storicricha resticula sp. nov., Storicricha umbella sp. nov. New records and information are provided for Dipentium latum Darby, 2019; Ptiliola semitaria Darby, 2018; Baeocrara minima Darby, 2019; Acrotrichis agricola Darby, 2019; Acrotrichis britteni Johnson, 1969; Acrotrichis bubalis Darby, 2019; Acrotrichis cognata (Matthews, 1877) and Acrotrichis cursitans (Nietner, 1856).
\end{abstract}

Keywords. Coleoptera, Ptiliidae, Sarawak, new species.

Darby M. 2019. New Ptiliidae (Coleoptera) from Sarawak in the spirit collection of the Natural History Museum, London. European Journal of Taxonomy 512: 1-50. https://doi.org/10.5852/ejt.2019.512

\section{Introduction}

This paper is based on collections of Ptiliidae from Sarawak (Malaysia) by N.M. Collins, March-May 1978 (103 specimens), I. Hanski, April-July 1978 ( \pm 1800 specimens), and P.M. Hammond and J. E. Marshall, May-July 1978 (105 specimens) in the spirit collection of the Natural History Museum, London (BMNH). All collectors worked in the Mulu World Heritage Area comprising some 52000 hectares of equatorial rainforest ranging from 50-2377 meters above sea level with many extensive cave systems and a geology including alluvial clays, sandstone and limestone formations all producing a large number of diverse habitats with many endemic species (Chung et al. 2000) (Fig. 1). Although many beetles have been recorded from Sarawak, there do not appear to be any specific records of Ptiliidae. 


\section{Material and methods}

Hanski and Collins confined their collecting to pitfall traps, those of the former mostly baited with fish and placed at different distances above sea level, whilst Hammond and Marshall concentrated on litter sampling.

After preliminary sorting to families, the insects were transferred into alcohol filled vials before being stored in a kilner jar in the Museum's spirit collection. All insects removed during the course of this study have either been mounted for pinning in the general collection or returned to the kilner jar. Recent research was carried out using a Leica M165C stereo microscope, an Olympus BH2 compound microscope fitted with Phase Contrast, and a Phenom scanning electron microscope. Images and measurements were made using the inbuilt software and cameras of the Phenom, a Leica DFC450 digital camera and associated software attached to the stereo microscope, and a Canon EOS 1100D digital camera with associated software attached to the Olympus microscope. The images were prepared for publication using Helicon stacking software and Corel Paint Shop Pro software care being taken not to alter or obscure any features. All specimens selected for detailed study were subsequently mounted on cards with dissections mounted in Euparal on acrylic sheet pinned with the dry mounted specimens and labels.

As set out in my previous papers the generic and species descriptions rely as much on figurative illustration and traditional morphometrics as on literal description, the specific intention being to convey as much information as possible for future workers without the need to study type material. Unless otherwise stated the habitus length measurement is taken from the front of the head to the apex of the elytra. Where several specimens are involved this is taken from the holotype or averaged from a series representing the smallest and largest judged by eye. Magnifications are those of the original SEM pictures. Colour is that of the mounted specimens, in all cases when not mounted and placed in transmitted light (i.e., in alcohol) most appear much paler. Genera are arranged alphabetically within tribes.

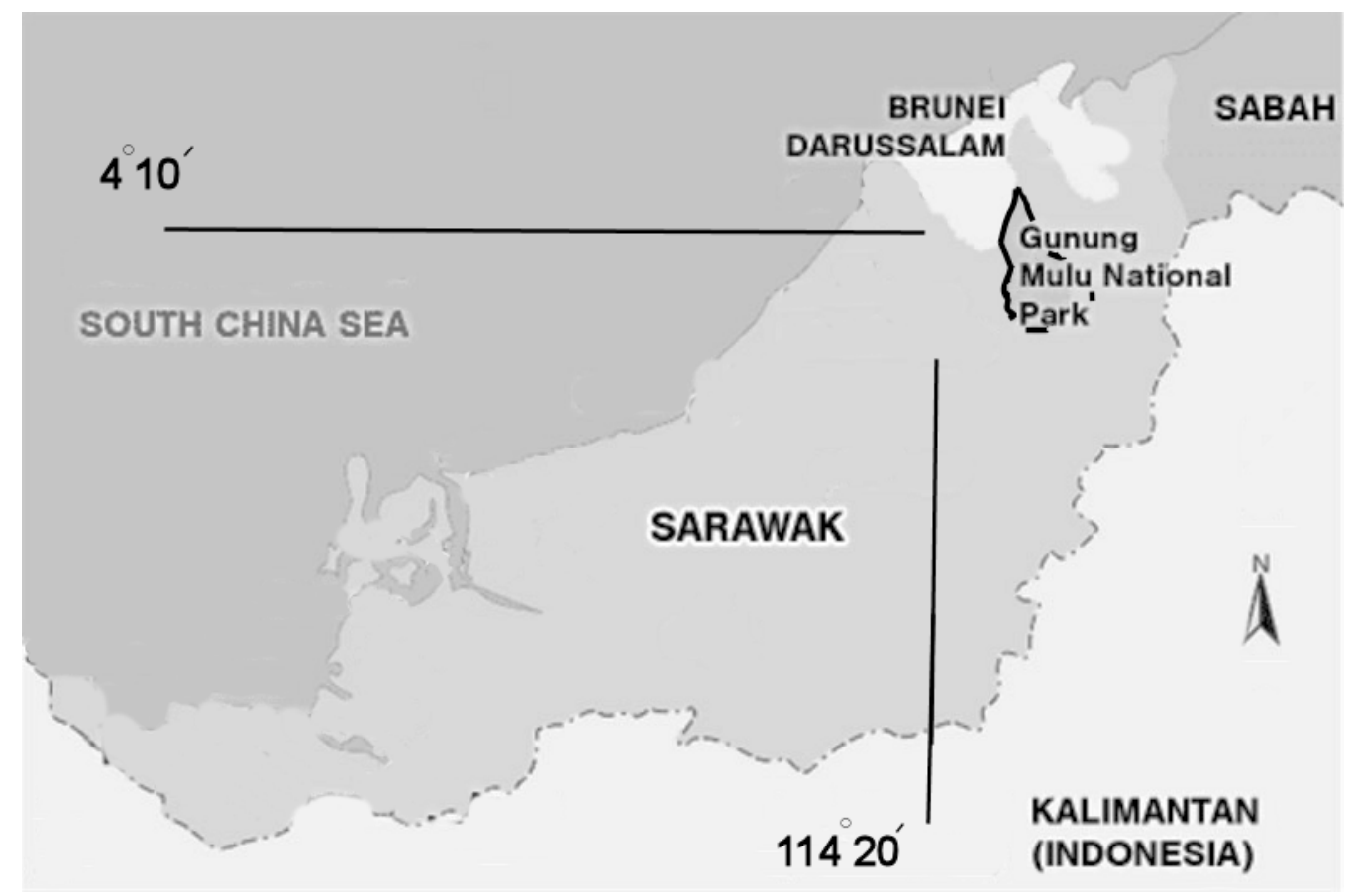

Fig. 1. Map of Sarawak showing location of the Gunung Mulu National Park where the Ptiliidae were collected. 
As explained below many of the specimens of Acrotrichis Motschulsky, 1848, Storicricha Johnson, 1988, Bambara Vuillet, 1911 and Ptiliola Haldeman, 1848 look very similar in alcohol and require dissection of the genitalia to determine species. This is clearly not possible given the number of specimens involved so that those not selected as holotypes and paratypes for pinning and dissection have been returned to the spirit collection determined where numbers permitted by association and without type designations.

I have had great difficulty in knowing whether the very faintly written locality information in many of the tubes referred to 'camp' or 'comp' and have rationalized all with comp on the basis that a camp site could be referred to as a type of compartment.

The institutional acronym BMNH used in the taxonomic treatment refers to the Natural History Museum, London (formerly British Museum: Natural History).

\section{Results}

\section{Subfamily, tribal and generic keys to the Ptiliidae of Sarawak}

\section{Subfamilies}

1. Metascutellum without lateral spurs

Ptiliinae

- Metascutellum with lateral spurs Acrotrichinae

\section{Tribes and genera of Ptiliinae}

1. Wing membrane without a clear medial constriction, metacoxae separated by a bifurcate extension of the metaventrum Ptenidiini (Sindosium Johnson, 2007)

- Wings with a clear median constriction and long peripheral setae

2. Small, flattened, yellow species with truncated elytra and widely separated metacoxae (usually found in corticular habitats)

Ptinellini (Niptella gen. nov. (Fig. 12A), Ptinella Motschulsky, 1844 (Fig. 13A))

- More rounded species without truncated elytra

3. Mesoventrum with a large spatulate plate, metacoxae separated by a bifurcate extension of the metaventrum (Fig. 11D)

- Without a mesoventral spatulate plate

4. Species with long legs and antennae clearly adapted for an active lifestyle ................................... 5

- Species with shorter antennae and legs

5. Antennomere XI with a medial constriction giving the appearance of a dumb-bell or hour-glass, mesoventrum without obvious perforations

Discheramocephalini (Cissidium Motschulsky, 1855)

- Antennomere XI without a medial constriction, pronotum with strongly sculpted linear foveae (Fig. 10B), mesoventrum clearly perforated

Discheramocepahlini (Discheramocephalus Johnson, 2007)

6. Small, yellow, fragile species, length $<0.7 \mathrm{~mm}$

- Larger, more robust species, length $>0.7 \mathrm{~mm}$

7. Metacoxae contiguous (Fig. 3A-C)

Ptiliini (Bambara Vuillet, 1911)

- Metacoxae separated by $\pm 1 / 5$ the width of the metaventrum (Fig. 5F)

Ptiliini (Ptiliola Haldeman, 1848) 
8. Mesoventral collar sharply pointed between the mesocoxae which are contiguous

Ptiliini (Erro Darby, 2017)

- Mesoventral collar square ended between the mesocoxae which are more widely separated

Ptiliini (Dipentium Johnson, 1982)

\section{Tribes and genera of Acrotrichinae}

1. Hind margin of the pronotum strongly sinuate before the hind angles which project backwards. Mesosternal collar curved posteriorly at humeri

Acrotrichini (Acrotrichis Motschulsky, 1848; Storicricha Johnson, 1988)

- Hind margin of pronotum much less markedly sinuate and the hind angles obtuse/right angled, mesosternal collar almost straight

.Nephanini (Baeocrara Thomson, 1859)

\section{Taxonomy}

Order Coleoptera Linnaeus, 1758

Family Ptiliidae Erichson, 1845

Subfamily Ptiliinae Erichson, 1845

Tribe Ptenidiini Flach, 1889

Genus Sindosium Johnson, 2007

Genus described on the basis of two species: S. foveatum Johnson, 2007 and S. opacipenne Johnson, 2007 from the Solomon Islands. An additional species S. bacchusi Darby, 2019 was subsequently described from Sabah (Darby 2019). The name is an anagram of Nossidium Erichson, 1845 to which genus it shows very close affinities particularly in the wing shape, male possession of parameres and the form of the meso- and metaventra.

\section{Sindosium collinsi sp. nov. urn:1sid:zoobank.org:act:E8C7E79C-4136-4C77-97DD-07373C1335D5}

Fig. 2

\section{Diagnosis}

Shares with S. foveatum the pair of sulci under the mesoventral collar but distinguished from that species by the foveolate pronotum without a clearly defined medial fovea and by the shorter pubescence. From S. opacipenne it may be distinguished by the foveolate mesoventrum and from S. bacchusi by the form of the hind angles of the pronotum lacking semi-circular incursions.

\section{Etymology}

Named after Nicholas M. Collins, the collector of the paratypes and of other Sarawak specimens.

\section{Type material}

\section{Holotype}

MALAYSIA-BORNEO • + ; Sarawak, $4^{\text {th }}$ Division, Gunung Mulu National Park; May-Aug. 1978; P.M. Hammond and J.E. Marshall leg., BM 1978-49; limestone forest litter; BMNH.

\section{Paratypes}

MALAYSIA-BORNEO $\bullet 1$ spec.; same data as for holotype; BMNH $\bullet 3$ specs (one example fragments only mounted as a slide); Sarawak; 200 m a.s.l.; 1978; N.M. Collins leg.; limestone forest, pitfalls; BMNH. 


\section{Description}

Size. Habitus (Fig. 2A), length $0.94 \mathrm{~mm}$.

CoLour. Elytra dark brown, pronotum and head yellowish brown, antennae and legs yellow. Pronotum and elytra with pale pubescence the setae arising from small foveolae (Fig. 2D).

HEAD. With scattered longer pubescence. Distance across eyes $0.27 \mathrm{~mm}$. Eyes prominent. Antennomeres III-XI, length $0.31 \mathrm{~mm}$. Mentum setae forming only two rows; submentum with a pair of long setae (Fig. 2C).

Pronotum. Length $0.24 \mathrm{~mm}$ width $0.41 \mathrm{~mm}$, with wide lateral borders and raised serrate margins, posterior border with raised margin (Fig. 2D).

ELYTRA. Length $0.56 \mathrm{~mm}$, width $0.48 \mathrm{~mm}$, undersides of lateral margins with a single row of setae.

VENTRUM. Proventrum narrow in front of procoxae, with rows of foveae along the anterior and posterior margins, coxal cavities open behind (Fig. 2C). Mesoventrum, without reticulation or pubescence, collar sloping posteriorly for a short distance onto lateral margins, without distinct humeri, with a narrow raised medial ridge extending posteriorly to raised, rounded projection, not extending between the mesocoxae, posterior margin of keel with a pair of deep fringed sulci (Fig. 2E). Mesocoxae separated by almost half their width (Fig. 2E). Metaventrum with scattered pubescence and strongly raised anterior margin between mesocoxae, posterior margin forming a narrow bifid projection between metacoxae, mesepiventral sutures apparent reaching posteriorly from mesocoxae to lateral margins. Wings of usual Sindosium type.

Female Genitalia. Spermatheca (Fig. 2B).

Male genitalia. Not known.
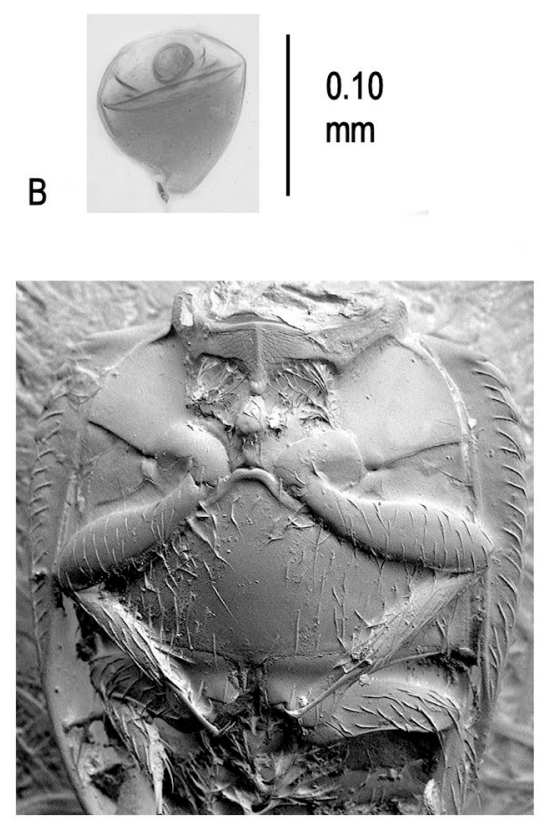

E

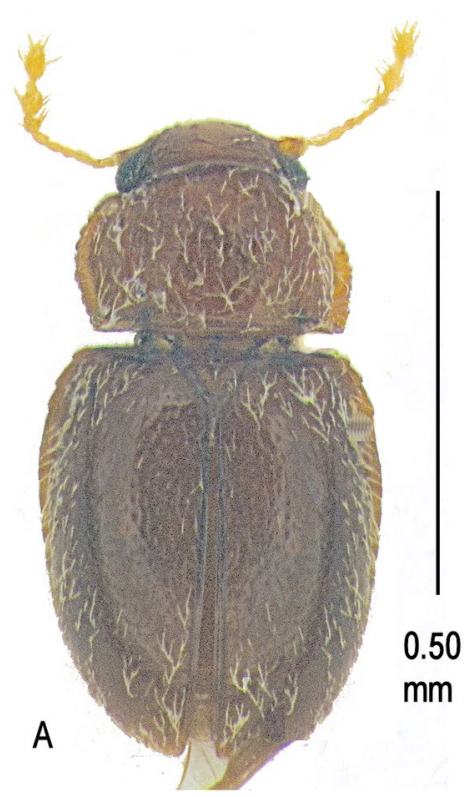

0.50
$\mathrm{~mm}$

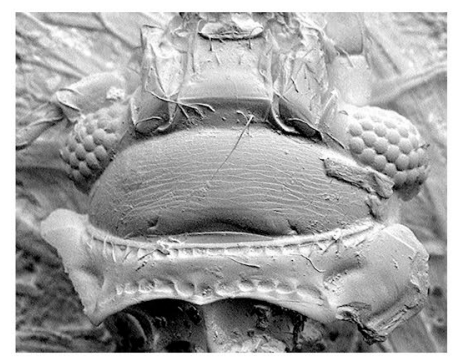

C

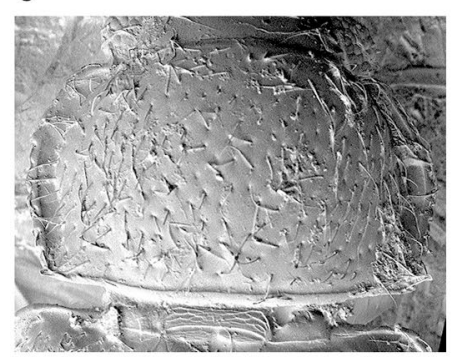

D

Fig. 2. Sindosium collinsi sp. nov. A. Habitus. B. Spermatheca. C. Ventral aspect of head and pronotum $\times 630$. D. Pronotum $\times 510$. E. Meso- and metaventra $\times 475$. 
Tribe Ptiliini Erichson, 1845

Genus Bambara Vuillet, 1911

Small, fragile and weakly sclerotised insects, widely distributed particularly in the tropics with many undescribed species. No published records from Sarawak. A careful study of the chaetotaxy of the head, legs, antennae, abdomen and other features failed to reveal the presence of any reliable differences to distinguish species. Similarly, no reliable features have been detected in the external skeleton. These findings correlate with those of Dybas (1966) and Johnson (1971) both confirming spermathecal differences as the best method of determining species. The use of elytral shape as used by the author in separating Madagascan Bambara has not proved to be helpful with these specimens, none of which possess elytra which are wider at, or close to, the humerus. No species were detected with a mesoventral collar extending onto the humeri as $B$. contorta Dybas, 1966 the only species in the genus recorded to date to exhibit this feature.

In dorsal view, species of Bambara are easily confused with some smaller, paler Acrotrichis and with species of Ptiliola, but are easily separated from the former by the longer elytra covering most of the abdomen and from the latter by the adjacent metacoxae separated only by the bifid extension of the metaventrum. Dimorphism involving blindness and aptery, similar to that exhibited by species of Ptinelliini, has been shown to be present in the genus (Darby 2014b) but was not detected in the Sarawak species.

\section{Bambara hammondi sp. nov. urn:1sid:zoobank.org:act:BBB2BBCB-2BB3-4D5F-996A-FF538DCFD659}

Fig. 3A, D

\section{Diagnosis}

Determined by the form of the spermatheca.

\section{Etymology}

Named after Peter Hammond, the collector of these specimens and of many other Sarawak species.

\section{Type material}

\section{Holotype}

MALAYSIA-BORNEO - + ; Sarawak, $4^{\text {th }}$ division, Gunung Mulu National Park, May-Aug. 1978; P.M. Hammond and J.E. Marshall leg., BM 1978-49; comp. 5 alluvial forest litter; BMNH.

\section{Paratype}

MALAYSIA-BORNEO • + ; same data as for holotype (mounted disarticulated on the slide); BMNH.

\section{Description}

Size. Habitus (Fig. 3A), length $0.65 \mathrm{~mm}$.

CoLour. Dark brown species, closely covered with very fine pale pubescence. Antennae very pale yellow almost translucent, antennomeres III-XI, length $0.23 \mathrm{~mm}$.

HEAD. Eyes small not prominent, distance across eyes $0.23 \mathrm{~mm}$.

Pronotum. Length $0.17 \mathrm{~mm}$, width $0.36 \mathrm{~mm}$, hind corners projected rearwards in dorsal view.

ELYTRA. Length $0.38 \mathrm{~mm}$, width $0.40 \mathrm{~mm}$. 
Female Genitalia. Spermatheca simple (Fig. 3D).

Male genitalia. Not known.

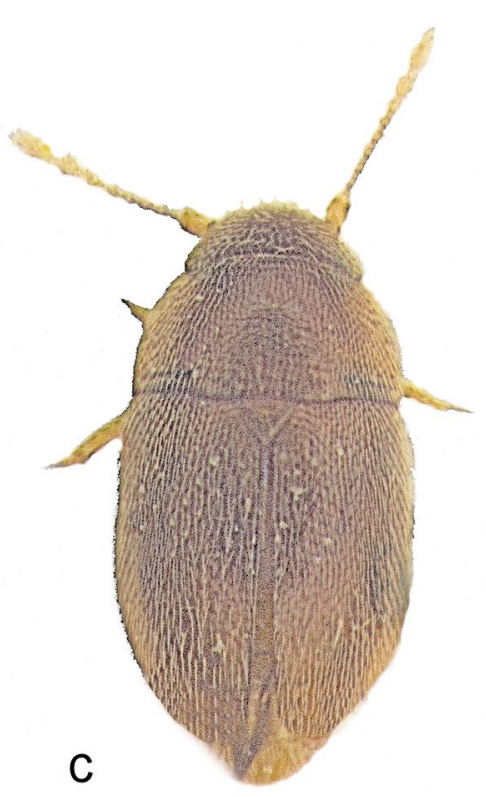

A
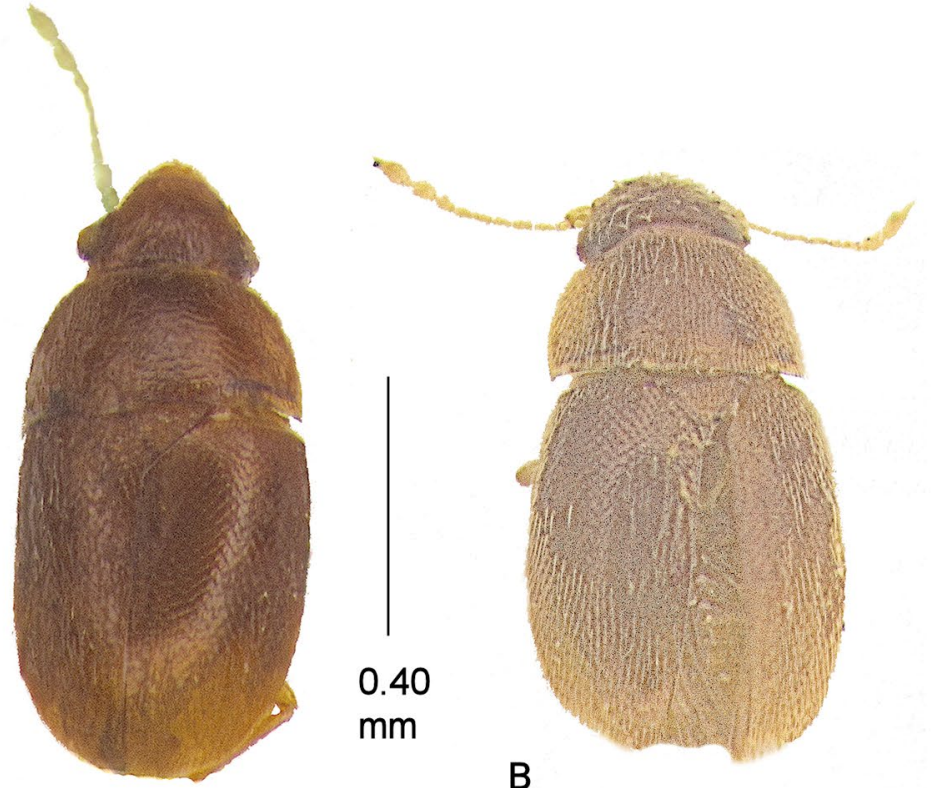

B

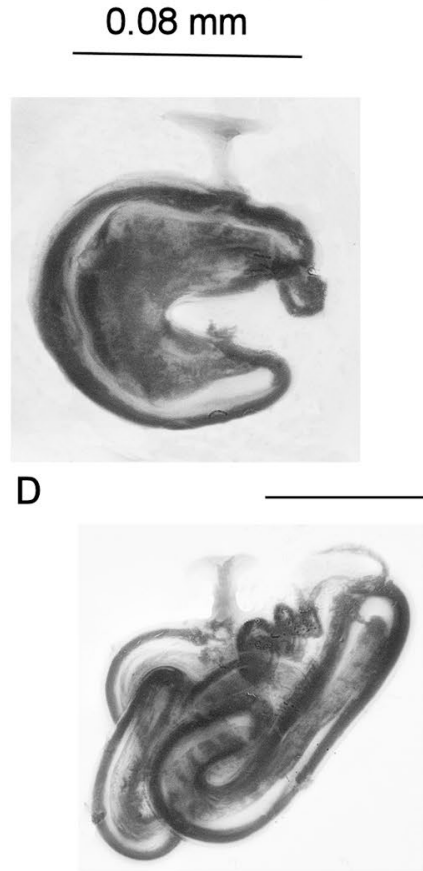

$\mathrm{Fa}$

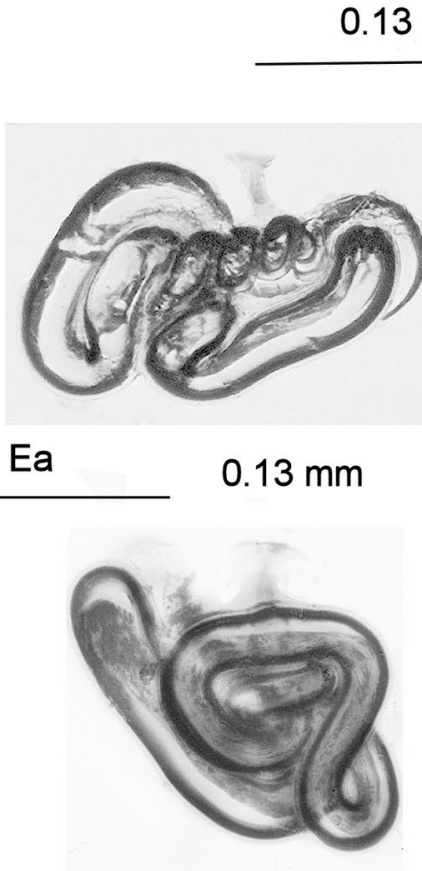

$\mathrm{Fb}$

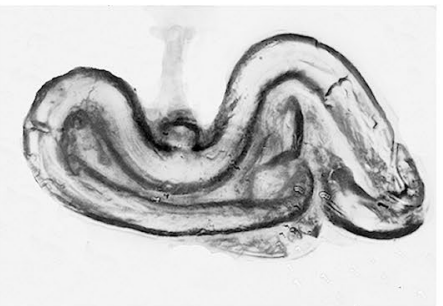

$\mathrm{Eb}$

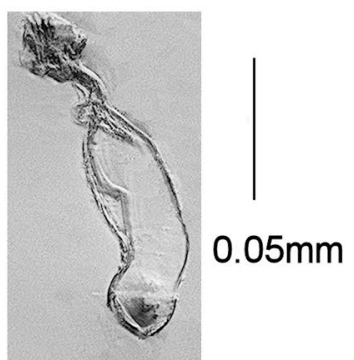

G

Fig. 3. A-C. Bambara spp., habitus. A. B. hammondi sp. nov. B. B. tortuosa sp. nov. C. B. subtortuosa sp. nov. D-F. Bambara spp., spermathecae. D. B. hammondi sp. nov. Ea-Eb. B. tortuosa sp. nov. FaFb. B. subtortuosa sp. nov. G. Bambara tortuosa sp. nov., aedeagus. 


\section{Bambara subtortuosa sp. nov. \\ urn:1sid:zoobank.org:act:D46EFC37-FA76-4684-8F8B-B773B8F59A48}

Fig. 3C, F

\section{Diagnosis}

Determined by the dark colouration and the form of the spermatheca which can only be confused with B. tortuosa sp. nov., but the 'corkscrew' in that species is longer and the coils arranged differently.

\section{Etymology}

Name recognises the close similarity of the spermatheca with that of $B$. tortuosa sp. nov.

\section{Type material}

\section{Holotype}

MALAYSIA-BORNEO • + ; Sarawak, $4^{\text {th }}$ division, Gunung Mulu National Park; ca $100 \mathrm{~m}$ a.s.1.; Mar.May 1978; I. Hanski leg., BM 1978-524; pitfall trap fish bait alluvial forest; BMNH.

\section{Paratypes}

MALAYSIA-BORNEO • 2 q $q$; same data as for holotype; BMNH.

\section{Description}

Size. Habitus (Fig. 3F), length $0.62 \mathrm{~mm}$.

Colour. Dark brown species, closely covered with short yellow pubescence. Antennae pale yellow, antennomeres III-XI, length $0.20 \mathrm{~mm}$.

HEAD. Eyes small, prominent, distance across eyes $0.20 \mathrm{~mm}$.

Pronotum. Length $0.15 \mathrm{~mm}$, width $0.31 \mathrm{~mm}$, hind corners projected rearwards in dorsal view.

ElYTRA. Length $0.39 \mathrm{~mm}$, width $0.32 \mathrm{~mm}$.

Female genitalia. Spermatheca robust with a small 'corkscrew' (Fig. 3Fa-3Fb).

MaLe GEnitalia. Males not known.

\section{Bambara tortuosa sp. nov. urn:1sid:zoobank.org:act:48770DC0-FE16-4AE6-B7A5-37A6E21EFB4C}

Fig. 3B, E, G

\section{Diagnosis}

Determined by the form of the spermatheca which can only be confused with B. subtortuosa sp. nov. (see below), but the 'corkscrew' in that species is smaller and the coils arranged differently.

\section{Etymology}

Name recognises the corkscrew-like appearance of part of the spermathecal duct.

\section{Type material}

\section{Holotype}

MALAYSIA-BORNEO • $q$; Sarawak, Gunung Mulu National Park; 200 m a.s.1.; 1978; N.M. Collins, BM leg.; limestone forest pitfalls; BMNH. 


\section{Paratypes}

MALAYSIA-BORNEO • 4 specs; Sarawak; 100-500 m a.s...; 26 Apr. 1978; I. Hanski leg., BM 1978524; pitfall trap fish bait, MD forest; $\mathrm{BMNH} \cdot 1 \mathrm{spec}$. (mounted disarticulated on the slide); same data as for preceding but slope 17-21; 500-800 $\mathrm{m}$ a.s.1.; Mar.-May 1978; BMNH $\bullet 3$ specs (2 dissected and mounted disarticulated on the slides); Sarawak, $4^{\text {th }}$ division, Gunung Mulu National Park; ca $150 \mathrm{~m}$ a.s.l.; Mar.-May 1978; I. Hanski leg., BM 1978-524; pitfall trap fish bait, kerangas extra; BMNH • 1 spec.; Sarawak, $4^{\text {th }}$ division, Gunung Mulu National Park; May-Aug. 1978; P.M. Hammond and J.E. Marshall leg., BM 1978-49; all litter sample below comp. 1; BMNH.

\section{Additional material}

$100+$ examples determined by association from various collections on the Gunung Mulu National Park including the above, retained in alcohol.

\section{Description}

SizE. Habitus (Fig. 3B), length $0.64 \mathrm{~mm}$.

Colour. Yellow brown species, closely covered with short yellow pubescence, dorsal surface clearly reticulate Antennae very pale yellow almost translucent, antennomeres III-XI, length $0.23 \mathrm{~mm}$.

HEAD. Eyes small not prominent, distance across eyes $0.21 \mathrm{~mm}$.

Pronotum. Length $0.17 \mathrm{~mm}$, width $0.31 \mathrm{~mm}$, hind corners not projected rearwards in dorsal view.

ELYTRA. Length $0.38 \mathrm{~mm}$, width $0.34 \mathrm{~mm}$.

Female genitalia. Spermatheca robust with part of the coils in the form of a corkscrew (Fig. 3Ea-Eb).

Male genitalia. Aedeagus (Fig. 3G).

\section{Remarks}

The commonest species in the Gunung Mulu National Park.

\section{Genus Dipentium Johnson, 1982}

Genus of eleven species of robust, strongly chitinised beetles recorded from various tropical and subtropical parts of the world, especially in the Madagascan and Indo-Australian regions. The genus includes species with pronota that are both wider than and the same width basally as the elytra. The form of the mesoventral collar with a narrow medial ridge extending posteriorly from the raised front margin is shared with Greensladella Johnson, 2007, Micridium Motschulsky, 1869 and Microptilium Matthews, 1872 in the Ptiliini, but they are much smaller and less robust species.

Dipentium latum Darby, 2019

\section{Material examined}

MALAYSIA-BORNEO -1 spec.; Sarawak, $4^{\text {th }}$ Division, Gunung Mulu National Park; May-Aug. 1978; P.M. Hammond and J.E. Marshall leg., BM 1978-49; alluvial forest litter near laboratory; BMNH - 1 spec.; Sarawak, Gunung Mulu National Park; 200 m a.s.1.; 1978; N.M. Collins leg.; limestone forest, pitfalls; BMNH. 


\section{Remarks}

These specimens do show some slight differences from the $D$. latum specimens from Sabah in the medially less densely foveolate metaventrum and in the shorter mesoventrum but these are not considered sufficient to designate them as a new species.

\section{Genus Erro Darby, 2017}

Genus of distinctive beetles erected to accommodate two species E. impiger Darby, 2017 and E. angolensis Darby, 2017 from Madagascar and Angola respectively. When describing the genus I declined to place it in a specific tribe simply stating that I considered it to be close to Discheramocephalini. (Darby 2017a). It is here placed in Ptiliini being the only suitable tribe available.

Erro brookei sp. nov.

urn:lsid:zoobank.org:act:D407C41C-3E0F-4A89-9B7C-081834E13585

Fig. 4

\section{Diagnosis}

Separated fom E. impiger and E. angolensis by the foveolate pronotum with acute hind angles.

\section{Etymology}

Named after James Brooke, the British explorer who became the first Rajah of Sarawak in 1841 and whose descendants continued to govern the kingdom until 1946.

\section{Type material}

\section{Holotype}

MALAYSIA-BORNEO - $\widehat{O}^{\text {; }}$; Sarawak, $4^{\text {th }}$ division, Gunung Mulu National Park, comp 5; May-Aug. 1978; P.M. Hammond and J.E. Marshall leg., BM 1978-49; alluvial forest litter; BMNH.

\section{Paratype}

MALAYSIA-BORNEO • $\widehat{\jmath}$; same data as for holotype; BMNH.

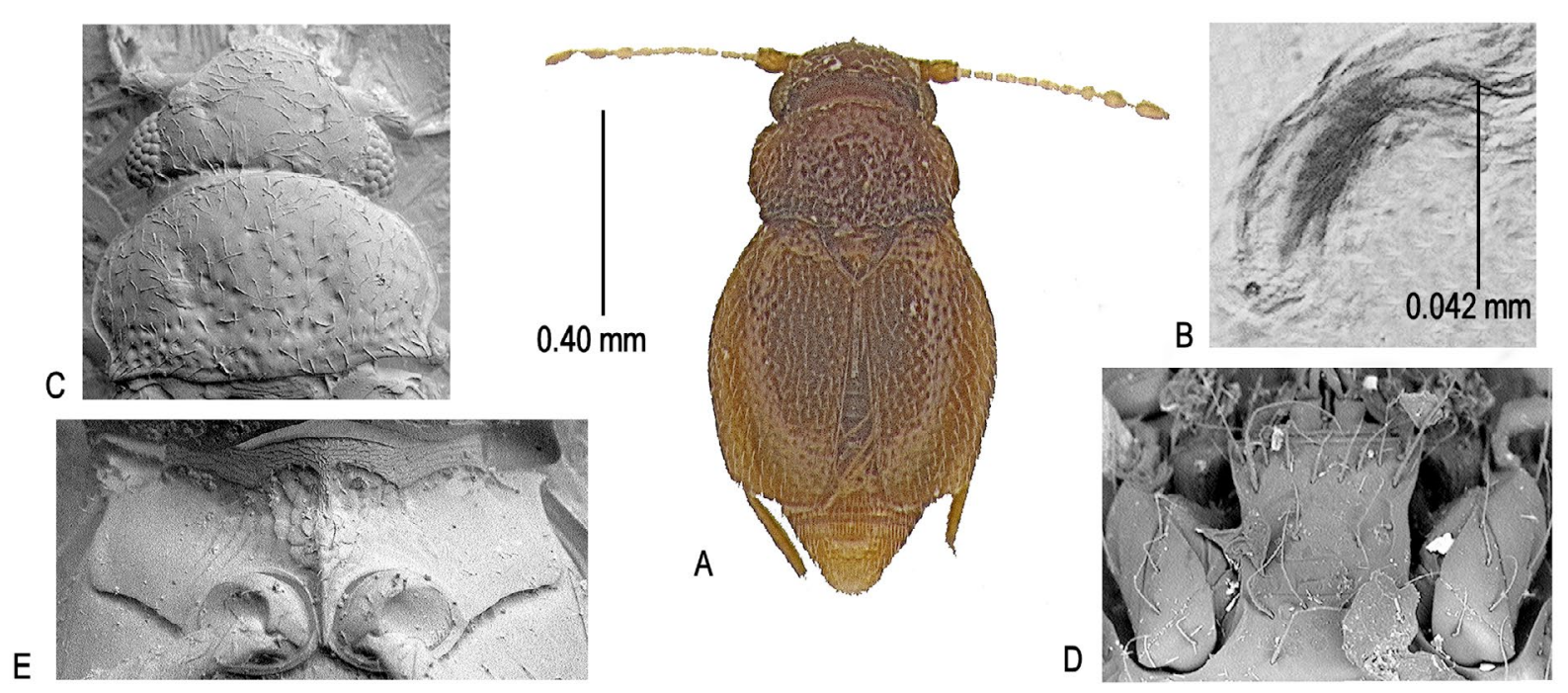

Fig. 4. Erro brookei sp. nov. A. Habitus. B. Aedeagus. C. Head and pronotum $\times 460$. D. Mentum and submentum $\times 1420$. E. Mesoventrum $\times 610$. 


\section{Description}

Size. Habitus (Fig. 4A), length $0.84 \mathrm{~mm}$ (including abdomen) $0.68 \mathrm{~mm}$ (excluding abdomen).

CoLour. Dark brown antennae and legs dusky yellow; dorsal surface pubescent.

HEAD. Antennomeres III-XI, length $0.34 \mathrm{~mm}$. Width across eyes $0.26 \mathrm{~mm}$. Head with a pair of foveolae on a level with the front of the eyes (Fig. 4C) and a longitudinal fossa behind the eyes. Mentum and submentum chaetotaxy (Fig. 4D).

Pronotum. Strongly foveolate in posterior third the foveolate area extending forward into two shallow depressions either side of disc, lateral margins strongly sinuate before acute hind angles, median portion of hind margin projected slightly backwards, length $0.21 \mathrm{~mm}$, width $0.33 \mathrm{~mm}$.

ELYTRA. Pubescence arising from foveolae but no additional depressions as on the pronotum, widest about middle, hind margin slightly truncated. length $0.43 \mathrm{~mm}$, width $0.43 \mathrm{~mm}$.

VENTRUM. Mesoventrum coarsely reticulate medially and with sharply pointed teeth at the anterior angles, collar sinuate with a narrow medial ridge extending posteriorly to a sharply pointed keel between the contiguous mesocoxae, posterior margins sinuate (Fig. 4E). Metaventrum pubescent without evidence of epiventral sutures, metacoxae separated by $\pm 1 / 4$ the width of the sclerite.

ABDOMEN. Pygidium margins barely rounded, tip slightly flattened without a central tooth.

Female GENitalia. Not known.

Male Genitalia. Aedeagus difficult to make out (Fig. 4B).

Genus Ptiliola Haldeman, 1848

Genus of very small beetles with six recognised species from Europe and Angola, and numerous undescribed species from the tropics. The dorsal and ventral characters provide minimal help in the separation of species although the chaetotaxy of the metaventrum was found useful by Vorst (2007) in distinguishing the European species P. flammifera Mlynarski, 1985.

Ptiliola semitaria Darby, 2018

Fig. 5

\section{Material examined}

MALAYSIA-BORNEO $\bullet 4$ specs ( 2 mounted disarticulated on the slides); Sarawak, $4^{\text {th }}$ division, Gunung Mulu National Park, 800-1700 m a.s.1.; 29 Apr. 1978; I. Hanski leg.; pitfall trap fish bait LMR forest slope 10-12; BMNH • 1 spec.; same data as for preceding; 100-500 m a.s.1.; Mar.-May 1978; MD forest; BMNH • 1 O; same data as for preceding; ca 100 m a.s.1.; Mar.-May 1978; alluv. forest; BMNH - 3 specs (1 mounted disarticulated on the slide); same data as for preceding; 800-1700 m a.s.1.; 29 Apr. 1978; slope 4-6; BMNH • 4 specs; same data as for preceding; 29 Apr. 1978; slope 7-9; BMNH.

\section{Additional material}

Many other examples determined by association retained in alcohol.

\section{Remarks}

In 2018, I described Ptiliola semitaria from Angola and illustrated alongside the figure of the spermatheca a second figure of a spermatheca of a specimen with a reduced length of duct between the pump and 
chamber which I suggested might be P. semitaria (Darby 2018). The spermathecae of Ptiliola from Sarawak include examples of similar ducts ranging in length between the two seeming to confirm that only one species is present. It is also worth noting that this form of spermatheca is similar to that of the European P. brevicollis (Matthews, 1860), but in that species the duct is shorter.

A figure of the spermatheca of the Sabah P. semitaria is included for reference (Fig. 5G) together with figures of the Sarawak insect (Fig. 5A-F).

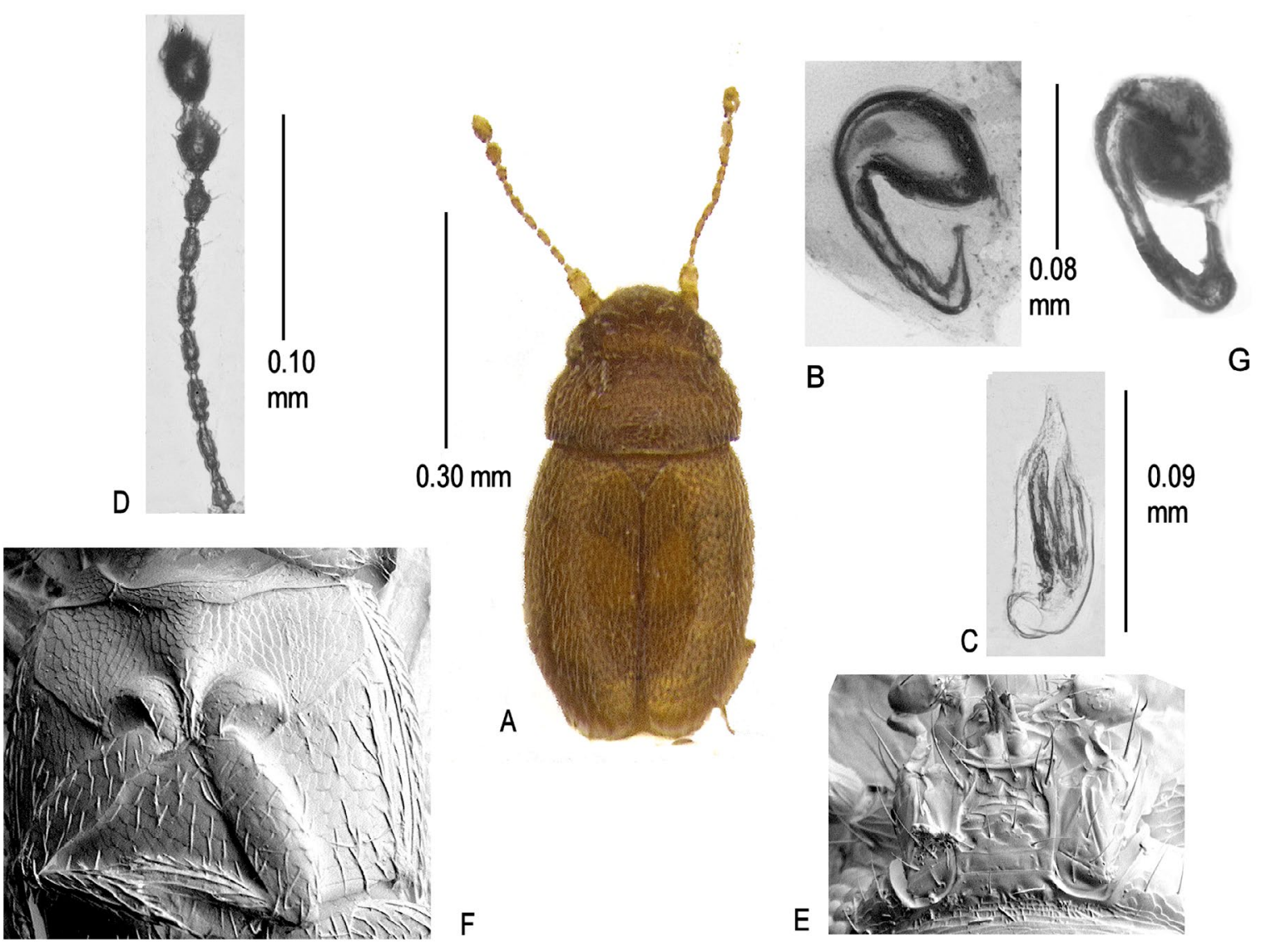

Fig. 5. Ptiliola semitaria Darby, 2018. A-F. Sarawak specimen. A. Habitus. B. Spermatheca. C. Aedeagus. D. Antennomeres II-XI. E. Mentum and submentum $\times 1680 ;$ F. Meso- and mentaventra $\times 695$. G. Angola specimen, spermatheca.

Tribe Discheramocephalini Grebennikov, 2009

Genus Cissidium Motschulsky, 1855

Genus of worldwide distribution particularly in the tropical regions with numerous species, many awaiting description. (Ongoing research by the author proposes to designate several subgenera.) The new species described below share the following features: body convex, pubescent, head finely margined at sides, eyes of male larger and more prominent than those of the female, antennae long, antennomere XI constricted medially producing a 'dumbell' or 'hour-glass' like figure easily mistaken for two separate antennomeres. Pronota broader than long, sides curved sometimes angulate with clearly marked raised margins, posterior margin with insinuation opposite scutellum. Elytra entire, longer than broad, generally 
leaving $2 / 3$ abdominal sclerites exposed. Prosternum very short anterior to procoxae which are contiguous. Mesosternum with a distinctive central keel reaching between the mesocoxae as a sharp point or wider, hind/side margin crenulate usually in posterior half, without clearly visible perforations [not withstanding that the tribe was erected to contain species with mesoventral perforations]. Metaventrum slightly longer than the mesoventrum, metacoxae separated by $\pm 1 / 3$ the width of the sclerite. Pygidium without teeth at apex. Dissections of the genitalia have not been attempted in some cases because external features are sufficient to determine the species and the risk of destruction to the specimens.

\section{Key to the Sarawak species of Cissidium}

1. Thorax without either foveae or distinct foveolae, mentum triangular (Figs 6F, 7B)

C. triangulum sp. nov.

- Thorax with either foveae or distinct foveolae, mentum broadly rectangular 2

2. Thorax with a series of foveae along the posterior margin the four central ones merging to form two larger ones (Fig. 7E) C. subfoveolatum sp. nov.

- Thorax foveolate but without foveae forming large depressions 3

3. Elytra without foveolae, larger more rounded species (Fig. 6C) C. globulum sp. nov.

- Elytra and pronotum foveolate 4

4. More rounded species, elytral foveolation less clearly marked than pronotum

C. marshallae sp. nov.

- Smaller, more parallel sided species 5

5. Lateral margins of mesoventrum straight forming a distinct angle with the posterior margin, mesoventral keel narrow, \pm parallel sided (Fig. 8D)

C. longum sp. nov.

- Lateral margins of mesoventrum rounded, thorax densely foveolate (Fig. 8B)

C. pauxillum sp. nov.

\section{Cissidium globulum sp. nov. urn:1sid:zoobank.org:act:39B85FCC-5554-497A-A152-6935FD0C75E2}

Figs $6 \mathrm{C}, 7 \mathrm{~A}, 8 \mathrm{~A}, 9 \mathrm{~A}$

\section{Diagnosis}

Identified by the globular appearance of the elytra and the shining dorsal surface frequently lacking pubescence. Might be confused with C. marshallae sp. nov. but that is a little smaller and more coarsely foveolate species.

\section{Etymology}

Refers to the rounded appearance of the elytra.

\section{Type material}

\section{Holotype}

MALAYSIA-BORNEO - + ; Sarawak, $4^{\text {th }}$ division, Gunung Mulu National Park; May-Aug. 1978; P.M. Hammond and J.E. Marshall leg., BM 1978-49; alluvial forest litter near laboratory; BMNH.

\section{Paratypes}

MALAYSIA-BORNEO • 1 spec.; same data as for holotype; BMNH $\bullet 1$ spec.; Sarawak, Gunung Mulu National Park; 200 m a.s.l.; 1978; N.M.Collins leg.; limestone forest pitfalls; BMNH • 3 specs (2 missing one elytron); Sarawak, $4^{\text {th }}$ division, Gunung Mulu National Park; May-Aug. 1978; P.M. Hammond and 
J.E. Marshall leg., BM 1978-49; limestone forest litter; BMNH • 2 specs; Sarawak, Mulu; 200 m a.s.l.; 1978; N.M. Collins leg.; limestone forest, pitfalls; BMNH • 1 spec.; Sarawak, $4^{\text {th }}$ division, Gunung Mulu National Park; May-Aug. 1978; P.M. Hammond and J.E. Marshall leg., BM 1978-49; base litter on hill[?]; BMNH - 1 spec.; Sarawak, $4^{\text {th }}$ division, Gunung Mulu National Park; May-Aug. 1978; P.M. Hammond and J.E. Marshall leg., BM 1978-49; comp. 5, alluvial forest litter; BMNH.

\section{Description}

SizE. Habitus (Fig. 6C), length $0.61 \mathrm{~mm}$.

Colour. Pronotum and head almost black, elytra dark brown, shining, pubescence, antennae and legs yellow.

HEAD. With a row of indistinctly formed foveolae on a level with the top of the eyes, antennomeres III-XI, length $0.25 \mathrm{~mm}$, mentum and submentum with \pm circular foveolae (not always clearly defined), wider anteriorly than posteriorly, anterior border rounded as Fig. 9C.

Pronotum. Length $0.19 \mathrm{~mm}$, width $0.29 \mathrm{~mm}$, foveolate throughout, two short carina at the base appearing only faintly or as a fusion of foveolae in some specimens, side margins angled medially, pubescence long, overlapping (but frequently abraded) (Fig. 7A).

Elytra. Length $0.43 \mathrm{~mm}$, width $0.40 \mathrm{~mm}$, smooth, evenly rounded, broadest at middle, pubescence long, overlapping (frequently very abraded).

VeNTRUM. Mesoventrum without pubescence, sharply angled at humeri, lateral margins with \pm two serrations only, keel parallel sided, narrow parallel sided between mesocoxae (Fig. 8A). Metaventrum with scattered pubescence, metacoxae separated by $1 / 3$ width of the sclerite.

\section{Remarks}

The pronotal sculpture is sometimes difficult to make out, side lighting is helpful.

Cissidium longum sp. nov. urn:1sid:zoobank.org:act:13E2EA7B-06BD-4758-9B6C-56BEDAD14F29

Figs $6 \mathrm{E}, 7 \mathrm{~B}, 8 \mathrm{D}$

\section{Diagnosis}

Identified by the form of the mesoventrum which is unlike any other Sarawak Cissidium.

\section{Etymology}

Refers to the form of the keel and lateral margins of the mesoventrum.

\section{Type material}

\section{Holotype}

MALAYSIA-BORNEO - + ; Sarawak, $4^{\text {th }}$ division, Gunung Mulu National Park; May-Aug. 1978; P.M. Hammond and J.E. Marshall leg., BM 1978-49; base comp, alluvial forest litter near laboratory; BMNH.

\section{Description}

Size. Habitus (Fig. 6E), length $0.67 \mathrm{~mm}$.

CoLour. Yellow, shining, antennae, legs and pubescence yellow. 
HeAd. Distance across eyes $0.20 \mathrm{~mm}$; antennomeres III-XI, length $0.37 \mathrm{~mm}$; mentum lateral margins sinuate, anterior border straight.

Pronotum. Length $0.19 \mathrm{~mm}$, width $0.29 \mathrm{~mm}$, foveolate throughout, foveolae forming short longitudinal depressions at base, side margins strongly sinuate, hind angles acute (Fig. 7B).

ELYTRA. Length $0.43 \mathrm{~mm}$, width $0.37 \mathrm{~mm}$, foveolate throughout, evenly rounded, broadest at middle.

Ventrum. Mesoventrum without pubescence, collar sharply angled posteriorly at humeri, angles projecting, lateral margins straight meeting posterior margin at rounded right angle, without serrations, keel flat topped and parallel sided, widening and stopping short of the collar, tapering slightly between

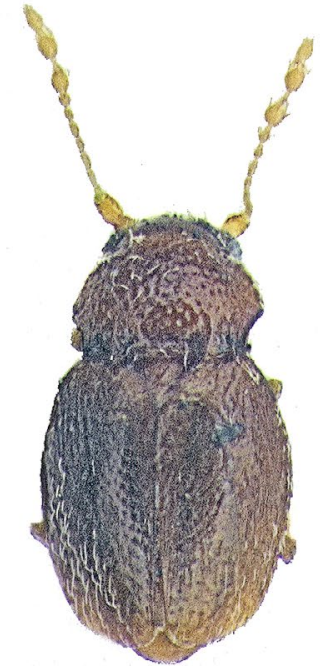

A

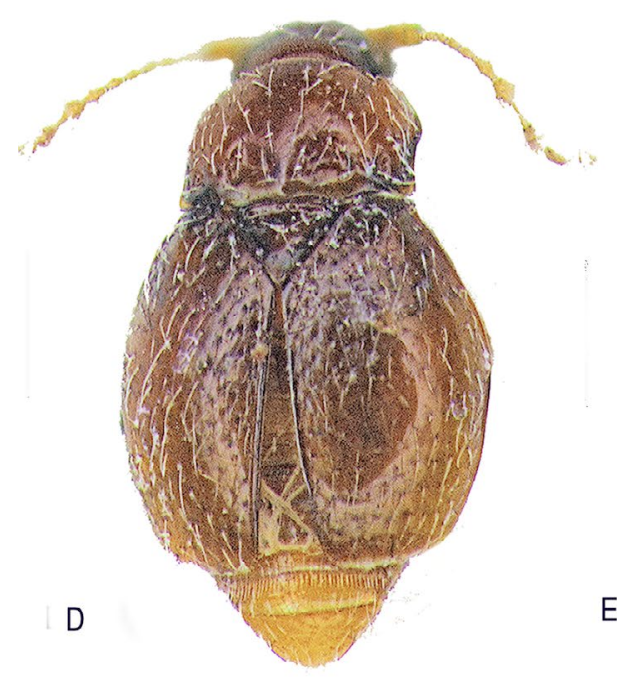

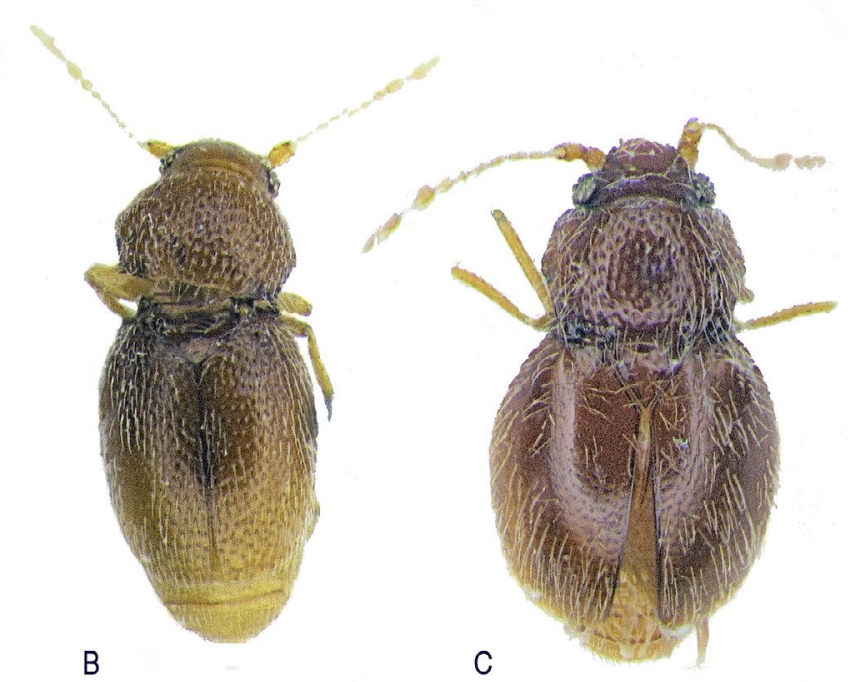

B

C

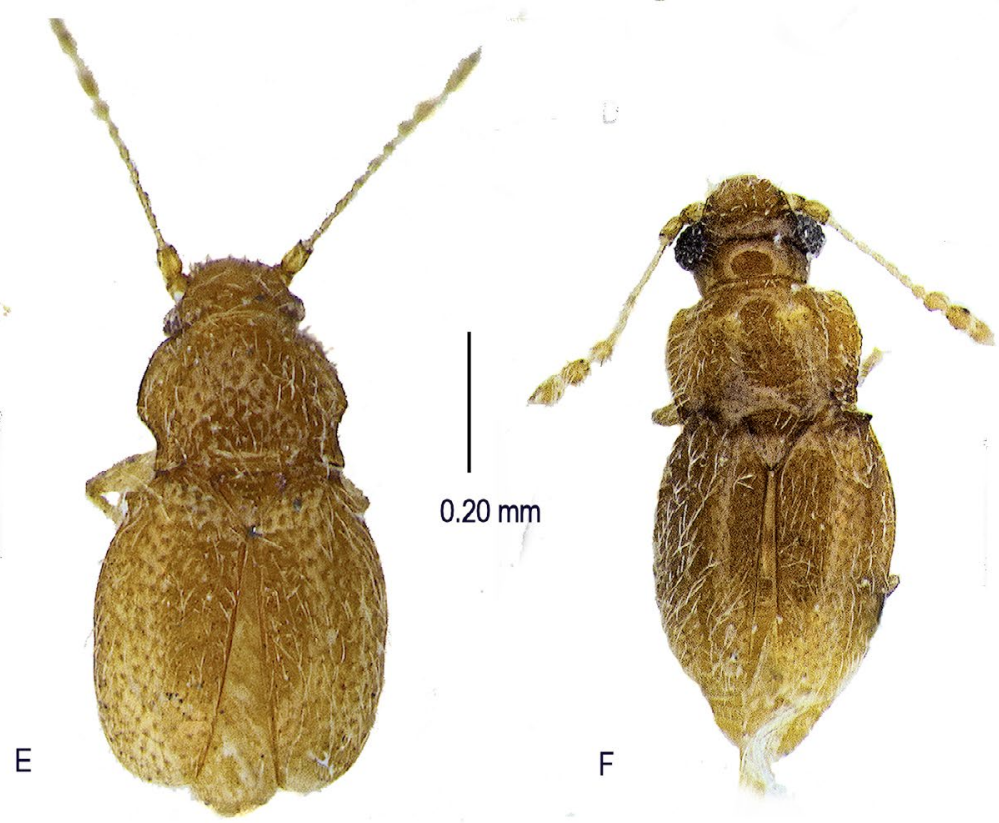

Fig. 6. Cissidium spp., habitus. A. C. marshallae sp. nov. B. C. pauxillum sp. nov. C. C. globulum sp. nov. D. C. subfoveolatum sp. nov. E. C. longum sp. nov. F. C. triangulum sp. nov. 
mesocoxae (Fig. 8D). Metaventrum with scattered pubescence, metacoxae separated by $1 / 3$ width of the sclerite.

\section{Remarks}

The mesoventral characters suggest that this species belongs either to a subgenus of Cissidium or to a separate genus.

\section{Cissidium pauxillum sp. nov. urn:1sid:zoobank.org:act:EAFD8663-FDE3-4910-8DE0-EB87E5F6C004}

Figs $6 \mathrm{~B}, 7 \mathrm{D}, 8 \mathrm{~B}$

\section{Diagnosis}

The densely foveolate pronotum, the sinuate border of the anterior margins of the keel and the sharply pointed keel between the mesocoxae distinguish this species.

\section{Etymology}

From the Latin adjective 'pauxillus', meaning 'small'.

\section{Type material}

\section{Holotype}

MALAYSIA-BORNEO - Sarawak, $4^{\text {th }}$ division, Gunung Mulu National Park; May-Aug. 1978; P.M. Hammond and J.E. Marshall leg., BM 1978-49; base comp, alluvial forest litter near laboratory; BMNH.

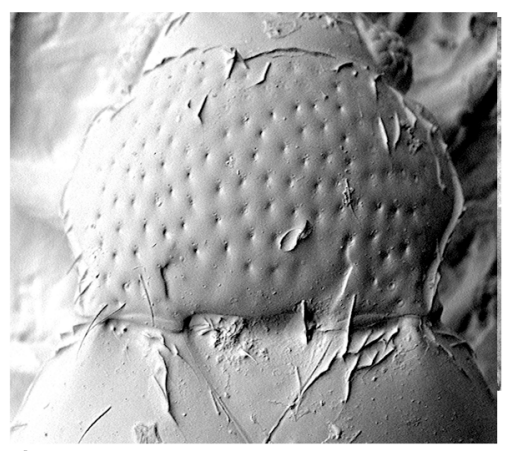

A

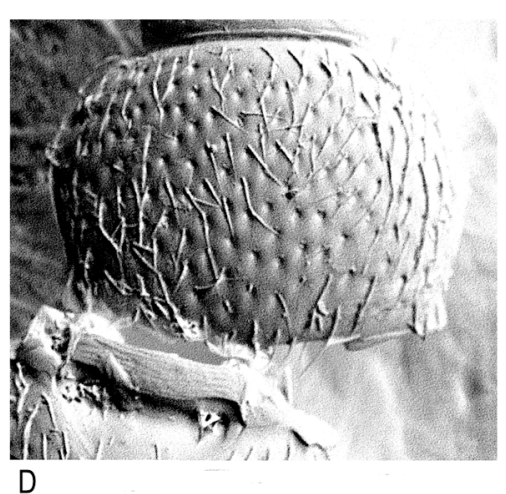

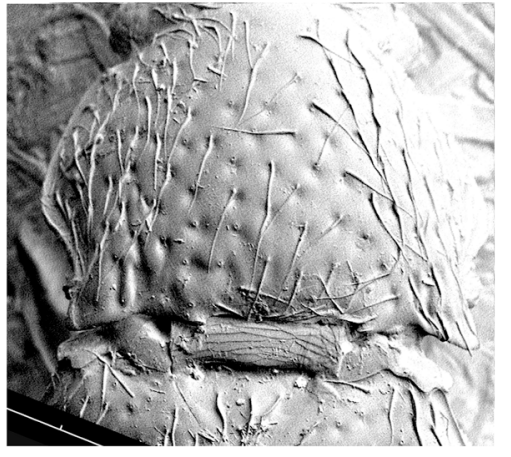

B

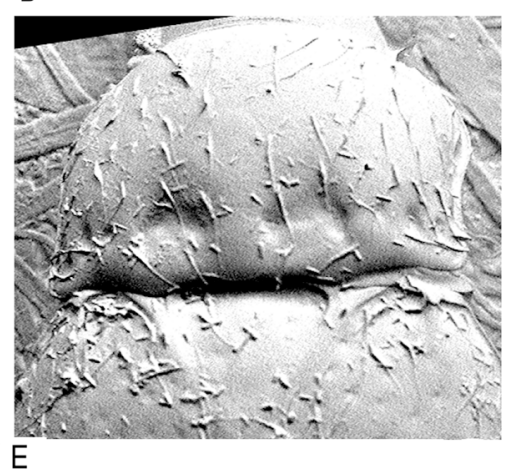

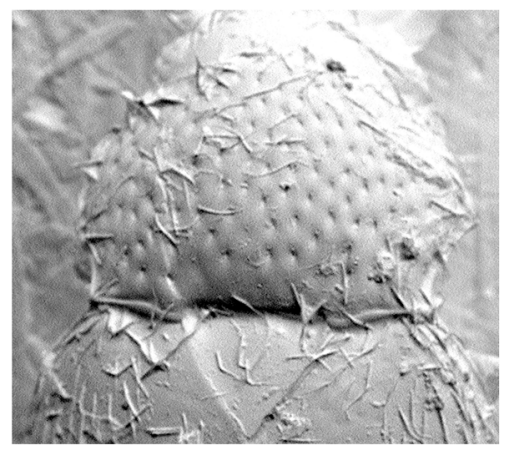

C

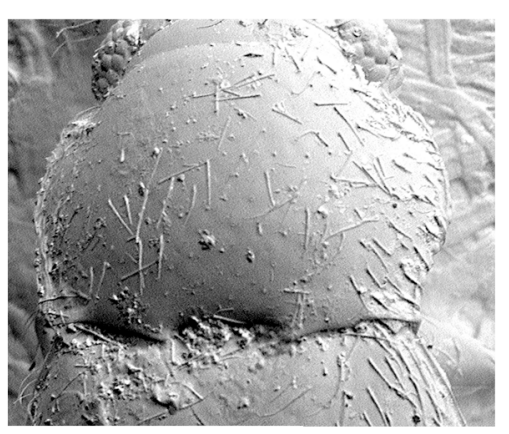

$\mathrm{F}$

Fig. 7. Cissidium spp., pronota. A. C. globulum sp. nov. $\times 450$. B. C. longum $\mathrm{sp}$. nov. $\times 590$. C. C. marshallae sp. nov. $\times 580$. D. . . pauxillum sp. nov. $\times 590$. E. C. subfoveolatum 5 . nov. $\times 485$. F. C. triangulum sp. nov. $\times 555$. 


\section{Description}

Size. Habitus (Fig. 6B), length $0.68 \mathrm{~mm}$.

CoLour. Yellow, antennae, legs and pubescence paler yellow.

HEAD. Distance across eyes $0.18 \mathrm{~mm}$; antennomeres III-XI, length $0.25 \mathrm{~mm}$; mentum widest anteriorly, anterior margin straight.

Pronotum. Length $0.17 \mathrm{~mm}$, width $0.27 \mathrm{~mm}$, densely foveolate and pubescent throughout, side margins evenly curved, hind angles right angled (Fig. 7D).

ELYTRA. Length $0.37 \mathrm{~mm}$, width $0.30 \mathrm{~mm}$, foveolate and pubescent throughout, evenly rounded, broadest at middle.

VENTRUM. Mesoventrum short, without pubescence, humeri with sharply projecting angles, lateral margins rounded to mesocoxae, serrate throughout, keel lateral margins sharply pointed with a sharply pointed posterior projection between the mesocoxae (Fig. 8B). Metaventrum with scattered pubescence, posterior margin between metacoxae concave, metacoxae separated by $\pm 1 / 3$ width of the sclerite.

\section{Cissidium marshallae sp. nov. urn:1sid:zoobank.org:act:9C826FB6-7885-4390-AF45-A6E5215FA683 \\ Figs $6 \mathrm{~A}, 7 \mathrm{C}, 8 \mathrm{C}$}

\section{Diagnosis}

Easily confused with $C$. globulum sp. nov., but $C$. marshallae sp. nov. is a little smaller, more coarsely sculpted insect, the elytra in particular more distinctly foveolate.

\section{Etymology}

Named after the collector, Jane Marshall.

\section{Type material}

\section{Holotype}

MALAYSIA-BORNEO - Sarawak, $4^{\text {th }}$ division, Gunung Mulu National Park; May-Aug. 1978; P.M. Hammond and J.E. Marshall leg., BM 1978-49; comp 5, alluvial forest litter; BMNH.

\section{Paratype}

MALAYSIA-BORNEO - 1 spec. (mounted disarticulated on the slide); same data as for holotype; BMNH.

\section{Description}

Size. Habitus (Fig. 6A), length $0.58 \mathrm{~mm}$.

CoLour. Dark brown, antennae, legs and pubescence yellow.

HEAD. Distance across eyes $0.19 \mathrm{~mm}$; antennomeres III-XI, length $0.29 \mathrm{~mm}$; mentum widest anteriorly, anterior margin curved.

Pronotum. Length $0.16 \mathrm{~mm}$, width $0.26 \mathrm{~mm}$, foveolate throughout, foveolae forming short longitudinal depressions at base, side margins sinuate, hind angles right angled (Fig. 7C). 
ELYTRA. Length $0.40 \mathrm{~mm}$, width $0.35 \mathrm{~mm}$, foveolate throughout, evenly rounded, broadest at middle.

VENTRUM. Mesoventrum without pubescence, humeri with sharply projecting angles, lateral margins rounded to mesocoxae with $2 / 3$ serrations, keel broad, parallel sided until narrowing sharply between mesocoxae (Fig. 8C). Metaventrum with scattered pubescence on the disc, metacoxae separated by $\pm 1 / 3$ width of the sclerite.

\section{Cissidium subfoveolatum sp. nov. urn:1sid:zoobank.org:act:A0D282BF-B3E0-45D4-8FC2-814F8202B9F7}

Figs $6 \mathrm{D}, 7 \mathrm{E}, 8 \mathrm{E}$

\section{Diagnosis}

The pronotal foveae distinguish this species from all others on Sarawak. From C. foveolatum Johnson, 1982 from New Zealand, which has similar large foveae on the pronotum, it may be distinguished by the more sinuate margins of the pronotum, the lack of a deep medial fovea on the forehead between the eyes and the wider keel between the mesocoxae.

\section{Etymology}

Refers to the large foveae on the pronotum.

\section{Type material}

\section{Holotype}

MALAYSIA-BORNEO $~+q$ (mounted ventral side uppermost); Sarawak, $4^{\text {th }}$ division, Gunung Mulu National Park; May-Aug. 1978; P.M. Hammond and J.E. Marshall leg., BM 1978-49; comp 5, alluvial forest litter; BMNH.

\section{Description}

Size. Habitus (Fig. 6D), length $0.89 \mathrm{~mm}$.

CoLour. Dark brown, antennae, legs and pubescence yellow.

HEAD. Distance across eyes $0.23 \mathrm{~mm}$; antennomeres III-XI, length $0.39 \mathrm{~mm}$; mentum parallel sided the lateral margins with slight insinuation, submentum with 4 long setae.

Pronotum. Length $0.22 \mathrm{~mm}$, width $0.32 \mathrm{~mm}$, with scattered pubescence and a row of foveae along the posterior margin, the four medial ones tending to form two large ones, side margins sinuate before the acute hind angles (Fig. 7E).

ELYTRA. Length $0.49 \mathrm{~mm}$, width $0.55 \mathrm{~mm}$, pubescent, shallowly foveolate, sides evenly rounded, broadest just before middle. Mesoventrum without pubescence, humeri with sharply projecting angles, lateral margins almost straight before turning to meet mesocoxae, each with $2 / 3$ serrations, keel parallel sided in posterior half widening slightly between the mesocoxae (Fig. 8E).

VENTRUM. Metaventrum with scattered pubescence, posterior margin with two sharp points at corners, metacoxae separated by $1 / 3$ width of the sclerite.

Fenale genitalia. Spermatheca globular. 


\section{Cissidium triangulum sp. nov.}

urn:Isid:zoobank.org:act:A30AC317-C75D-4534-8360-F895711D5285

Figs $6 \mathrm{~F}, 7 \mathrm{~F}, 8 \mathrm{~F}, 9 \mathrm{~B}$

\section{Diagnosis}

The triangular shape of the mentum distinguishes this species from all others.

\section{Etymology}

Refers to the form of the mentum.
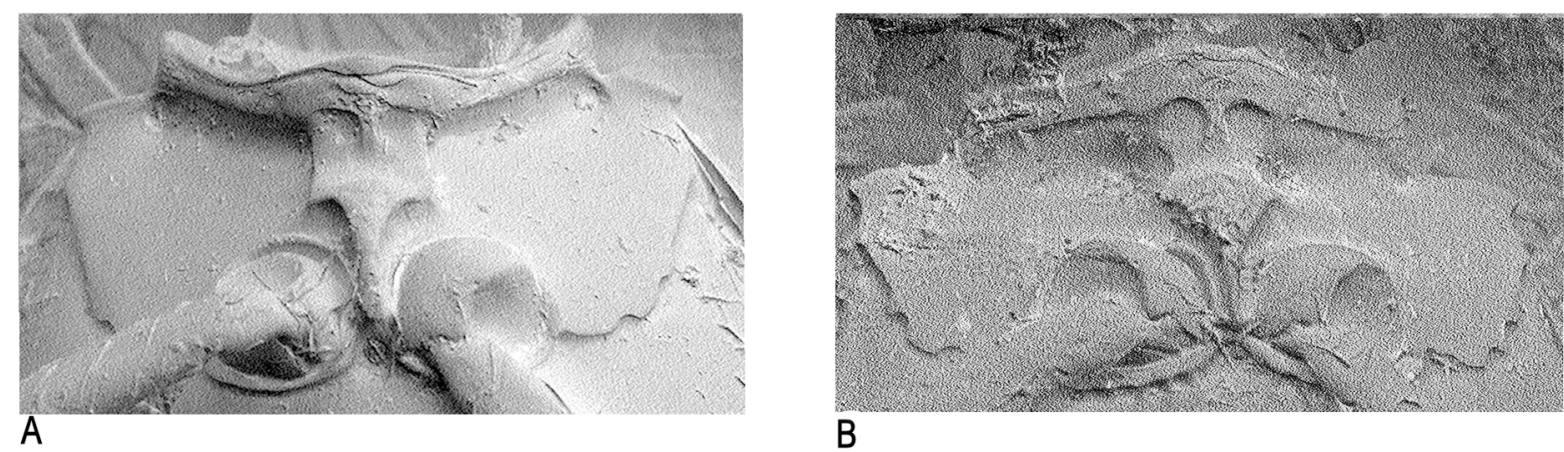

\section{B}
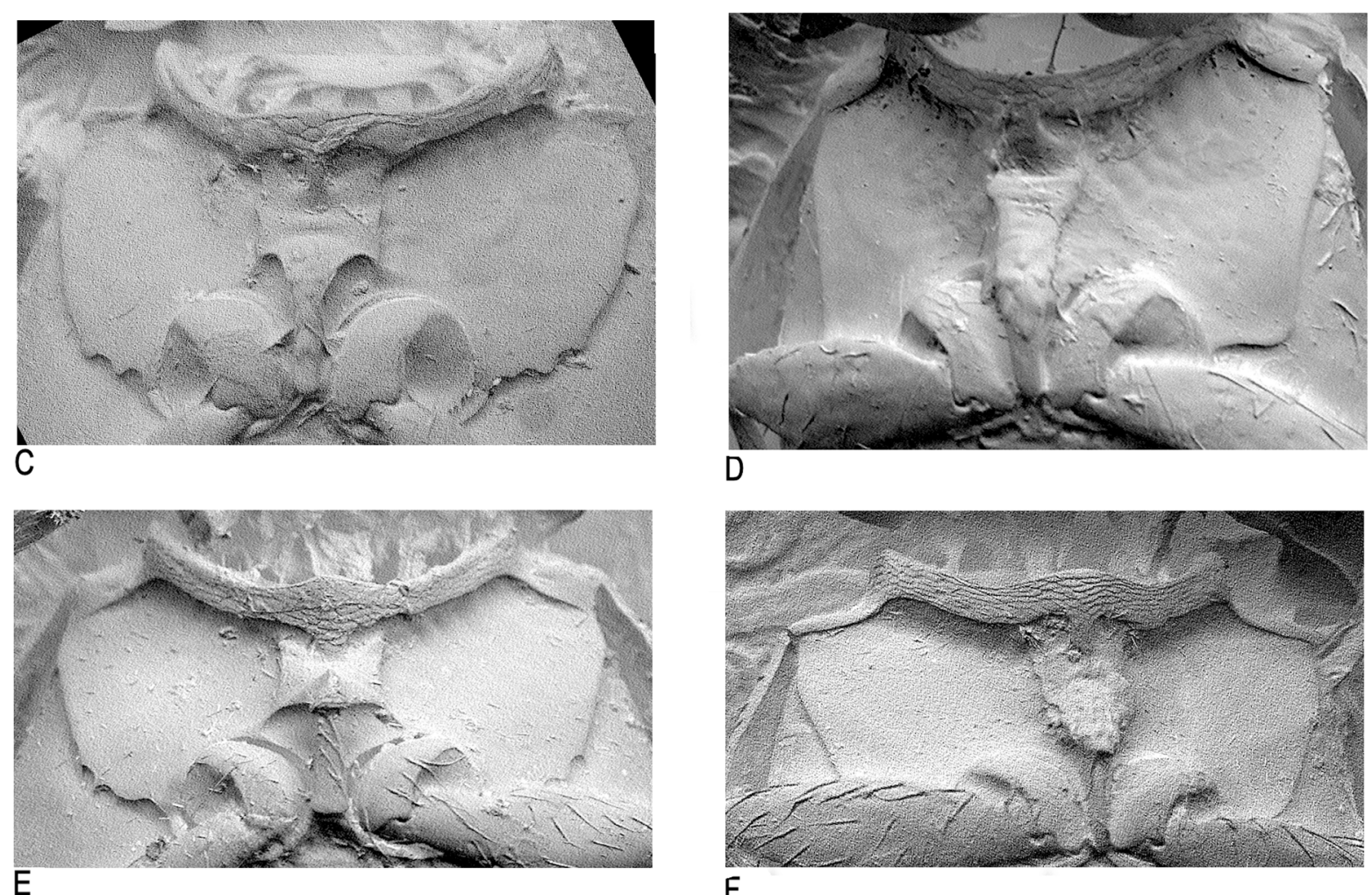

$\mathrm{F}$

Fig. 8. Cissidium spp., mesoventra. A. C. globulum sp. nov. $\times 470$. B. C. pauxillum sp. nov $\times 725$. C. C. marshallae sp. nov $\times 335$. D. C. longum sp. nov. $\times 450$. E. C. subfoveolatum $\mathrm{sp}$. nov. $\times 455$. F. C. triangulum sp. nov. $\times 575$. 


\section{Type material}

\section{Holotype}

MALAYSIA-BORNEO • Sarawak, Mulu; Mar. 1978; N.M. Collins leg.; pitfalls in alluvial forest; BMNH.

\section{Paratypes}

MALAYSIA-BORNEO • 1 spec.; same data as for holotype but 13 Mar. 1978; BMNH • 1 spec.; Sarawak, $4^{\text {th }}$ division, Gunung Mulu National Park; May-Aug. 1978; P.M. Hammond and J.E. Marshall leg., BM 1978-49; base comp litter around long house; BMNH.

\section{Description}

Size. Habitus (Fig. 6F), length $0.79 \mathrm{~mm}$.

CoLour. Elytra dark brown, pronotum and head yellow brown, antennae, legs, dorsal surface covered with long yellow pubescence.

HeAd. Distance across eyes $0.22 \mathrm{~mm}$; antennomeres III-XI, length $0.31 \mathrm{~mm}$; mentum triangular the anterior margin much longer than the basal, stipes also triangular, broadest at base (Fig. 9B).

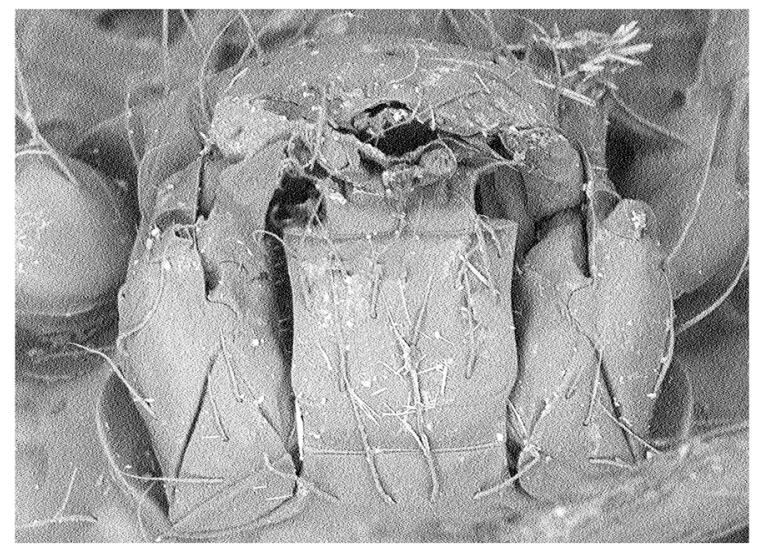

A

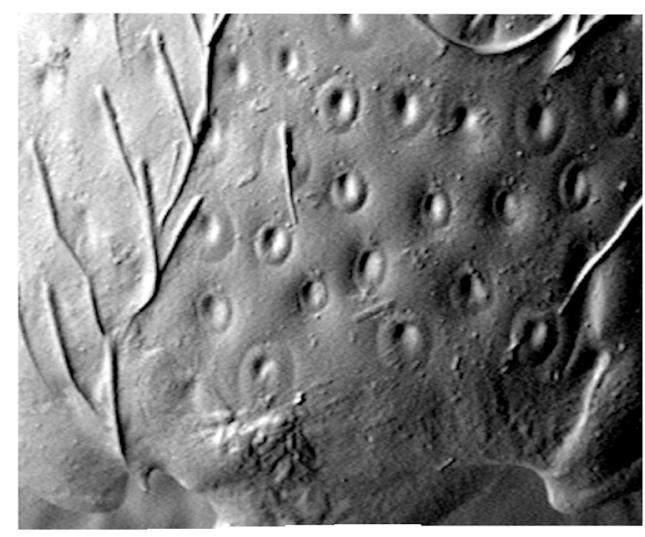

C

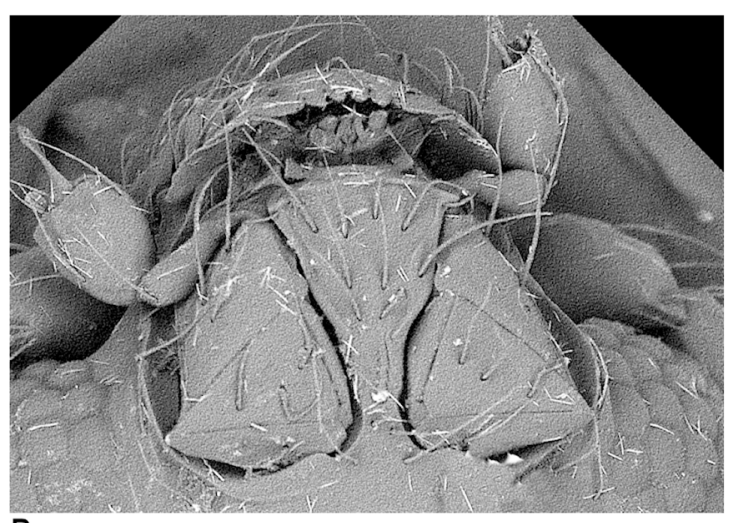

B

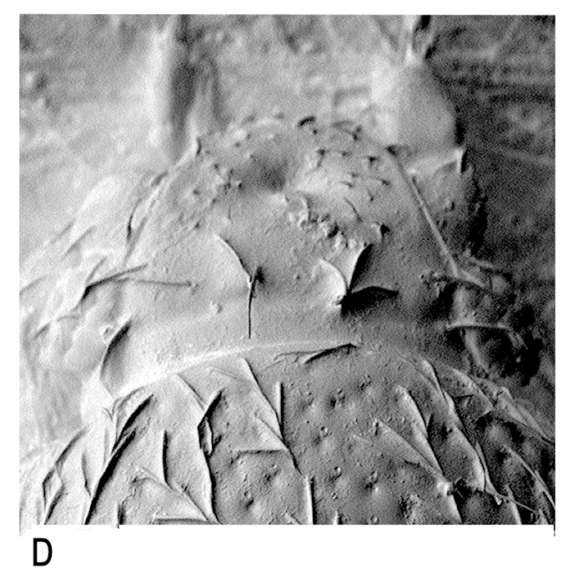

Fig. 9. Cissidium spp., menta. A. C. globulum sp. nov. $\times 1400$. B. C. triangulum sp. nov. $\times 1200$. C. Indeterminate Cissidium showing foveolae on pronotum $\times 1400$. D. Indeterminate Cissidium showing fovea on head $\times 575$. 
Pronotum. Length $0.19 \mathrm{~mm}$, width $0.28 \mathrm{~mm}$, shallowly foveolate, sides straight before right angled hind angles, disc without pubescence (Fig. 7F).

ELYTRA. Length $0.41 \mathrm{~mm}$, width $0.34 \mathrm{~mm}$, pubescent, shallowly foveolate, sides evenly rounded, broadest before middle.

VentRUM. Mesoventrum without pubescence, collar extending onto humeri without a terminal tooth, lateral margins almost straight before turning to meet mesocoxae, keel becoming rugose before narrowing to a point between the mesocoxae (Fig. 8F). Metaventrum with scattered pubescence throughout, posterior margin between metacoxae with two sharp points at corners, metacoxae separated by $1 / 4$ width of the sclerite.

\section{Remarks}

The form of the mentum and the mesoventral characters suggest that this species belongs either to a subgenus of Cissidium or to a separate genus.

\section{Cissidium spp.}

Several other species of Cissidium were also present in the material as fragments, one with a foveate head (Fig. 9D), another with ringed pronotal foveolae (Fig. 9C). These have not been considered complete enough to be described as new or determined as existing species.

Genus Discheramocephalus Johnson, 2007

Fifteen species have been described to date from Madagascar, Peru, Solomon Islands, Indonesia and Africa, and Johnson stated that he had also seen specimens from Brazil and Sri Lanka (Johnson 2007).

Discheramocephalus nigritus sp. nov. urn:1sid:zoobank.org:act:9FAADB43-B9A8-4B23-8223-16A129D2D088

Fig. 10

\section{Diagnosis}

Easily distinguished from all other Ptiliidae in Sarawak by the longitudinal foveae on the pronotum, and by the pair of deep sulci on abdominal ventrite VIII (most easily seen in dissections but not showing in Fig. 10F).

\section{Etymology}

Named after the Latin adjective 'niger', meaning 'dark', and referring to the insect's colouration.

\section{Type material}

\section{Holotype}

MALAYSIA-BORNEO • Sarawak, $4^{\text {th }}$ division, Gunung Mulu National Park; 800-1700 m a.s.1.; 26 Apr. 1978; I. Hanski leg., BM 1978-524; pitfall trap fish baited, LMR forest slope 4-6; BMNH.

\section{Description}

Size. Habitus (Fig. 10A), length $0.55 \mathrm{~mm}$.

Colour. Almost black, shining, antennae and legs dusky yellow. 
HEAD. With a deep transverse fossa behind the eyes extending laterally to the ventral surface and a group of setae in clearly defined foveae behind each eye (Fig. 10D). Antennomeres III-XI, length $0.21 \mathrm{~mm}$. Distance across eyes $0.17 \mathrm{~mm}$.

Pronotum. Length $0.12 \mathrm{~mm}$, width $0.19 \mathrm{~mm}$, with a pair of longitudinal foveae on the disk and another pair close to the lateral margins, in between these two much smaller foveae close to the posterior margin on each side (Fig. 10B). Scutellum with a sharp central keel (Fig. 10E).

ElYTRA. Length $0.33 \mathrm{~mm}$, width $0.27 \mathrm{~mm}$.

Ventrum. Proventrum depressed in front of procoxae and with raised angular humeri, extending posteriorly. Mesoventrum with a broad strongly reticulated medial keel and concave lateral margins before posterior termination, keels present extending to sides of mesocoxae, mesocoxae separated by their width, posterior margins obliterated. Metaventrum with scattered pubescence, anterior margins extending in form of a lobe between the mesocoxae, metacoxae almost adjacent.

ABDOMEn. Depressed laterally apparently for reception of metatibiae and tarsi, first visible segment with a serrated posterior margin, ventrite VIII with a pair of deep sulci. Pygidium with \pm 10 spines and two

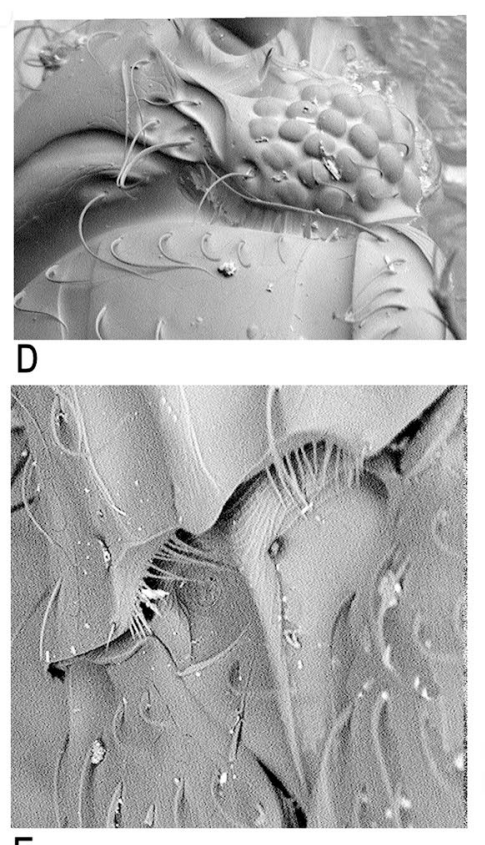

$\mathrm{E}$
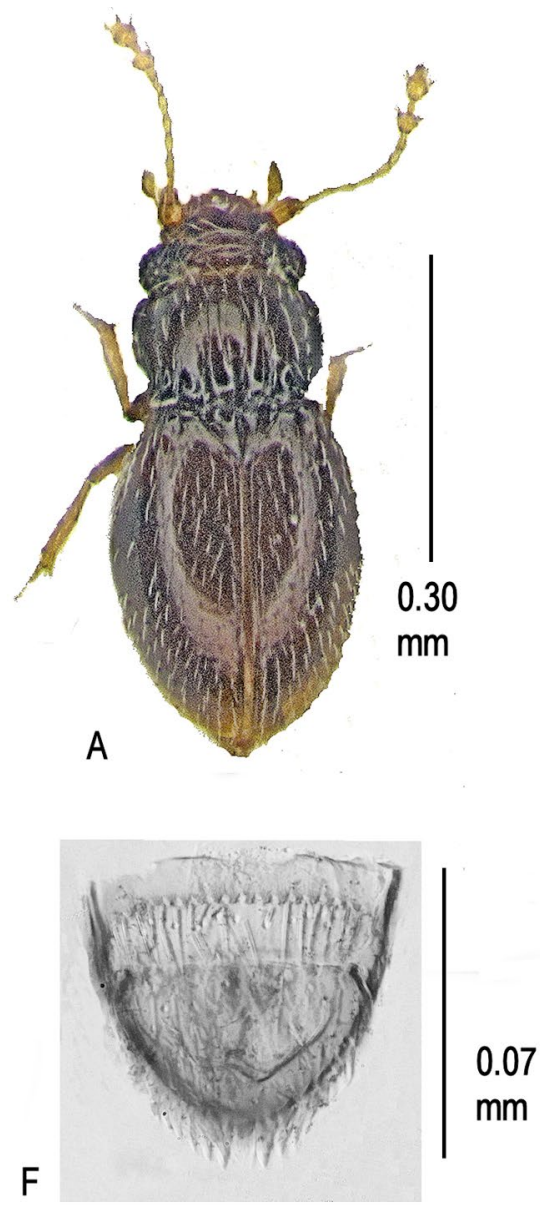

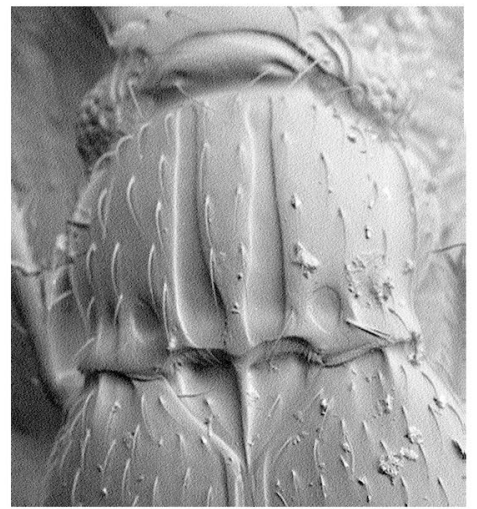

B

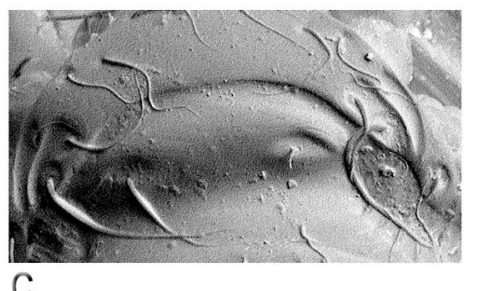

C

Fig. 10. Discheramocephalus nigritus sp. nov. A. Habitus. B. Pronotum $\times 625$. C. Back of head $\times 600$. D. Fovea behind eye $\times 1800$. E. Scutellum $\times 1500$. F. Pygidium. 
coarse setae near the anterior corners (Fig. 10F). Wings of usual ptiliid type. Dissection failed to reveal any genitalia to determine sex, but size of eyes suggests male (females in this genus usually have smaller eyes).

Tribe Nanosellini Barber, 1924

Genus Kuschelidium Johnson, 1982

Described by Johnson on the basis of a single specimen K. maori Johnson, 1982 from New Zealand. The rounded body form and possession of a spatulate plate covering the mesocoxae, are similar features to those possessed by members of the termitophilous subfamily Cephaloplectinae, but in those species the plate is an extension of the proventrum and not of the mesoventrum (incorrectly referred to as the metaventrum by Sawada \& Hirowatari 2002). In describing the genus Johnson (1982) refrained from placing it firmly in a subfamily suggesting that the almost contiguous metacoxae and entire elytra placed it closest to some of the nanoselline genera including Mikado Matthews, 1889 and Throscidium Matthews, 1872. Sawada \& Hirowatari agreed when describing K. okinawense Sawada \& Hirowatari, 2002 from Japan and this is followed here, although the very clear morphological differences between the genus and most other genera in the tribe may well see it change in the future.

Kuschelidium sarawakense sp. nov.

urn:1sid:zoobank.org:act:8B032B6E-E974-4BA3-99CA-0B3917C53279

Fig. 11

\section{Diagnosis}

Quickly separated from the two other species of Kuschelidium by the large size of the spatulate mesoventral plate.
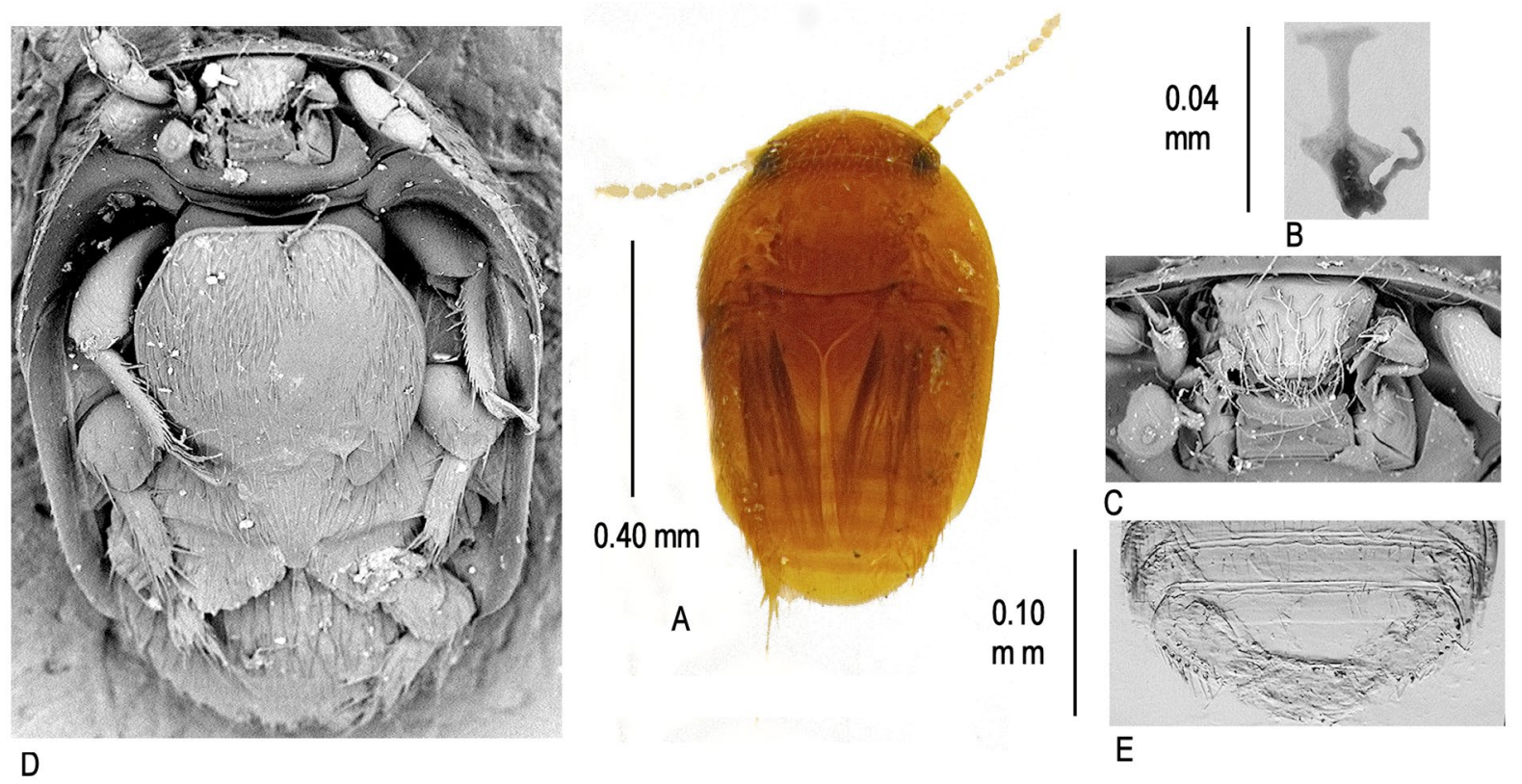

Fig. 11. Kuschelidium sarawakense sp. nov. A. Dorsal habitus. B. Spermatheca. C. Head $\times 695$. D. Ventral habitus $\times 370$. E. Pygidium. 


\section{Etymology}

Named after the district where it was found.

\section{Type material}

\section{Holotype}

MALAYSIA-BORNEO • + ; Sarawak, Mulu; 13 Mar. 1978; N.M. Collins leg.; pitfalls in alluvial forest; BMNH.

\section{Description}

Size. Habitus (Fig. 11A), length $0.72 \mathrm{~mm}$.

Colour. Body ovoid, narrowing posteriorly, dark yellowish, densely covered with fine pubescence. Legs and antennae paler yellow.

HEAD. Head and antennal insertions concealed beneath pronotum in dorsal view but eyes visible; distance across eyes $0.29 \mathrm{~mm}$, antennal grooves present (Fig. 11B). Mentum very contracted length $0.03 \mathrm{~mm}$, width $0.06 \mathrm{~mm}$, without prominent setae in the anterior corners and with a wide anterior margin; submentum with two setae only (Fig. 11B). Labrum densely pubescent. Antennomeres III-VIII length $0.13 \mathrm{~mm}$, antennomere V slightly longer than IV and VI, antennomeres IX-XI length $0.12 \mathrm{~mm}$ forming a loosely jointed club.

Pronotum. Strongly domed, anterior margin with projecting corners to acco mmodate eyes, posterior margin sinuate the medial portion shallowly concave and the corners acutely angled. Prosternum almost absent in front of procoxae. Mesosternum with a large spatulate plate of length $0.22 \mathrm{~mm}$, width $0.25 \mathrm{~mm}$, covering the pro- and mesocoxae and extending over half of the metaventrum, the hind margin with an incursion to allow for the raised medial portion of the metasternum (Fig. 11D).

ELYTRA. Length $0.44 \mathrm{~mm}$, width $0.42 \mathrm{~mm}$, leaving three abdominal tergites exposed.

VENTRUM. Metaventrum short, no epiventral sutures apparent, metacoxae almost contiguous separated by short rounded process, coxal plates large rounded/triangular (Fig. 11C). Wings of usual ptiliid form.

Abdomen. Pygidium (Fig. 11E).

Female genitalia. Spermatheca very small and difficult to locate (Fig. 11B).

Male genitalia. Not known.

\section{Remarks}

Placed in Kuschelidium on grounds of priority. The size of the mesoventral spatulate plate which is much larger than that of any described species of Kuschelidium begs the question as to whether the new species belongs in a different genus. I have seen an undescribed species from Tioman, Malaysia, with a similar plate of smaller size but larger than K. maori and given the presence of this possibly transitional species, it seems safer to assign the new species to Kuschelidium until more specimens have been found to provide a better basis for analysis. Although the specimen was not found in association with termites its peculiar morphological modifications do suggest a life adapted for the hostile environment of the termites' nest. 
Tribe Ptinellini Reitter, 1906

Niptella gen. nov.

urn:1sid:zoobank.org:act:73AC2927-0DF7-4BA7-BF3A-FBC6E0D52586

\section{Type species}

Niptella gutta gen. et sp. nov.

\section{Etymology}

The name is an anagram of the genus name Ptinella.

\section{Description}

Body shallowly convex, rather broad, with clear reticulation, densely foveolate and pubescent, the pubescence, barely overlapping, longer along the lateral margins. Head broad, with a row of pustulate setae behind the eyes; mentum with sharply pointed anterior angles, the two longer anterior setae set behind two shorter setae, disc with two rows of two setae, reticulation sharply marked, submentum with four prominent setae at lateral margins; antennae 11 segmented, antennomeres XI-XI forming a loosely jointed club. Pronotum with two depressions marked by coarser reticulation, sides evenly rounded to obtuse posterior angles, lateral and posterior margins with a fine raised border, scutellum triangular sharply pointed. Metascutellum without lateral setae. Elytra evenly rounded, without epipleura, setae arising from concave border of cells. Proventrum, reticulate, broad in front of contiguous procoxae, with a ridged anterior border and row of short setae, coxal cavities closed behind. Mesoventrum reticulate, without pubescence, collar not extending onto the humeri which are sharply toothed, lateral and posterior margins evenly rounded, keel rounded anteriorly not reaching collar, flat topped and 'teardrop' shaped, extending to a point between the mesocoxae. Metaventrum reticulate and pubescent, posterior margin between metacoxae broad, half the width of the sclerite, without lateral points, metepisternal sutures absent. Pygidium with a small medial point. Female spermatheca very small, globular. Male aedeagus arcuate with a short projection at the anterior end.

\section{Remarks}

The form of the mesoventral keel distinguishes this genus from all others in the Ptinellini. (Darby, unpublished). Throscidium species have a similarly shaped keel, but the sharply defined semi-circular lateral margins of the mesoventrum of that genus are entirely different.

Niptella gutta gen. et sp. nov. urn:1sid:zoobank.org:act:B6E16C2B-3B88-418C-9536-6E235936248C

Fig. 12

\section{Diagnosis}

Determined by the form of the mesoventral keel.

\section{Etymology}

From the Latin 'gutta', meaning 'drop', and referring to the shape of the mesoventral keel.

\section{Type material}

\section{Holotype}

MALAYSIA-BORNEO • + ; Sarawak, $4^{\text {th }}$ division, Gunung Mulu National Park; 1930 m a.s.l.; MayAug. 1978; P.M. Hammond and J.E. Marshall leg., BM 1978-49; BMNH. 


\section{Paratypes}

MALAYSIA-BORNEO - ${ }^{7}$; same data as for holotype; BMNH $\bullet 2$ specs; same data as for preceding; 1800-1900 m a.s.l.; litter; BMNH 1 spec. (mounted disarticulated on the slide); Sarawak, $4^{\text {th }}$ division, Gunung Mulu National Park; May-Aug. 1978; P.M. Hammond and J.E. Marshall leg., BM 1978-49; litter below comp. 4; BMNH • 1 spec.; Sarawak, Mulu; 13 Mar. 1978; N.M. Collins leg.; pitfalls in alluvial forest; $\mathrm{BMNH}$.

\section{Description}

Size. Habitus (Fig. 12A), length $0.65 \mathrm{~mm}$.

Colour. Yellowish brown shining, closely covered with fine pale pubescence.

HEAD. With row of postulate setae behind the eyes (Fig. 12F). Antennae very pale yellow almost translucent, antennomeres III-XI, length $0.28 \mathrm{~mm}$. Eyes prominent, distance across eyes $0.24 \mathrm{~mm}$. Mentum and submentum (Fig. 12D).

Pronotum. Length $0.19 \mathrm{~mm}$, width $0.30 \mathrm{~mm}$ (Fig. 12F).

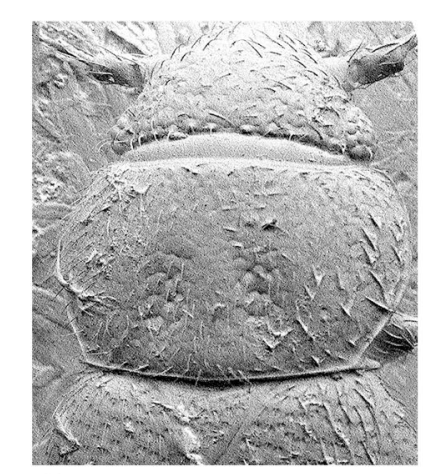

$\mathrm{F}$

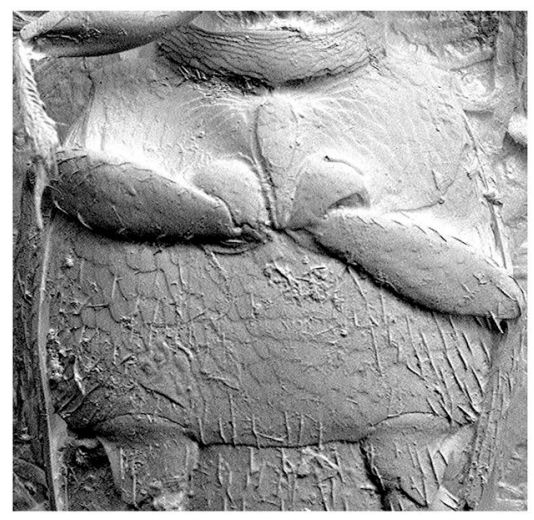

G
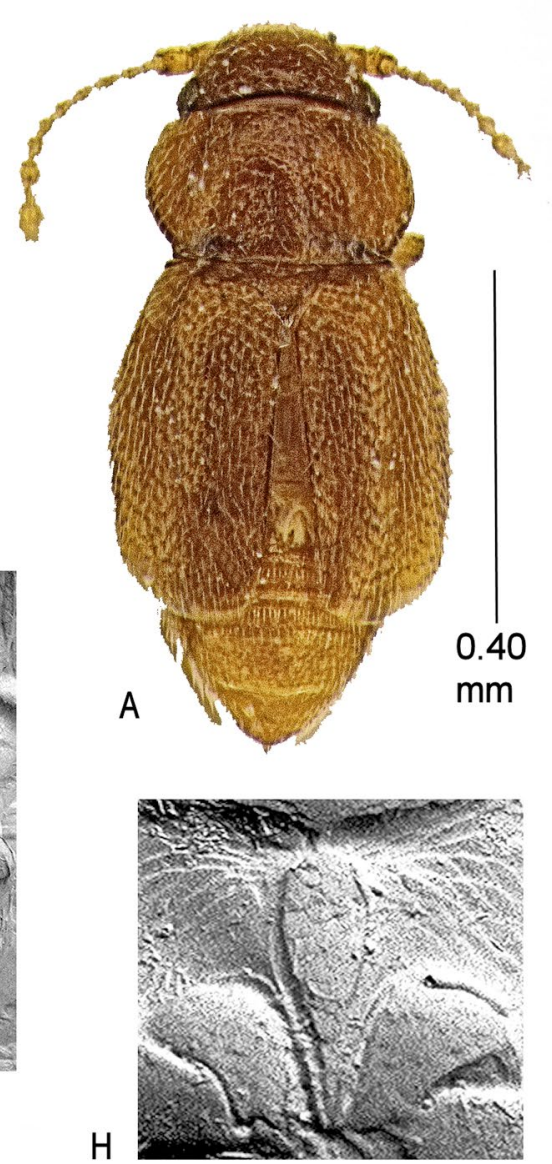

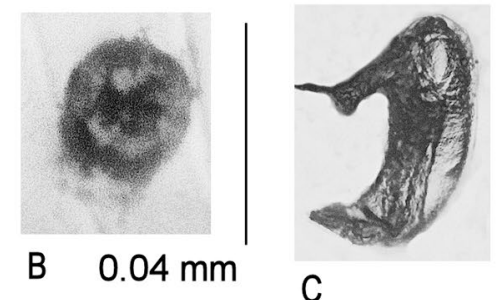

B $\quad 0.04 \mathrm{~mm}$

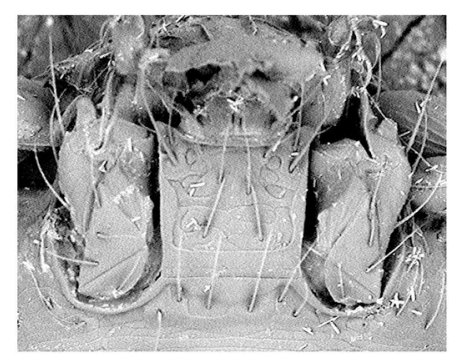

D

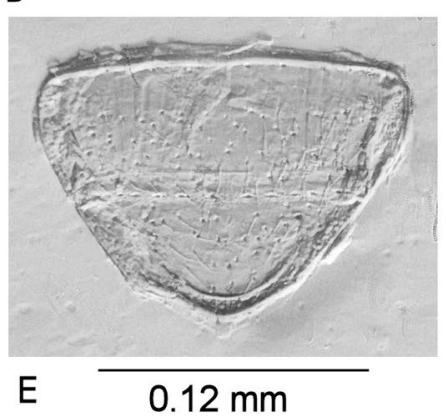

Fig. 12. Niptella gutta gen. et sp. nov. A. Habitus. B. Spermatheca. C. Aedeagus. D. Mentum and submentum $\times 860$. E. Pygidium. F. Pronotum $\times 540$. G. Meso- and metaventra $\times 470$. H. Mesoventral keel $\times 1060$. 
ELYTRA. Length $0.39 \mathrm{~mm}$, width $0.35 \mathrm{~mm}$. truncate.

VentRum. Proventrum wide before contiguous procoxae, reticulate, with scattered setae. Mesoventrum (Fig. 12G), collar not extending onto sharply toothed humeri, keel in shape of a peardrop stopping short of collar and narrowing to a point between the mesocoxae (Fig. 12H). Metaventrum (Fig. 12G), metacoxae separated by half the width of the sclerite.

Abdomen. Pygidium (Fig. 12E).

Female Genitalia. Spermatheca globular, very small and difficult to detect (Fig. 12B).

Male genitalia. Aedeagus large (Fig. 12G).

Genus Ptinella Motschulsky, 1844

Widespread genus of small and fragile species associated with saproxylic habitats. Dimorphism is a common feature, the dominant form (aptera) being characterised by being depigmented, blind or with reduced eyes and apterous. Normal individuals (alata) are usually more pigmented, often have less truncate elytra and possess eyes and wings.

Ptinella alisonae sp. nov. urn:1sid:zoobank.org:act:4BDD6A5D-9D57-4879-98CD-670F69CF33E5

Fig. 13

\section{Diagnosis}

Separated from all other Ptinella spp. by the form of the spermatheca and the presence of the projecting setae on the pronotum. Differs from the indeterminate species below in lacking sinuate hind angles to the pronotum.

\section{Etymology}

Named after Miss Alison Michie, a lifelong family friend and fond of botanical knowledge.

\section{Type material}

\section{Holotype}

MALAYSIA-BORNEO - O'; Sarawak, $4^{\text {th }}$ division, Gunung Mulu National Park; May-Aug. 1978; P.M. Hammond and J.E. Marshall leg., BM 19078-49; base comp logs near laboratory; BMNH.

\section{Paratypes}

MALAYSIA-BORNEO • 4 specs; same data as for holotype; BMNH.

\section{Note}

A $6^{\text {th }}$ specimen without genitalia and with a damaged head, from MDF pitfalls in the Gunung Mulu National Park, 16 Mar. 1978, N.M. Collins leg., BMNH, may be this species.

\section{Description}

Size. Habitus (Fig. 13A), length $0.78 \mathrm{~mm}$.

Colour. Body shallowly convex, pubescent and shining; dusky yellow, antennae and legs paler.

HEAD. Without a transverse fossa behind and with no obvious reticulation, antennomeres III-XI, length $0.25 \mathrm{~mm}$. distance across eyes $0.20 \mathrm{~mm}$, mentum and submentum chaetotaxy (Fig. 13D). 
Pronotum. Almost as wide as the elytral base, without obvious reticulation, lateral margins with three projecting setae and without a sinuation before the hind angles, posterior margin slightly sinuate the central portion projecting posteriad, length $0.13 \mathrm{~mm}$, width $0.23 \mathrm{~mm}$ (Fig. 13E).

ELYTRA. Without obvious reticulation, length $0.26 \mathrm{~mm}$, width $0.25 \mathrm{~mm}$.

VENTRUM. Proventrum broad anterior to procoxae, pubescent, reticulate. Mesoventrum without pubescence, reticulate, humeri angled and with only a very tiny tooth, lateral/posterior margins broadly rounded, collar not distinguished by a posterior margin, keel shallow before terminating in a point between the adjacent mesocoxae (Fig. 13G). Metaventrum pubescent, reticulate, metacoxae widely separated.

Abdomen. Pygidium with an apical tooth. Dimorphic.

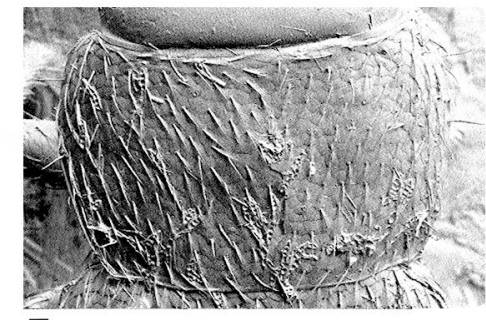

E
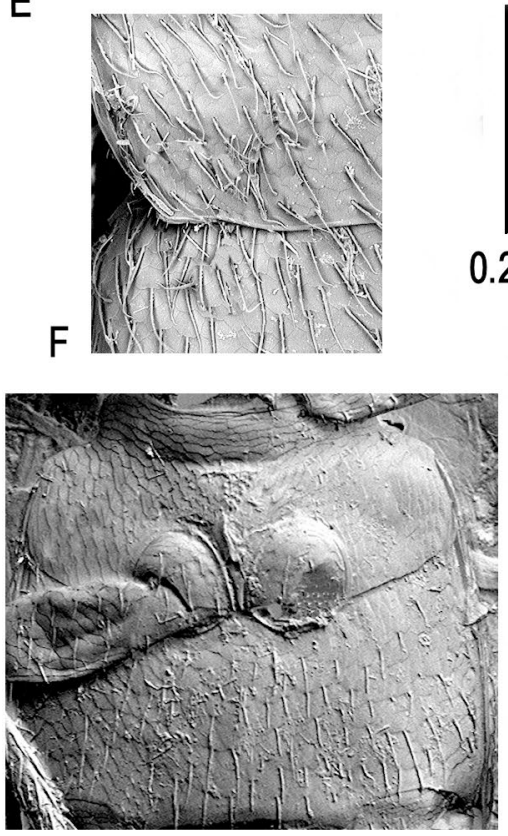

G

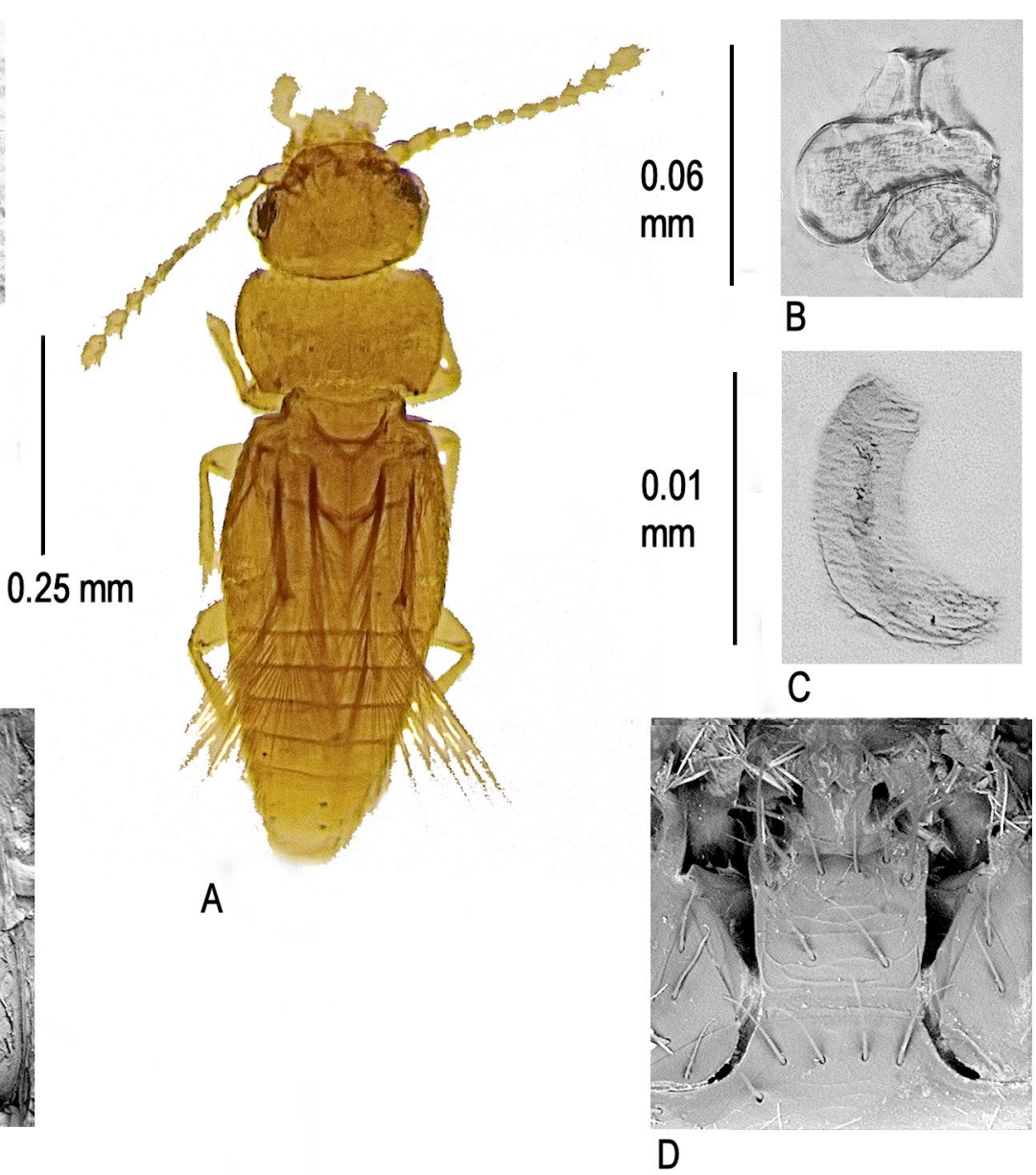

Fig. 13. Ptinella alisonae sp. nov. A. Habitus. B. Spermatheca. C. Aedeagus. D. Mentum and submentum $\times 1340$. E. Pronotum $\times 620$. F. Pronotal hind angle $\times 1380$. G. Meso- and metaventra $\times 555$.

\section{Ptinella sp.}

Several examples of a second species of Ptinella are present in the material but no spermathecae were found in the dissections and consequently they have not been determinable for the reasons given above. 
Subfamily Acrotrichinae, Reitter, 1909

Tribe Nephanini Portevin, 1929

Genus Baeocrara Thomson, 1859

Seven species of Baeocrara have been described from Europe, Japan, India, Sri Lanka, Nepal, Philippines, Zaire (Johnson 1988) and Sabah (Darby 2019).

Baeocrara minima Darby, 2019

Fig. 17B

\section{Material examined}

MALAYSIA-BORNEO • 1 đ̧; Sarawak, $4^{\text {th }}$ division, Gunung Mulu National Park; ca $100 \mathrm{~m}$ a.s.l.; Mar.-May 1978; I. Hanski leg.; pitfall trap fish bait, alluvial forest; BMNH.

\section{Remarks}

The distinctive mesoventral collar (Fig. 17B) separates the species from all other genera in the tribe, and the form of the aedeagus from all other species in the genus. Baeocrara minima has also been recorded from Sabah. The Sabah specimens are slightly larger than the Sarawak specimen, but apparently possess no other features to merit description of the latter as a new species.

Tribe Acrotrichini Reitter, 1909

Genus Acrotrichis Motschulsky, 1848

The largest ptiliid genus, distributed worldwide, with numerous described species. Unless stated otherwise, all species share the following features: body elongate, usually rather broad, relatively flat, dorsal surface including the head pubescent. Antennae with 11 antennomeres I-II forming the scape and pedicel being much larger than III-XI, and IX-XI forming a loosely formed and tapering club; all antennomeres bearing long setae. Sides of pronotum with a narrow raised margin, and hind angles produced backwards. Scutellum without distinguishing features. Metascutellum with a single lateral spine or spur on each side (not present in any other Ptiliidae subfamily (Hall 2000). Elytra truncate apically exposing \pm four abdominal segments. Proventrum narrow in front of the procoxae. Mesoventrum with a well-developed collar extending across the pleura and a raised keel between the mesocoxae. Metasternum pubescent, posterior margin between the metacoxae with sharp lateral points. Metacoxae with rounded plates tapering towards the lateral margins. Abdominal tergites II-V with wing folding spicule patches. Pygidium composed of tergites IX and X fused seamlessly together with or without $2 / 3$ teeth. Abdominal ventrite I without femoral lines. Male ventrite VI with a more or less curved excision, ventrite VII small, covering the excision in ventrite VI, and with an anteriorly directed apodeme. Aedeagus symmetrical in dorsal/ventral view often, but not always, with two hooks. Spermatheca well developed. Wings of usual featherwing type. Parthenogenetic species have been recorded.

Several attempts have been made to establish subgenera and, more recently, species groups within specific geographic faunas. However, the validity of some of these classifications is questionable if a more holistic view is taken and allowance made for new criteria resulting both from the discovery of many new species and also from better descriptions of old ones. For this reason and until the genus is better understood, no attempt is made here to assign species to particular groups and they are treated instead in one alphabetic sequence. Further information together with a more detailed account of the morphological features useful in separating species of Acrotrichis is included in Darby (2014a). 


\section{Key to the Sarawak species of Acrotrichis and Storicricha}

1. Metaventral extension between metacoxae bifid the two spines united (Fig. 23H) ....................... 2

- Spines on metaventral extension not united (though gap in A. bidens sp. nov. is short) .................. 3

2. Female spermathecal pump fan shaped (Fig. 24D)

Storicricha umbella sp. nov.

- Female spermathecal pump flat topped, duct linear Storicricha resticula sp. nov.

3. Elytral cells microtrichiate (Fig. 17D)

A. cognata (Matthews, 1877)

- Elytral cells without microtrichae

4. Submentum with $>15$ outstanding setae (Fig. 17F)

A. bubalis sp. nov.

- Submentum with $<12$ setae, not so outstanding

5. Insect of globose form, elytra with wide epipleura (Fig. 19F)

A. globosa sp. nov.

- Insect more elongate, elytral epipleura if present much shorter and narrower 6

6. Pronotal lateral margins sinuate, hind angles clearly acute (Figs 14B, 20B) 7

- Pronotal angles not clearly acute

7. Large species, $>0.85 \mathrm{~mm}$, pronotal sinuation less pronounced A. acuta sp. nov.

- Smaller species $<0.85 \mathrm{~mm}$ A. hanskii sp. nov.

8. Male with a long row of setae on ventrite VI (Fig. 17G)

- Male genitalia without a long row of setae on ventrite VI A. cursitans (Nietner, 1856)

9. Separation of metacoxae very short (Fig.16H) A. bidens sp. nov.

- Separation of metacoxae wider 10

10. Large species $>0.95 \mathrm{~mm}$, aedeagus (Fig. 17C)

- Smaller species $<0.90 \mathrm{~mm}$ A. agricola Darby, 2019

11. Larger species $>0.70 \mathrm{~mm}$ 12

- Smaller species $<0.70 \mathrm{~mm}$ 13

12. Metacoxae widely separated (Fig. 22G) A. plaga sp. nov.

- Separation of metacoxae shorter A. geiseri sp. nov.

13. Pronotal angles broad and flattened (Fig. 15B)

- Pronotal angles not broad and flattened

A. belli sp. nov.

14. Female spermatheca without a long coiled duct (Fig. 17E)

- Female spermatheca with a long coiled duct (Fig. 21E)

A. britteni Johnson, 1969 A. muluensis sp. nov.

Acrotrichis acuta sp. nov. urn:1sid:zoobank.org:act:D8360D7E-A1D5-49C3-BD76-78C0BD62A0BE

Fig. 14

\section{Diagnosis}

The acute angles of the pronotum and form of the spermatheca distinguish this species. 


\section{Etymology}

Refers to the sharp corners of the pronotum.

\section{Type material}

\section{Holotype}

MALAYSIA-BORNEO • $\overbrace{}^{\text {; }}$; Sarawak, $4^{\text {th }}$ division, Gunung Mulu National Park; 800-1700 m a.s.l.; 29 Apr. 1978; I. Hanski leg., BM 1978-524; pitfall trap fish bait, LMR forest slope 13-16; BMNH.

\section{Paratype}

MALAYSIA-BORNEO • + ; same data as for holotype; 100-500 m a.s.1.; Mar.-May 1978; MD forest; BMNH.

\section{Description}

Size. Habitus (Fig. 14A), length $0.93 \mathrm{~mm}$.
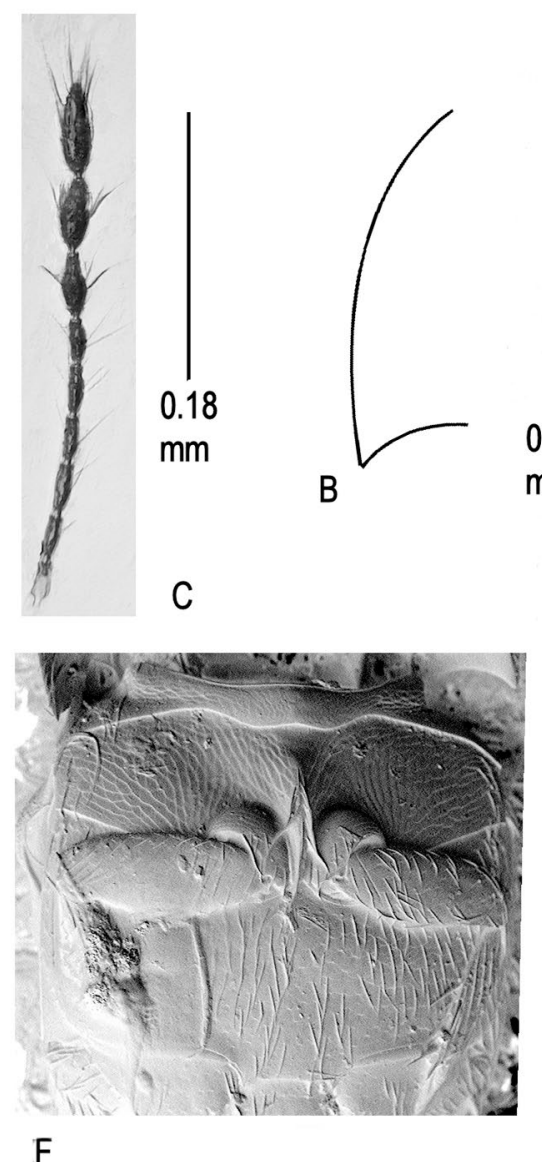

G

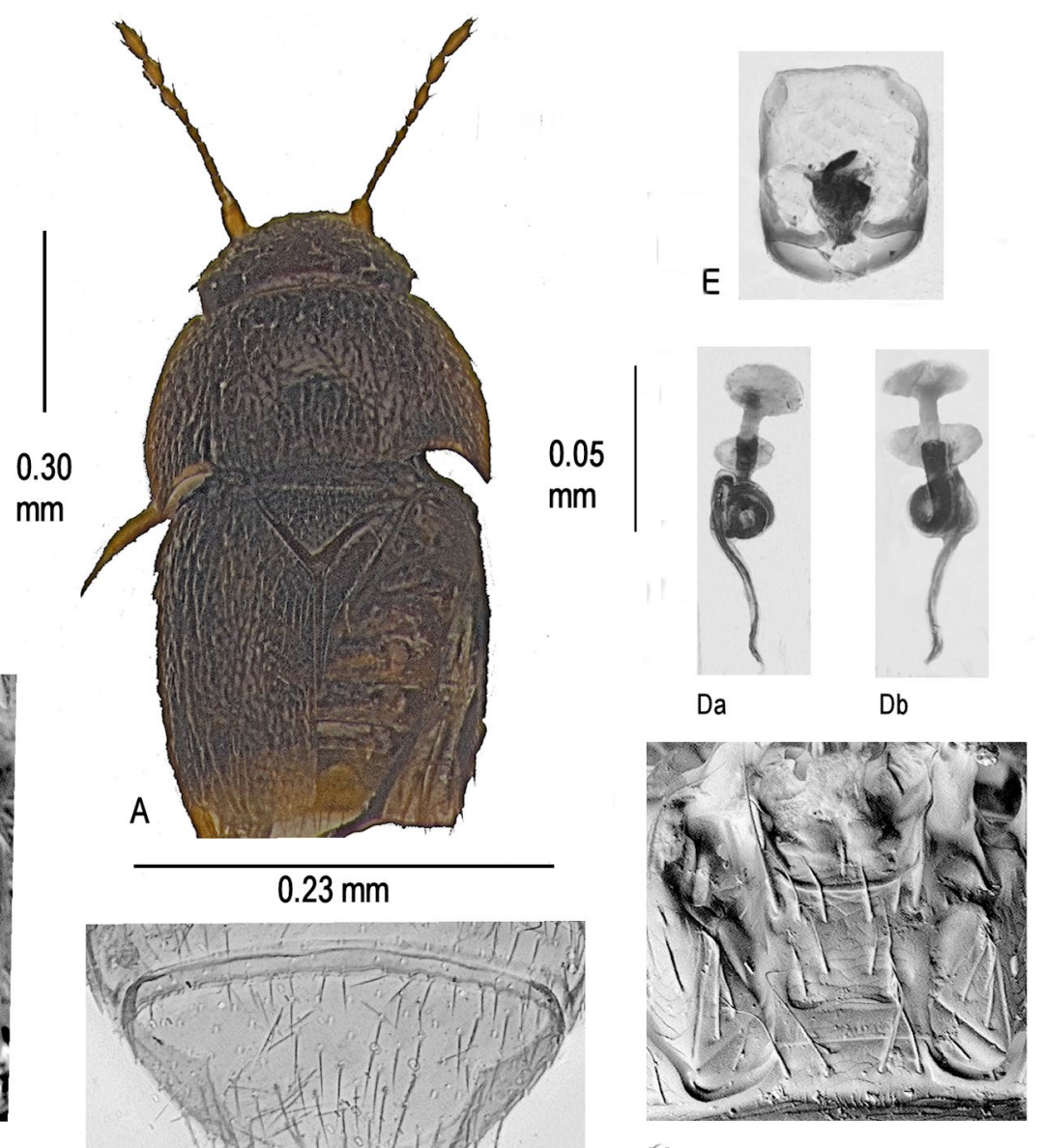

$\mathrm{H}$

Fig. 14. Acrotrichis acuta sp. nov. A. Habitus. B. Hind angle of pronotum viewed at $45^{\circ}$. C. Antennomeres III-XI. Da-Db. Spermatheca. E. Aedeagus. F. Meso- and metaventra $\times 325$. G. Pygidium. H. Mentum and submentum $\times 820$. 
CoLour. Head black, pronotum dark brown, elytra yellow brown, antennae and legs dusky yellow, dorsal surface covered with yellow pubescence.

HEAD. Distance across eyes $0.34 \mathrm{~mm}$; antennomeres III-XI, length $0.36 \mathrm{~mm}$; mentum and submentum chaetotaxy (Fig. 14H).

Pronotum. Length $0.30 \mathrm{~mm}$, width $0.55 \mathrm{~mm}$, pubescence not arising from foveolae, hind angles acute (viewed from $45^{\circ}$ ) (Fig. 14B), with a small projecting seta, posterior margin strongly arcuate towards lateral margins, with a short upright seta anteriorly. Scutellum, pubescence arising from shallow foveolae, pubescence along anterior margin short.

ElYTRA. Length $0.57 \mathrm{~mm}$, width $0.56 \mathrm{~mm}$, pubescence arising from arcuate shallow foveolae, less shining than pronotum.

VENTRUM. Mesoventrum reticulate without pubescence, collar extending onto humeri sloping posteriorly to meet lateral margin, lateral margins short, keel pointed between mesocoxae, obliterated anteriorly before collar (Fig. 14F). Metaventrum reticulate, pubescent, posterior margin between metacoxae with two sharp points at corners, metacoxae separated by $1 / 4$ width of the sclerite (Fig. 14F).

AbDomen. Pygidium (Fig. 14G).

Female genitalia. Spermatheca (Fig. 14Da, Db).

Male genitalia. Aedeagus (Fig. 14E).

Acrotrichis agricola Darby, 2019

Fig. 17C

\section{Material studied}

MALAYSIA-BORNEO - + ; Sarawak, $4^{\text {th }}$ Division, Gunung Mulu National Park; May-Aug. 1978; P.M. Hammond and J.E. Marshall leg., BM 1978-49; alluvial forest litter; BMNH.

\section{Remarks}

Previously known only from Sabah. The form of the spermatheca distinguishes the species (Fig. 17C).

Acrotrichis belli sp. nov. urn:1sid:zoobank.org:act:E6F809AC-FF7D-4180-9964-6F47AE3001C8

Fig. 15

\section{Diagnosis}

The flattened hind angles of the pronotum together with the form of the genitalia distinguish this species.

\section{Etymology}

Named after Mark Bell, the engineer who services my SEM.

\section{Type material}

\section{Holotype}

MALAYSIA-BORNEO • 9 ; Sarawak, $4^{\text {th }}$ Division, Gunung Mulu National Park; 500-800 m a.s.1.; Mar.-May 1978; I. Hanski leg., BM 1978-524; pitfall trap fish bait MD forest slope 17-21, in alluvial forest; BMNH. 


\section{Paratypes}

MALAYSIA-BORNEO $1 \AA, 1 q$ (the $q$ mounted disarticulated on the slide); same data as for holotype; BMNH.

\section{Description}

Size. Habitus (Fig. 15A), length $0.60 \mathrm{~mm}$.

Colour. Dark brown, antennae and legs yellow, dorsal surface shallowly foveolate, densely covered with fine yellow pubescence.

HEAD. Distance across eyes $0.27 \mathrm{~mm}$; antennomeres III-XI, length $0.26 \mathrm{~mm}$; mentum lateral margins rounded towards apex; submentum with two long setae (Fig. 15H).

Pronotum. Length $0.20 \mathrm{~mm}$, width $0.40 \mathrm{~mm}$, hind angles noticeably broad and flat (Fig. 15B).
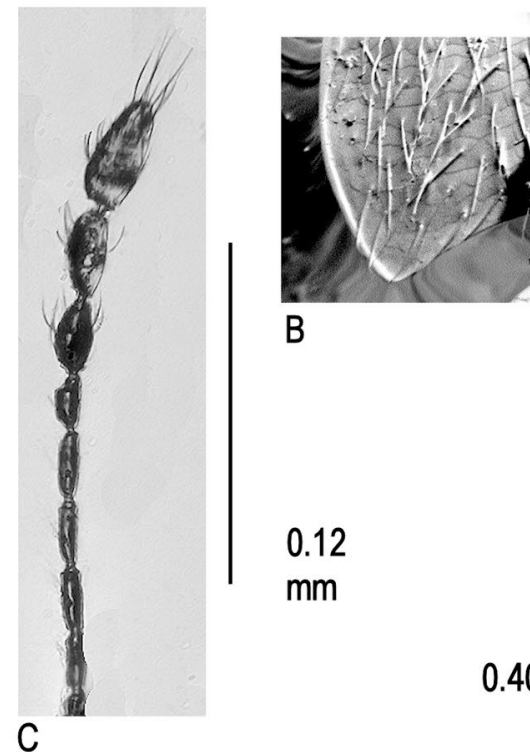

B

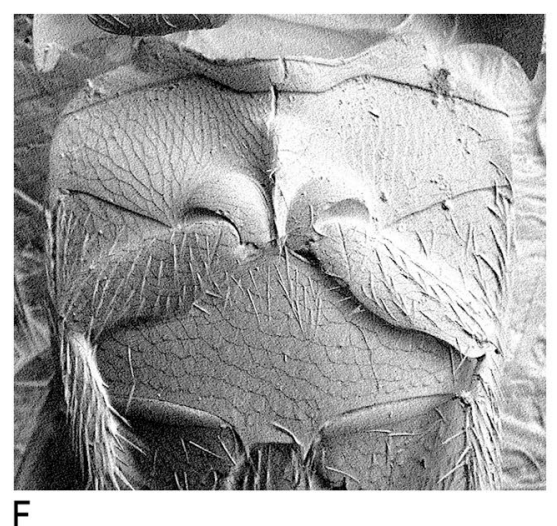

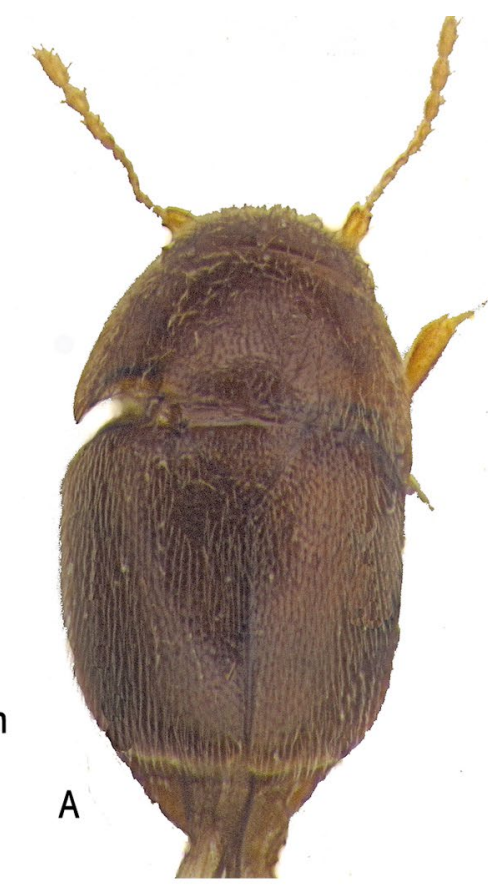

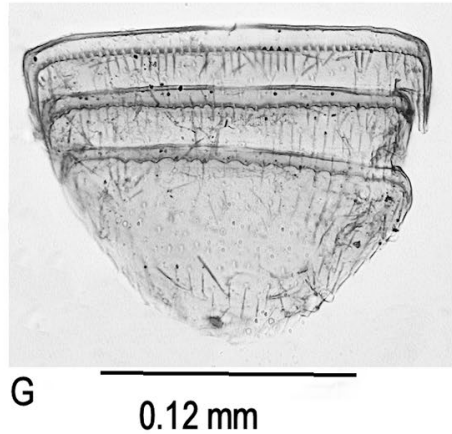

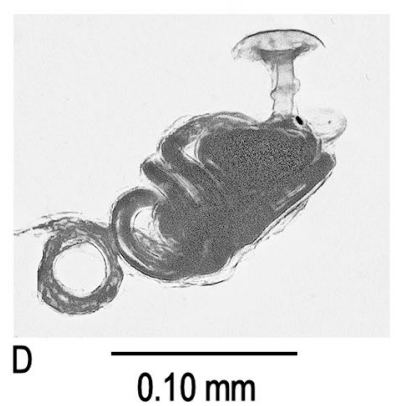
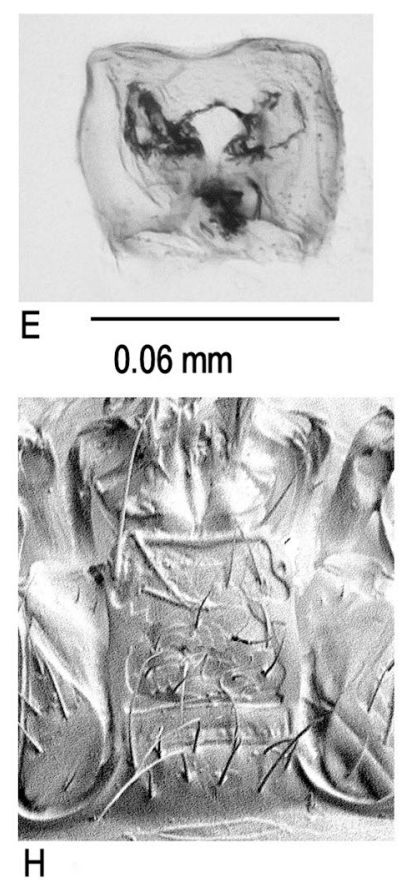

Fig. 15. Acrotrichis belli sp. nov. A. Habitus. B. Hind angle of pronotum $\times 1460$. C. Antennomeres III-XI. D. Spermatheca. E. Aedeagus. F. Meso- and metaventra $\times 420$. G. Pygidium. H. Mentum and submentum $\times 1500$. 
ELYTRA. Length $0.39 \mathrm{~mm}$, width $0.40 \mathrm{~mm}$.

VENTRUM. Mesoventrum reticulate, without pubescence, posterior margin of collar almost straight before meeting lateral margins of mesoventrum, keel obliterated anteriorly before collar, extending posteriorly to a sharp point between the mesocoxae (Fig. 15F). Metaventrum reticulate with scattered pubescence particularly in anterior half, posterior margin between metacoxae with two sharp points at corners, metacoxae separated by $\pm 1 / 5$ the width of the sclerite (Fig. 15F).

Female Genitalia. Spermatheca (Fig. 15D).

Male Genitalia. Aedeagus (Fig. 15E).

\section{Acrotrichis bidens sp. nov. urn:1sid:zoobank.org:act:3B41E644-05C6-48F5-99B5-A128A2AC458E}

Fig. 16

\section{Diagnosis}

The short metaventral termination and form of the genitalia distinguish this species.

\section{Etymology}

Named after the form of the metaventral termination between the metacoxae.

\section{Type material}

\section{Holotype}

MALAYSIA-BORNEO • $\%$; Sarawak, $4^{\text {th }}$ Division, Gunung Mulu National Park; $800-1700 \mathrm{~m}$ a.s.l.; 29 Apr. 1978; I. Hanski leg., BM 1978-524; pitfall trap fish bait LMR forest slope 10-12; BMNH.

\section{Paratypes}

MALAYSIA-BORNEO • 3 specs; same data as for holotype; BMNH.

\section{Description}

Size. Habitus (Fig. 16A), length $0.73 \mathrm{~mm}$.

CoLour. Dark yellowish brown, antennae and legs yellow, dorsal surface densely covered with fine overlapping yellow pubescence.

HEAD. Distance across eyes $0.29 \mathrm{~mm}$; antennomeres III-XI, length $0.31 \mathrm{~mm}$; mentum and submentum chaetotaxy (Fig. 16F).

Pronotum. Length $0.22 \mathrm{~mm}$, width $0.47 \mathrm{~mm}$, hind angles with a tiny sinuation in the lateral margin creating an acute angle (viewed from $45^{\circ}$ ).

ELYTRA. Length $0.46 \mathrm{~mm}$, width $0.47 \mathrm{~mm}$, clearly reticulate.

Ventrum. Mesoventrum reticulate, without pubescence, keel obliterated anteriorly before collar, extending posteriorly to a sharp point between the mesocoxae (Fig. 16G). Metaventrum reticulate with scattered pubescence at lateral margins, posterior margin between metacoxae very short, with two sharp points at corners (Fig. 16H).

Aвdomen. Pygidium with three teeth and a row of setae along the anterior border (Fig. 16I). 
Female genitalia. Spermatheca elongate (Fig. 16E).

Male Genitalia. Aedeagus narrowing to a short flat tip (Fig. 16D).

\section{Remarks}

The close proximity of the metacoxae makes this a marginal choice for placement in Storicricha (see below).
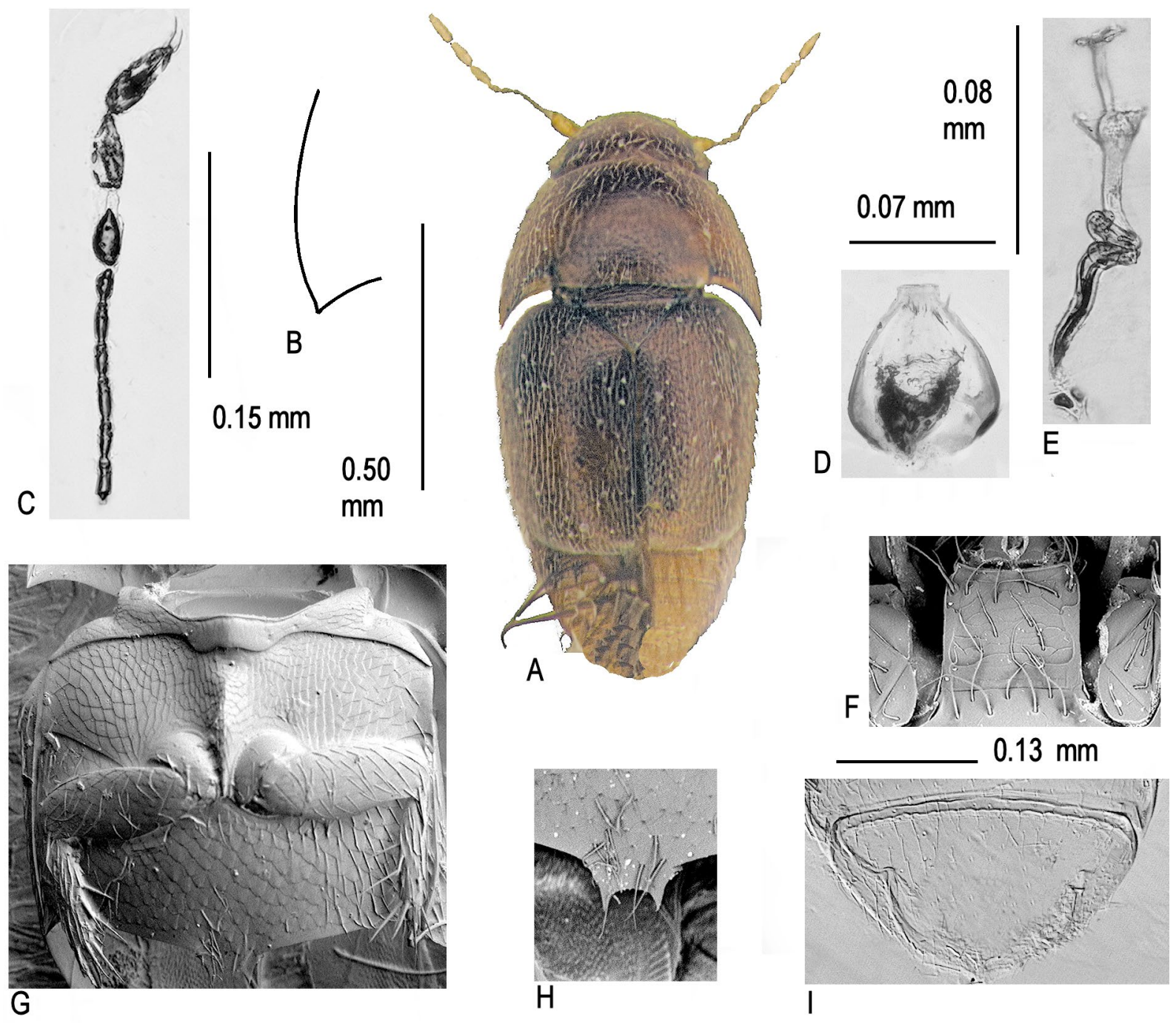

Fig. 16. Acrotrichis bidens sp. nov. A. Habitus. B. Hind angle of pronotum viewed at $45^{\circ}$. C. Antennomeres III-XI. D. Aedeagus. E. Spermatheca. F. Mentum and submentum. G. Meso- and metaventra. H. Bifid process of the metaventrum between the metacoxae. I. Pygidium

Acrotrichis britteni Johnson, 1969

Fig. 17A

\section{Diagnosis}

The form of the spermatheca distinguishes this species (Fig. 17A). 


\section{Material examined}

MALAYSIA-BORNEO • 1 क, Sarawak; May-Aug. 1978; P.M. Hammond and J.E. Marshall leg., BMNH 1978-49; Marndi grass heaps; BMNH 11 9 , Sarawak, $4^{\text {th }}$ Division, Gunung Mulu National Park; May-Aug. 1978; P.M. Hammond and J.E. Marshall leg., BMNH 1978-49; under buffalo dung; BMNH.

\section{Remarks}

Tropical, mainly synanthropic species recorded from various parts of tropical Asia. Johnson (1985) noted that he had seen only females from the Seychelles and Mascarenes and considered that the species was parthenogenetic; he added the rider, however, that he had also seen possible males from West Bengal. More recently, he determined males taken by myself in Kerala, S. India, in association with females as possibly britteni (unpublished).

Acrotrichis bubalis Darby, 2019

Fig. $17 \mathrm{~F}$

\section{Diagnosis}

The setiose submentum (Fig. 17F) distinguishes this species.

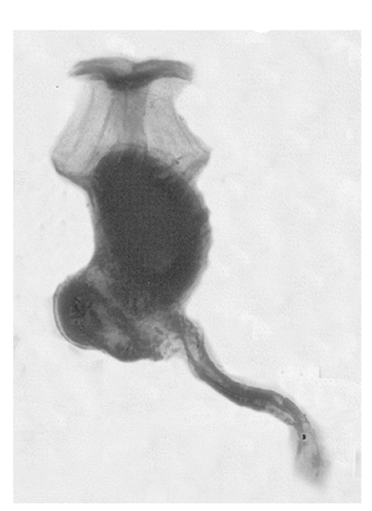

A

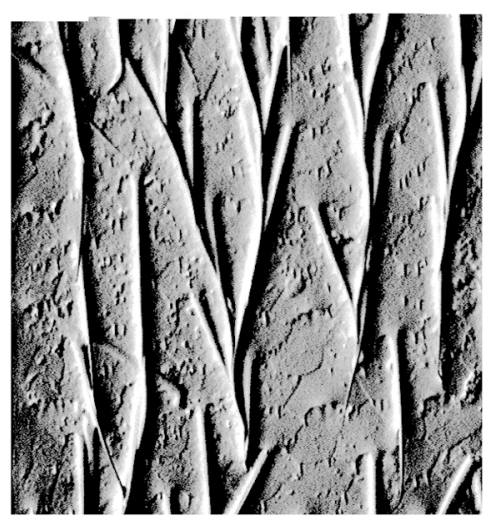

D

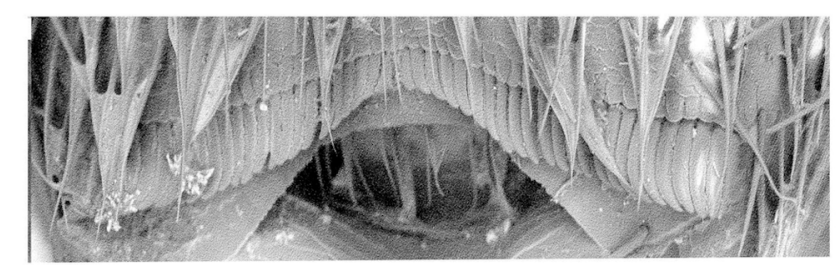

B

$0.07 \mathrm{~mm}$
$0.30 \mathrm{~mm}$

C

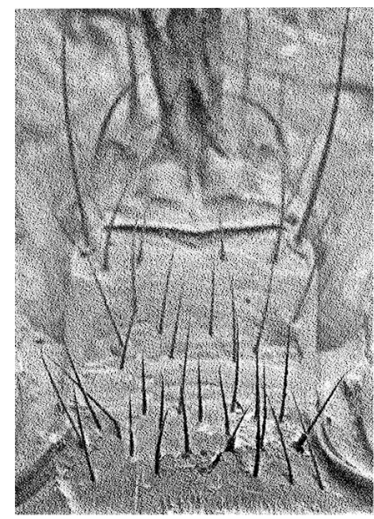

$\mathrm{F}$

Fig. 17. A. Acrotrichus britteni Johnson, 1969, spermatheca. B. Acrotrichis cursitans Nietner, 1856, setae on ventrite VI $\times 1420$. C. Acrotrichis agricola Darby, 2019, spermatheca. D. Acrotrichis cognata (Matthews, 1877), microtrichae on elytra $\times 1520$. E. Baeocrara sp., medial portion of collar $\times 3150$. F. Acrotrichis bubalis Darby, 2019, setae on submentum $\times 1320$. 


\section{Material examined}

MALAYSIA-BORNEO $\bullet 7$ specs ( 1 mounted, remainder in alcohol); Sarawak, $4^{\text {th }}$ Division, Gunung Mulu National Park; 88-1700 m a.s.1.; 29 Apr. 1978; I. Hanski leg., BM 1978-524; pitfall trap, fish bait, LMR forest slope 4-6; BMNH -52 specs ( 2 mounted, remainder in alcohol); same data as for preceding; above $1700 \mathrm{~m}$ a.s.l.; traps 1-6; BMNH $\bullet 6$ specs; same data as for preceding; May-Aug. 1978; traps extra; BMNH - 3 specs; same data as for preceding; above $1700 \mathrm{~m}$ a.s.l.; BMNH $\bullet 2$ specs; same data as for preceding; May-Aug. 1978; P.M. Hammond and J.E. Marshall leg., BM 1978-49; comp 4 human faeces; BMNH.

\section{Remarks}

Previously only known from Sabah.

Acrotrichis cognata (Matthews, 1877)

Fig. 17D

\section{Diagnosis}

The microtrichiate elytra (Fig. 17D) and the shape of the spermatheca distinguish this species. The elytral microtrichiae give the elytra a dull appearance rather than the blue-grey iridescent sheen of Nearctic and Palaearctic specimens which I have seen tempting a determination as the very similar, both morphologically and in the form of the spermatheca, with the equally widespread $A$. josephi Matthews, 1872.

\section{Material examined}

MALAYSIA-BORNEO • 1 \%; Sarawak, $4^{\text {th }}$ division, Gunung Mulu National Park; 800-1700 m a.s.l.; 29 Apr. 1978; I. Hanski leg., BM 1978-525; pitfall trap fishbait, LMR forest slope 4-6; BMNH.

\section{Remarks}

Adventive, synanthropic, parthenogenetic species recorded from North America and New Zealand.

Acrotrichis cursitans (Nietner, 1856)

Fig. $17 \mathrm{G}$

\section{Diagnosis}

The long row of setae on the male abdominal ventrite VI distinguishes it (Fig. 17B).

\section{Material examined}

MALAYSIA-BORNEO • 5 specs; Sarawak; May-Aug. 1978; P.M. Hammond and J.E. Marshall leg., BMNH 1978-49; marndi grass heaps; BMNH.

\section{Remarks}

Widespread and common tropical to temperate, mainly synanthropic species but also occurring in natural habitats.

Acrotrichis geiseri sp. nov. urn:1sid:zoobank.org:act:59A948B3-4DF3-4595-9201-C8E0A43FE169

Fig. 18

\section{Diagnosis}

Only likely to be confused with $A$. belli sp. nov., but the longer and narrower body and form of the genitalia distinguish it. 


\section{Etymology}

Named after Michael Geiser, my colleague in the Department of Life Sciences NHM.

\section{Type material}

\section{Holotype}

MALAYSIA-BORNEO • $\widehat{\lambda}$, Sarawak, $4^{\text {th }}$ division, Gunung Mulu National Park; above $1700 \mathrm{~m}$ a.s.l.; May-Aug. 1978; I. Hanski leg., BM 1978-524; UMR forest fish bait traps; BMNH.

\section{Paratypes}

MALAYSIA-BORNEO • 4 specs ( $1+$ mounted disarticulated on the slide); same data as for holotype; BMNH 1 spec.; same data as for holotype; Mar.-May 1978; forest 'ridge' extra; BMNH.

\section{Description}

SizE. Habitus (Fig. 18A), length $0.83 \mathrm{~mm}$.

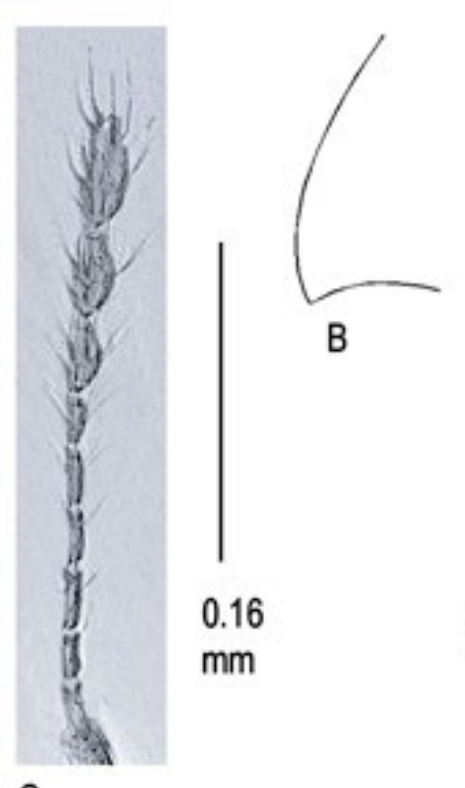

$\mathrm{C}$

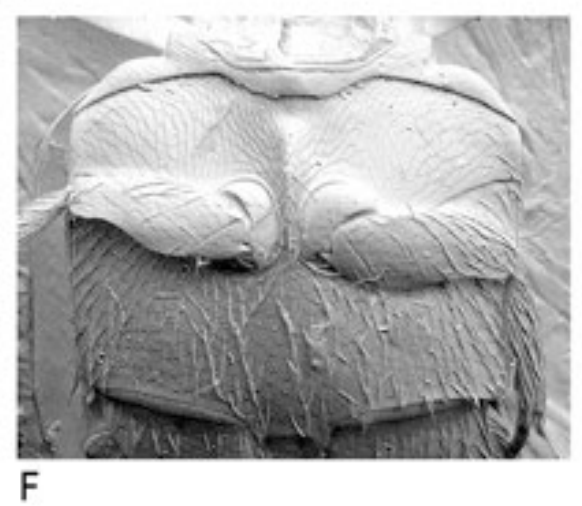

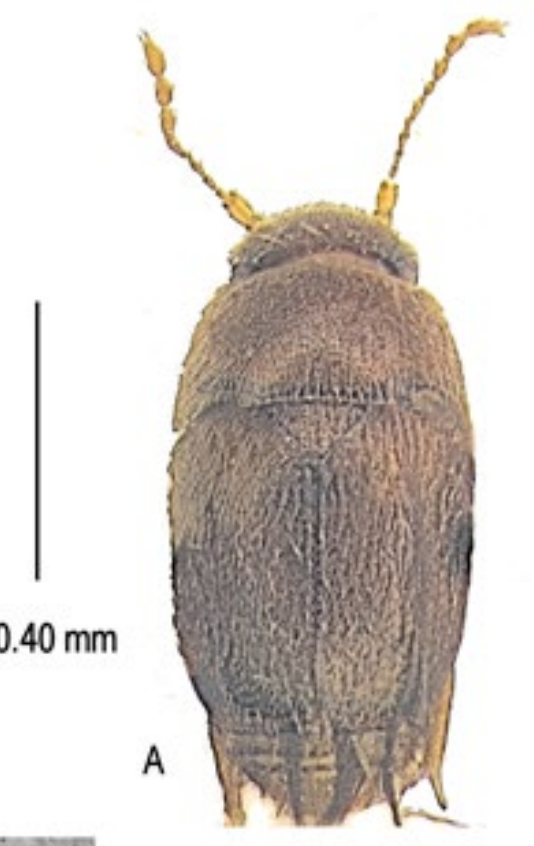

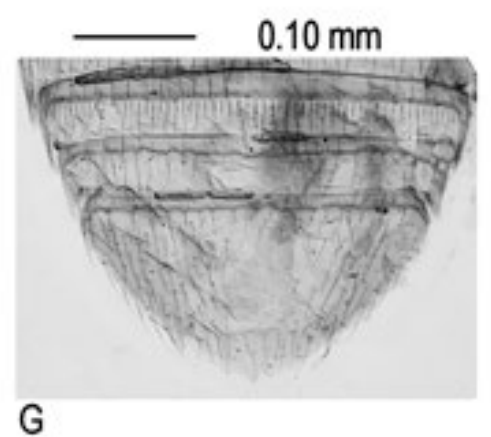

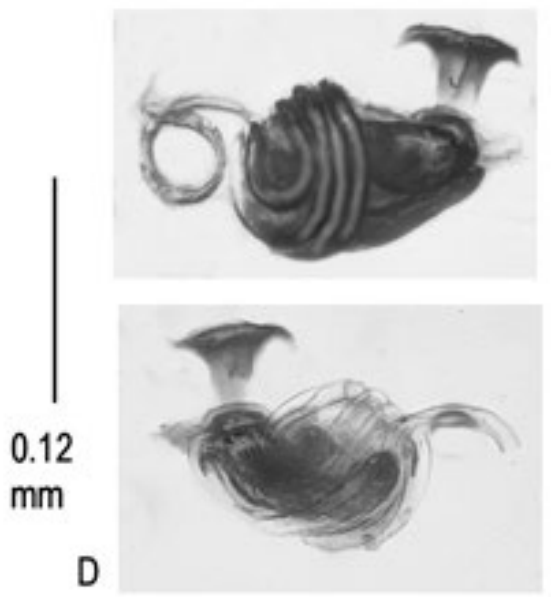
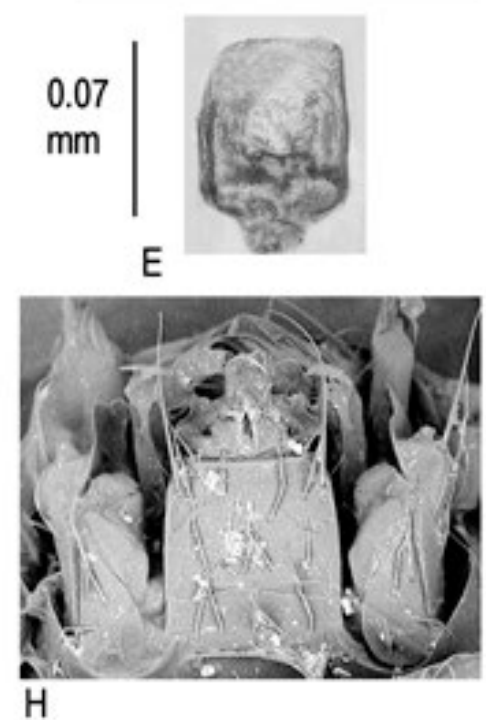

Fig. 18. Acrotrichis geiseri sp. nov. A. Habitus. B. Hind angle of pronotum viewed at $45^{\circ}$. C. Antennomeres III-XI. D. Spermatheca. E. Aedeagus. F. Meso- and metaventra $\times 355$. G. Pygidium. H. Mentum and submentum $\times 965$. 
CoLour. Dark yellowish brown, antennae and legs yellow, dorsal surface covered with fine yellow pubescence.

HEAD. Distance across eyes $0.28 \mathrm{~mm}$; antennomeres III-XI, length $0.33 \mathrm{~mm}$; mentum and submentum chaetotaxy (Fig. 18H).

Pronotum. Length $0.23 \mathrm{~mm}$, width $0.43 \mathrm{~mm}$, lateral margins strongly rounded (viewed from $45^{\circ}$ ), hind angles right angled (Fig. 18B).

ELYTRA. Length $0.45 \mathrm{~mm}$, width $0.44 \mathrm{~mm}$, elongate.

VENTRUM. Mesoventrum reticulate, without pubescence, keel obliterated anteriorly before collar, extending posteriorly as a long, narrow, parallel sided ridge to between the mesocoxae (Fig. 18F). Metaventrum reticulate, pubescent, posterior margin between metacoxae with two sharp points at corners, metacoxae separated by $\pm 1 / 7$ the width of the sclerite (Fig. 18F).

Abdomen. Pygidium with two teeth and a medial point, and a row of setae on the anterior margin (Fig. 18G).

Female genitalia. Spermatheca (Fig. 18D).

Male gentitalia. Aedeagus (Fig. 18E).

Acrotrichis globosa sp. nov. urn:1sid:zoobank.org:act:87156BD9-1A60-4E21-84F4-4A96D82E9FA2

Fig. 19

\section{Diagnosis}

The rounded body form, possession of elytra with wide epipleura and a medial foveola in the mesoventral collar distinguish this species.

\section{Etymology}

Refers to the globular form of the species.

\section{Type material}

\section{Holotype}

MALAYSIA-BORNEO - + ; Sarawak, $4^{\text {th }}$ Division, Gunung Mulu National Park; May-Aug. 1978; P.M. Hammond and J.E. Marshall leg., BM 1978-49; comp 5, alluvial forest litter; BMNH.

\section{Paratypes}

MALAYSIA-BORNEO 1 $1 \widehat{\partial}, 1$; same data as for holotype; BMNH $\bullet 1+$, same data as for holotype; comp 1, litter near stream; BMNH.

\section{Description}

SizE. Habitus (Fig. 19A), length $0.82 \mathrm{~mm}$.

Colour. Yellowish brown, antennae and legs pale yellow, dorsal surface densely covered with short yellow pubescence.

HEAD. Distance across eyes $0.38 \mathrm{~mm}$; antennomeres III-XI, length $0.34 \mathrm{~mm}$; mentum and submentum chaetotaxy (Fig. 19G). 
Pronotum. Length $0.29 \mathrm{~mm}$, width $0.63 \mathrm{~mm}$, hind angles right angled (viewed from $45^{\circ}$ ) (Fig. 19B).

ELYTRA. Length $0.48 \mathrm{~mm}$, width $0.62 \mathrm{~mm}$, widest across humeri, with wide epipleura in basal half(Fig. 19F).

VentRUM. Mesoventrum reticulate with scattered pubescence at lateral margins which are shallowly concave, collar with a small medial fovea, keel obliterated anteriorly before collar, posteriorly narrowing to a point between the mesocoxae (Fig. 19F). Metaventrum reticulate, pubescent, posterior margin between metacoxae wide, with two sharp points at corners, metacoxae separated by $\pm 1 / 5$ the width of the sclerite.

Female genitalia. Spermatheca (Fig. 19D).

Male genitalia. Aedeagus (Fig. 19E).
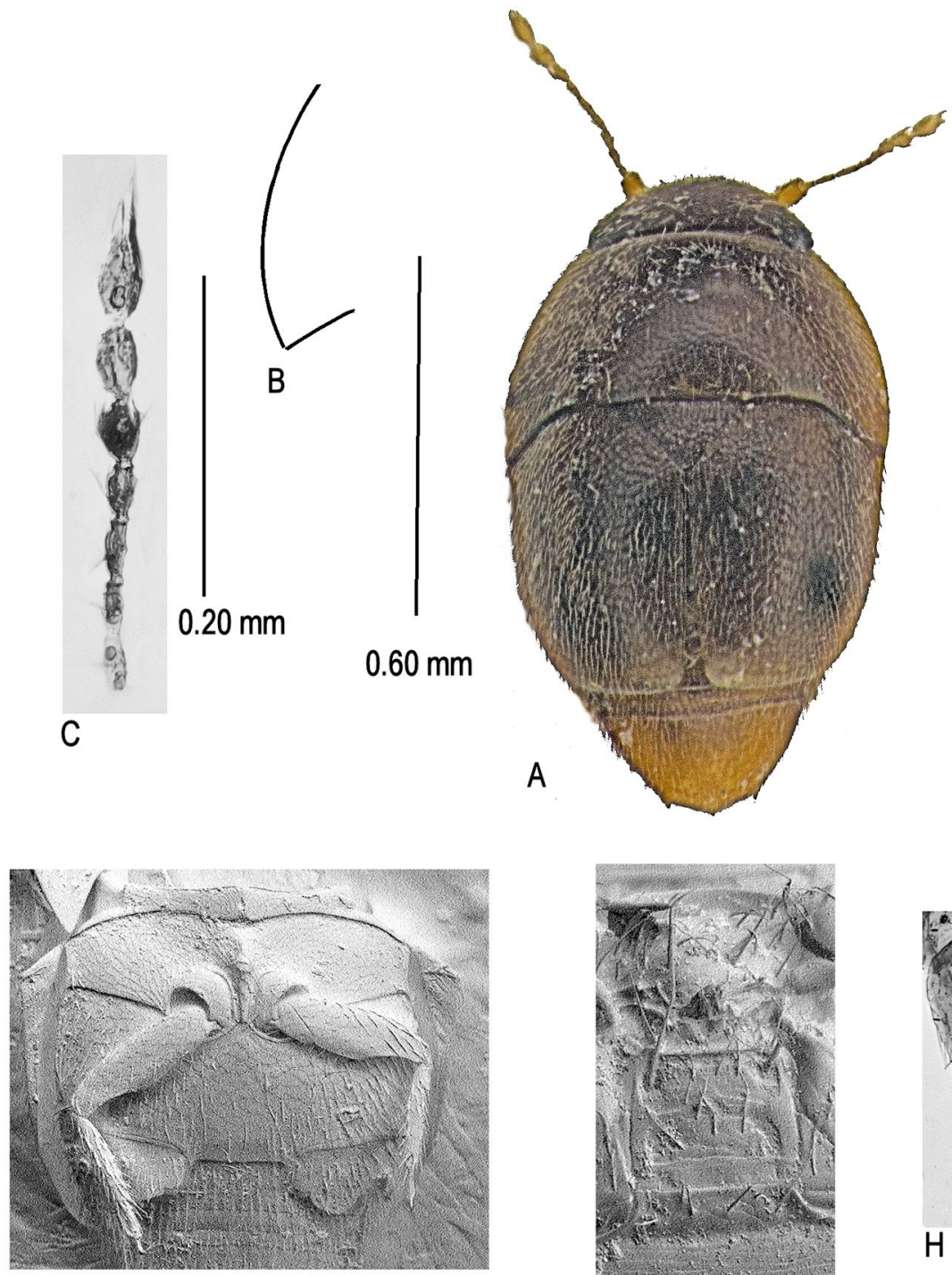

$\mathrm{F}$
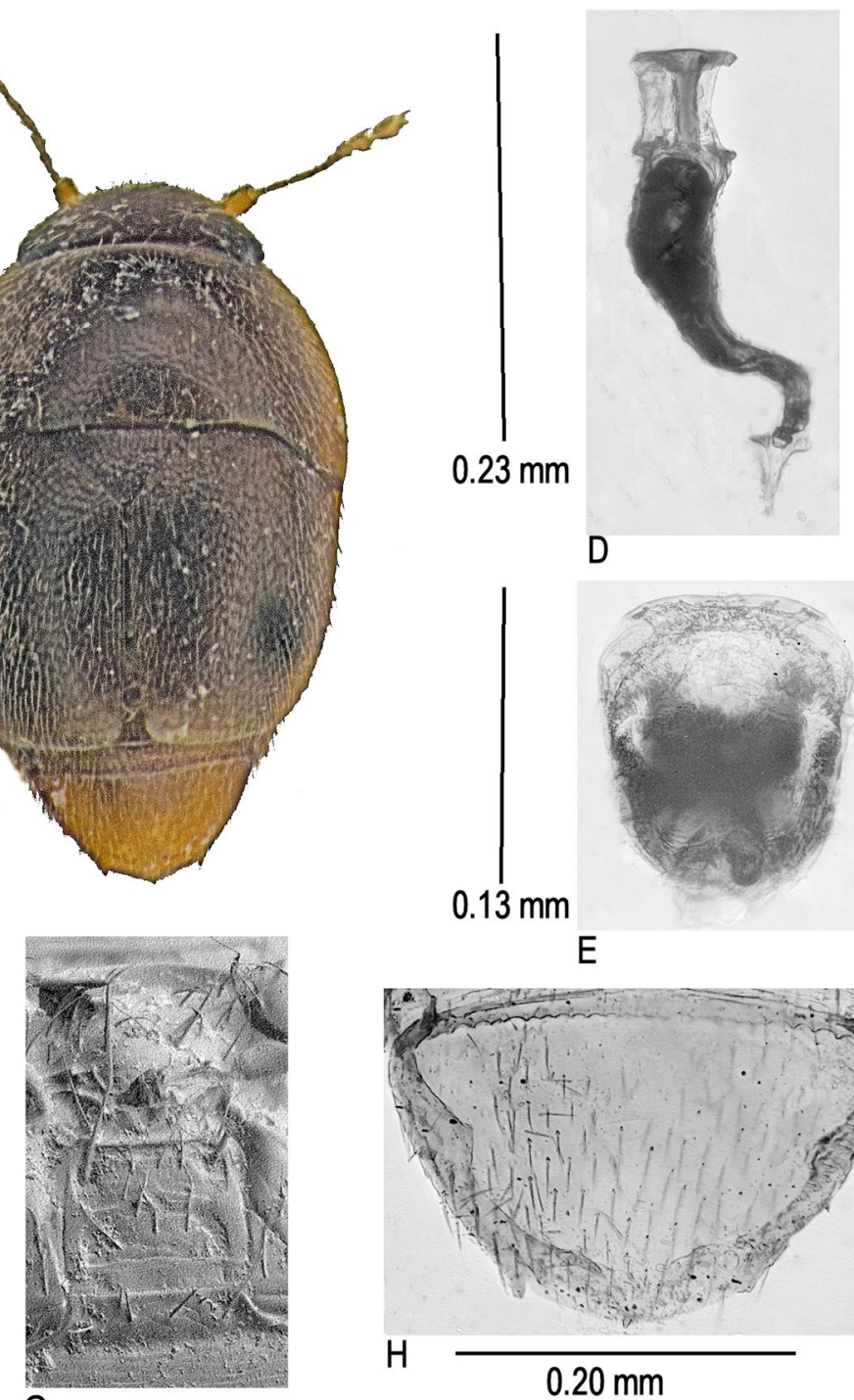

D

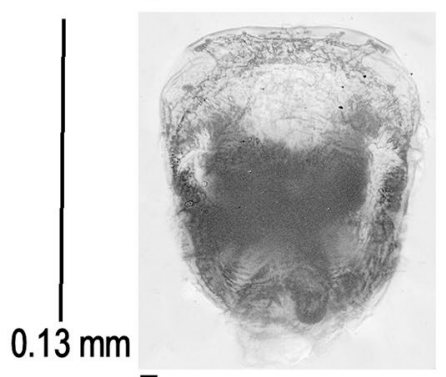

$E$

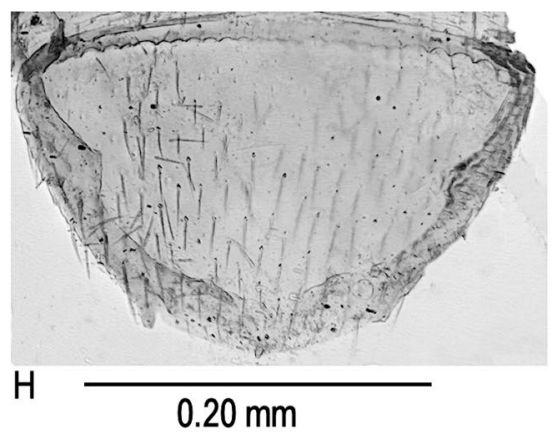

Fig. 19. Acrotrichis globosa sp. nov. A. Habitus. B. Hind angle of pronotum viewed at $45^{\circ}$. C. Antennomeres III-XI. D. Spermatheca. E. Aedeagus. F. Meso- and metaventra $\times 280$. G. Mentum and submentum $\times 800$. H. Pygidium. 
Acrotrichis hanskii sp. nov.

urn:1sid:zoobank.org:act:28ADD572-CE8E-4C39-9C75-60F541DE898F

Fig. 20

\section{Diagnosis}

The form of the genitalia distinguishes this species.

\section{Etymology}

Named after the collector, Ilkka Hanski.

\section{Type material}

\section{Holotype}

MALAYSIA-BORNEO • 9 ; Sarawak, $4^{\text {th }}$ division, Gunung Mulu National Park; 800-1700 m a.s.1.; 29 Apr. 1978; I. Hanski leg., BM 1978-524; pitfall trap fish bait, LMR forest slope 4-6; BMNH.
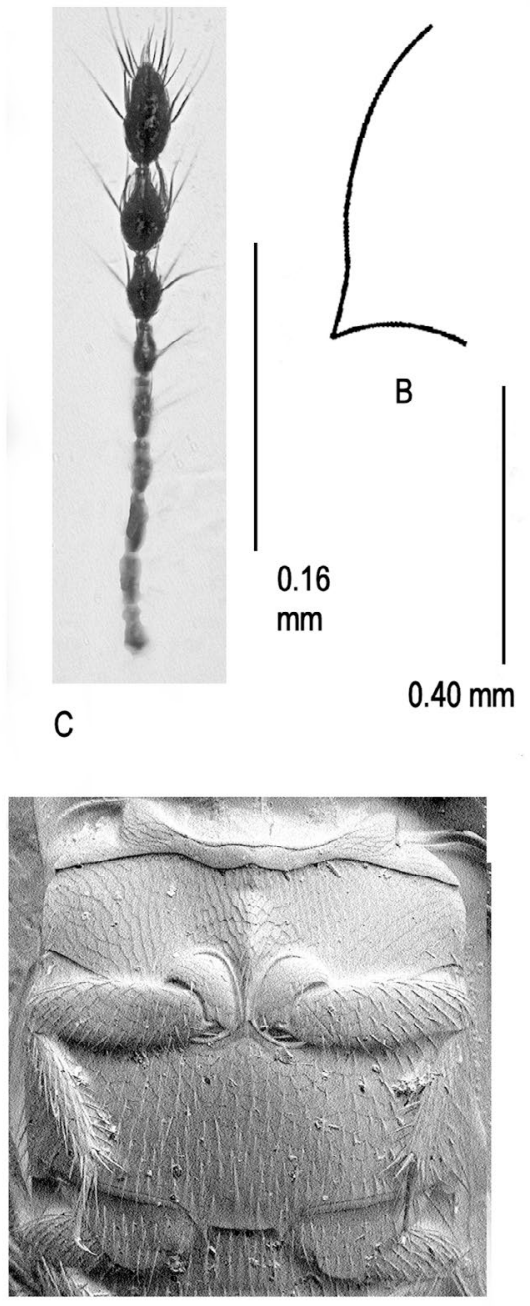

$\mathrm{F}$
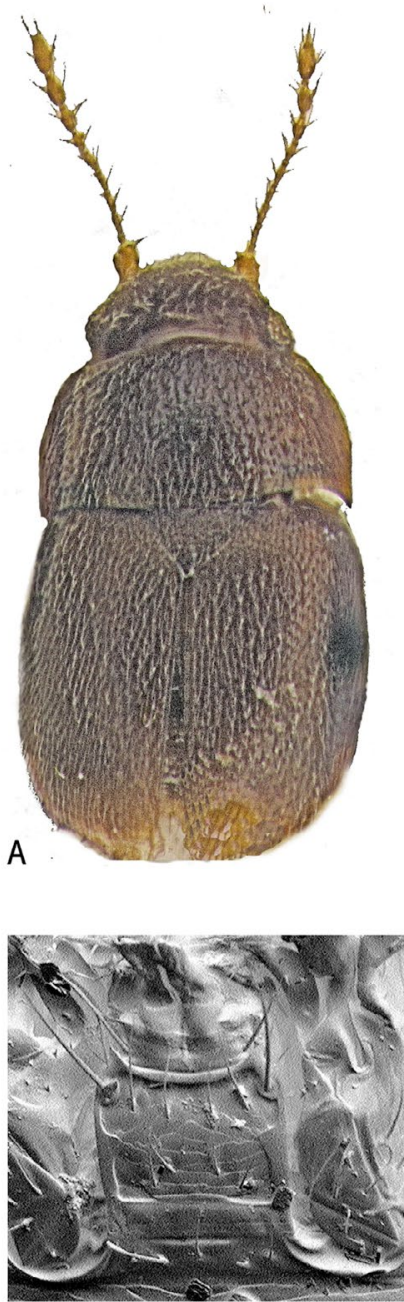

G

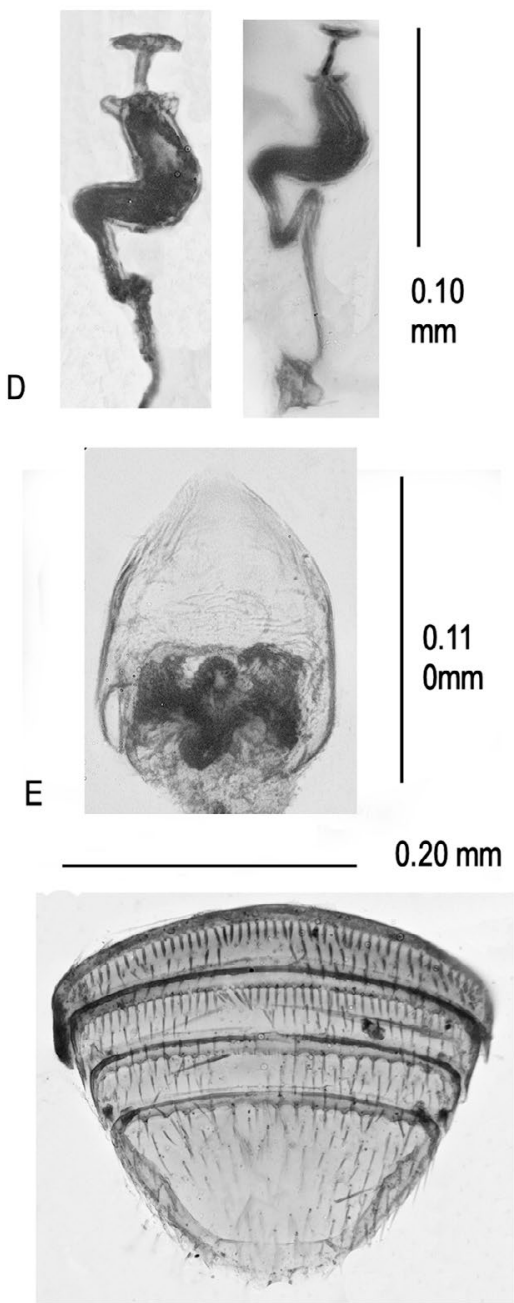

$\mathrm{H}$

Fig. 20. Acrotrichis hanskii sp. nov. A. Habitus. B. Hind angle of pronotum viewed at $45^{\circ}$. C. Antennomeres III-XI. D. Spermatheca. E. Aedeagus. F. Meso- and metaventra $\times 425$. G. Mentum and submentum $\times 1600$. H. Pygidium. 


\section{Paratypes}

MALAYSIA-BORNEO $1 \hat{\jmath}, 1 q$ (the $\widehat{\jmath}$ mounted disarticulated on the slide); same data as for holotype; BMNH.

\section{Description}

Size. Habitus (Fig. 20A), length $0.76 \mathrm{~mm}$.

Colour. Dark brown, antennae, and legs yellow, dorsal surface covered with fine yellow pubescence.

HEAD. Distance across eyes $0.28 \mathrm{~mm}$; antennomeres III-XI, length $0.33 \mathrm{~mm}$; mentum anterior margin concave, angles acute (Fig. 20G).

Pronotum. Length $0.19 \mathrm{~mm}$, width $0.28 \mathrm{~mm}$, lateral margins sinuate before acute hind angles (viewed from $45^{\circ}$ ) (Fig. 20B).

ELYTRA. Length $0.44 \mathrm{~mm}$, width $0.44 \mathrm{~mm}$.

VenTRUM. Mesoventrum reticulate, without pubescence, sides shallowly convex, collar with a narrow raised anterior margin, keel obliterated before collar, extending posteriorly to a fine point between the mesocoxae (Fig. 20F). Metaventrum reticulate, pubescent throughout, posterior margin between metacoxae with two sharp points at corners, $\pm 1 / 5$ the width of the sclerite (Fig. 20F).

Abdomen. Pygidium with indistinct teeth and medial point, anterior border with row of setae (Fig. 20H).

Female Genitalia. Spermatheca (Fig. 20D).

Male Genitalia. Aedeagus (Fig. 20E).

Acrotrichis muluensis sp. nov. urn:1sid:zoobank.org:act:910829FF-4316-4109-A7BC-12C0D115A618

Fig. 21

\section{Diagnosis}

The form of the genitalia distinguishes this species.

\section{Etymology}

Refers to the place of capture.

\section{Type material}

\section{Holotype}

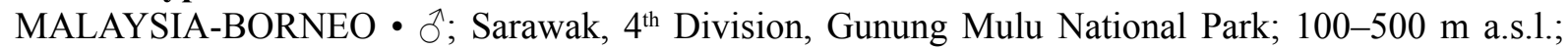
I. Hanski leg., BM 1978-524; pitfall trap fish bait, MD forest; BMNH.

\section{Paratypes}

MALAYSIA-BORNEO $\bullet 4$ specs; same data as for holotype; BMNH $\bullet 4$ specs; Sarawak, $4^{\text {th }}$ division, Gunung Mulu National Park; 100-500 m a.s.1.; Mar.-May 1978; I. Hanski leg., BM 1978-524; pitfall trap fish bait MD forest; BMNH $\bullet 1$ (mounted disarticulated on the slide); same data as for preceding; 500-800 m a.s.1.; forest slope 17-21; BMNH.

\section{Note}

Many further examples of this species by association from these and other locations returned to alcohol. 


\section{Description}

Size. Habitus (Fig. 21A), length $0.68 \mathrm{~mm}$.

CoLour. Dark yellowish brown, head darker, antennae and legs yellow, covered with yellow overlapping pubescence.

HEAD. Distance across eyes $0.28 \mathrm{~mm}$; antennomeres III-XI, length $0.30 \mathrm{~mm}$; mentum anterior margin concave, corners obtuse, anterior margin shorter than posterior (Fig. 21F).

Pronotum. Length $0.22 \mathrm{~mm}$, width $0.44 \mathrm{~mm}$, sides strongly rounded in posterior half, angles right angled (viewed from $45^{\circ}$ ), posterior margin strongly sinuate.

ELYTRA. Length $0.42 \mathrm{~mm}$, width $0.44 \mathrm{~mm}$, with narrow epipleura in anterior half.

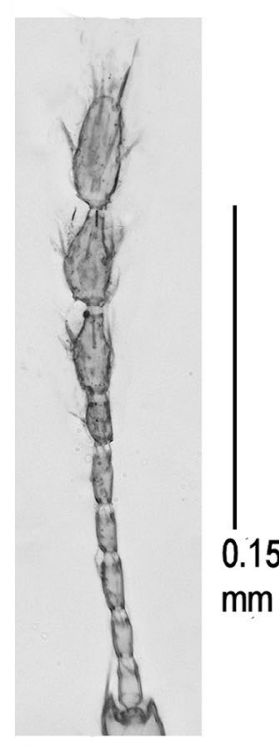

C

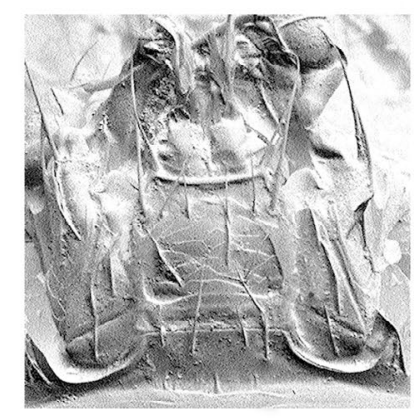

F
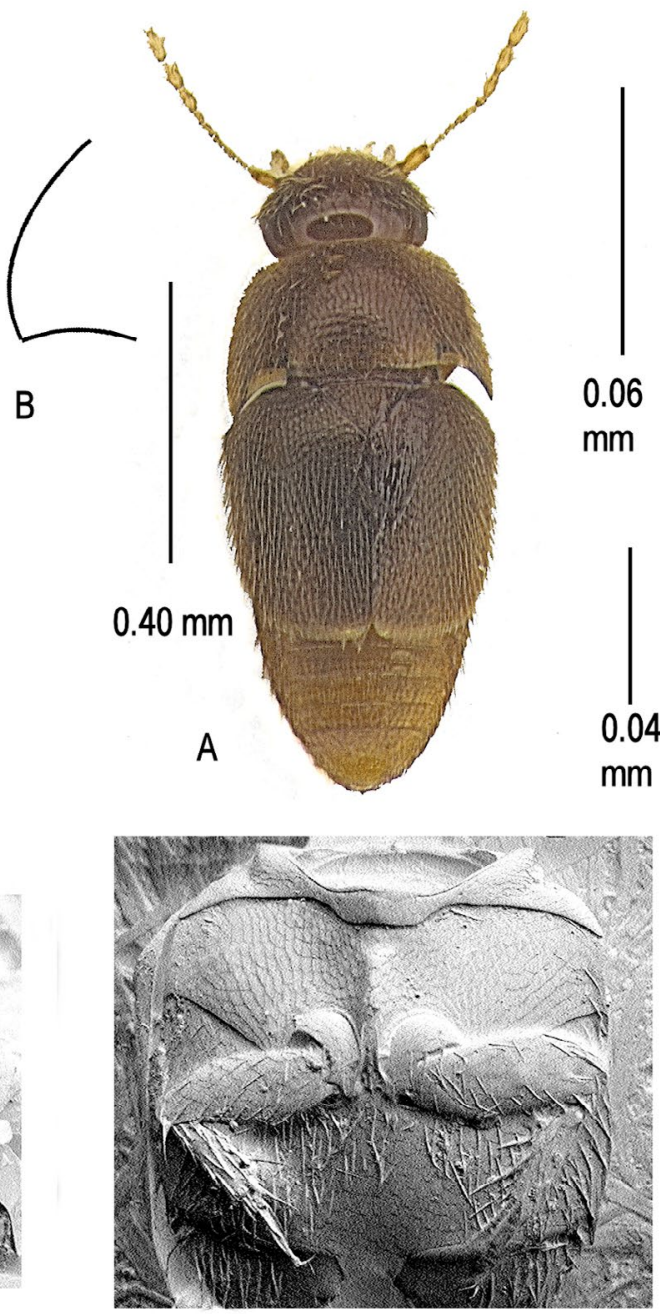

G
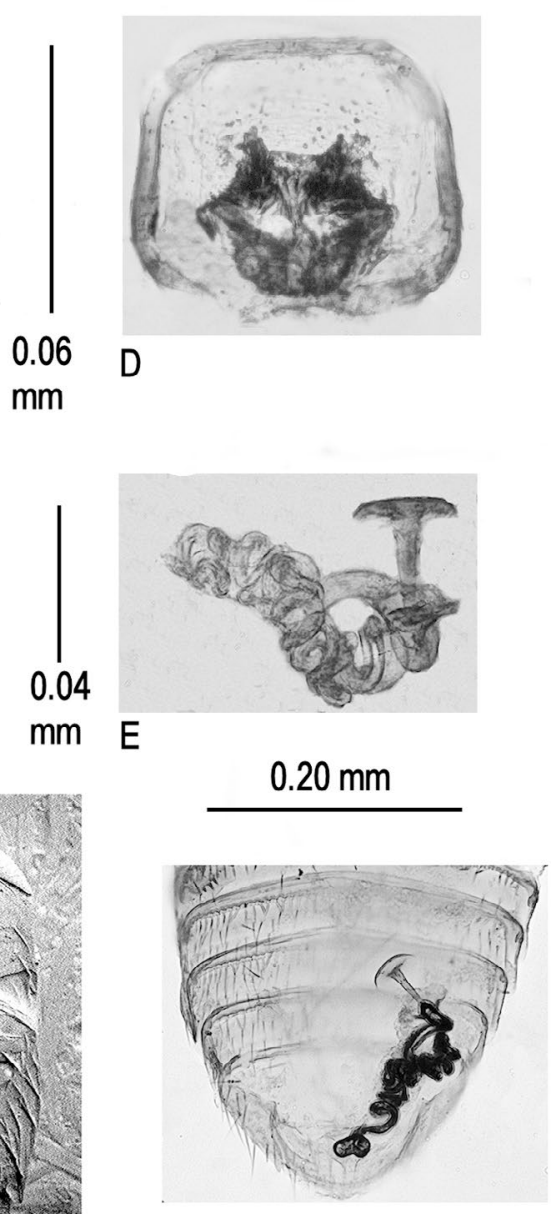

$\mathrm{H}$

Fig. 21. Acrotrichis muluensis sp. nov. A. Habitus. B. Hind angle of pronotum viewed at $45^{\circ}$. C. Antennomeres III-XI. D. Aedeagus. E. Spermatheca. F. Mentum and submentum $\times 1120$. G. Mesoand metaventra $\times 305$. H. Pygidium. 
Ventrum. Mesoventrum reticulate, without pubescence, keel obliterated before collar, tapering posteriorly to a fine point between the mesocoxae (Fig. 21G). Metaventrum reticulate, pubescent, posterior margin between metacoxae narrow with two right angled points at corners, $\pm 1 / 6$ the width of the sclerite.

Abdomen. Pygidium with three pairs of longer setae on lateral margins and a pointed apex, anterior border with setae.

Female genitalia. Spermatheca (Fig. 21E, H).

Male genitalia. Aedeagus (Fig. 21D).

Acrotrichis plaga sp. nov.

urn:Isid:zoobank.org:act:C2827DE7-D0B5-43CB-9296-51C3DFF5A076

Fig. 22

\section{Diagnosis}

The large size, wide separation of the metacoxae and form of the genitalia distinguish this species.

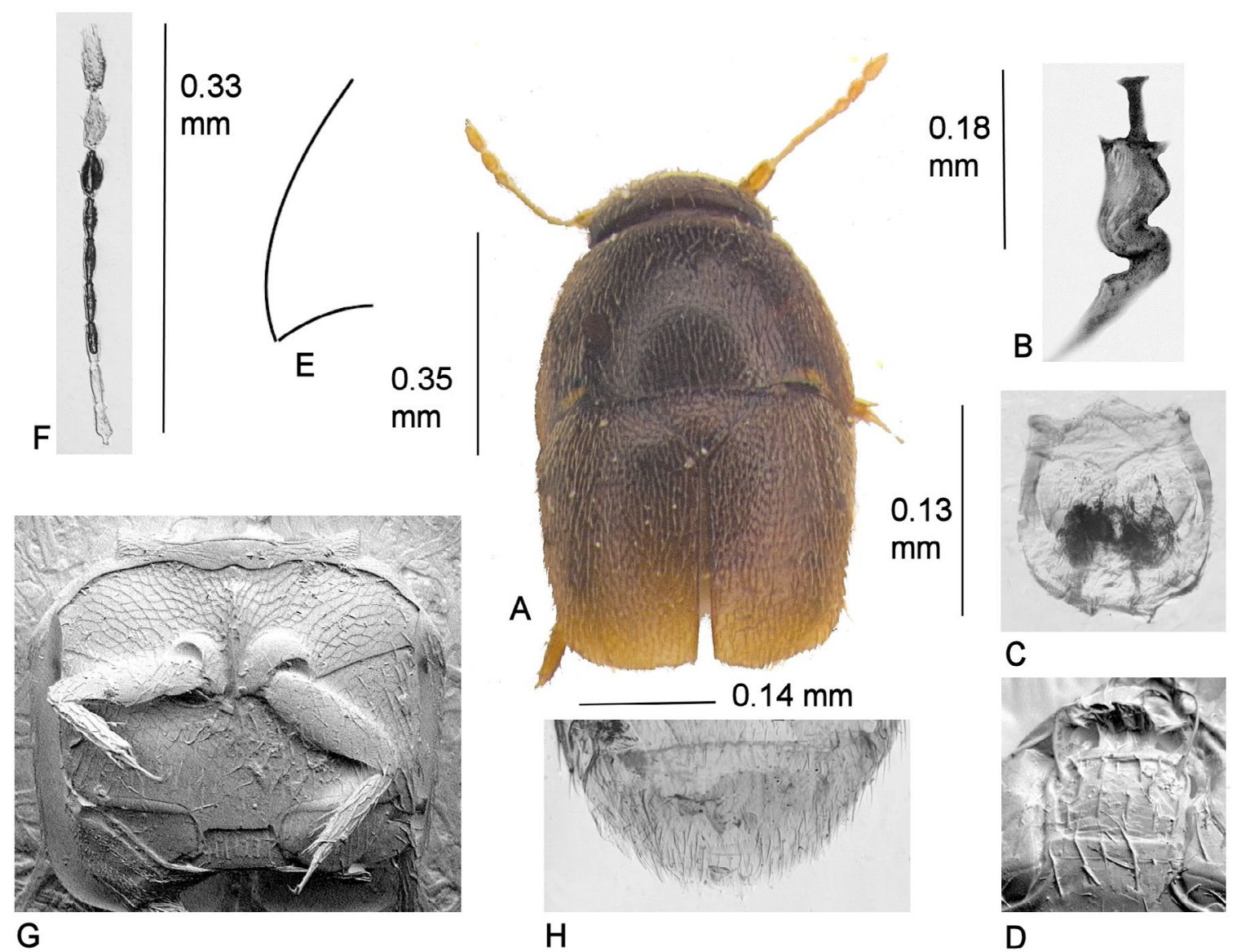

Fig. 22. Acrotrichis plaga sp. nov. A. Habitus. B. Spermatheca. C. Aedeagus. D. Mentum and submentum $\times 1580$. E. Hind angle of pronotum viewed at $45^{\circ}$. F. Antennomeres III-XI. G. Meso- and metaventra $\times 272$. H. Pygidium. 


\section{Etymology}

From the Latin 'plaga', meaning 'trap', and referring to the similarity of the spermatheca to a plumber's trap.

\section{Type material}

\section{Holotype}

MALAYSIA-BORNEO - + ; Sarawak, $4^{\text {th }}$ Division, Gunung Mulu National Park; May-Aug. 1978; P.M. Hammond and J.E. Marshall leg., BM 1978-49; comp 5, alluvial forest litter; BMNH.

\section{Paratype}

MALAYSIA-BORNEO • 1 đ; same data as for holotype; BMNH.

\section{Description}

Size. Habitus (Fig. 22A), length $0.85 \mathrm{~mm}$.

CoLour. Dark brown, head almost black, elytra yellowish through transmitted light, covered with fine pale pubescence.

HEAD. Distance across eyes $0.34 \mathrm{~mm}$; antennomeres III-XI, length $0.33 \mathrm{~mm}$; mentum and submentum chaetotaxy (Fig. 22D).

Pronotum. Length $0.33 \mathrm{~mm}$, width $0.57 \mathrm{~mm}$, sides strongly rounded in posterior half, angles right angled (viewed from $45^{\circ}$ ), posterior margin strongly sinuate.

ELYTRA. Length $0.50 \mathrm{~mm}$, width $0.55 \mathrm{~mm}$, with short epipleura in anterior half.

VENTRUM. Mesoventrum reticulate, without pubescence, keel obliterated before reaching collar anteriorly, tapering posteriorly to a fine point between the mesocoxae (Fig. 22G). Metaventrum reticulate, pubescent, posterior margin between metacoxae wide, $\pm 1 / 4$ the width of the sclerite, with two sharp points at corners (Fig. 22G).

AbDOMEN. Pygidium with two teeth and apical point, anterior margin with row of setae.

Female genitalia. Spermatheca (Fig. 22B).

Male genitalia. Aedeagus (Fig. 22C).

Genus Storicricha Johnson, 1988

In describing this genus, which was based on two species from Sri Lanka, Johnson (1988) noted that there were no features distinguishing it from Acrotrichis except for the approximate metacoxae separated only by a narrow bifurcate extension of the metaventrum. Future research on the subgenera of Acrotrichis (in progress) may reduce the status of Storicricha to that level. Four additional species have been added to the genus recently from Peru (Darby 2017b).

Storicricha resticula sp. nov. urn:lsid:zoobank.org:act:B5C10EEB-971E-45BB-B96C-F0428F4FF140

Fig. 23

\section{Diagnosis}

The bifid termination of the metaventrum and form of the spermatheca distinguish this species. 


\section{Etymology}

From the Latin 'resticula', meaning 'rope', and referring to the form of the spermatheca duct.

\section{Type material}

\section{Holotype}

MALAYSIA-BORNEO - + ; Sarawak, $4^{\text {th }}$ division, Gunung Mulu National Park; May-Aug. 1978; P.M. Hammond and J.E. Marshall leg., BM 1978-49; litter below comp 4; BMNH.

\section{Paratypes}

MALAYSIA-BORNEO - 1 spec.; Sarawak, $4^{\text {th }}$ division, Gunung Mulu National Park; 29 Apr. 1978; I. Hanski leg.; pitfall trap fish bait LMR forest, slope 10-12; BMNH • $1 \mathrm{spec}$. (mounted disarticulated on the slide); same data as for preceding; above $1700 \mathrm{~m}$ a.s.l.; UMR forest, traps 1-6; BMNH -2 specs; Sarawak, Mulu; 16 Mar. 1978; N.M. Collins leg.; MDF pitfalls; BMNH $\bullet 1$ §, 1 ㅇ (one mounted disarticulated on the slide); same data as for preceding; May-Aug. 1978; P.M. Hammond and J.E. Marshall leg., BM 1978-491; comp 4, human faeces; BMNH • 1 spec.; same data as for preceding; under bark of log; $\mathrm{BMNH} \bullet 2$ specs; same data as for precedings; moss; BMNH.
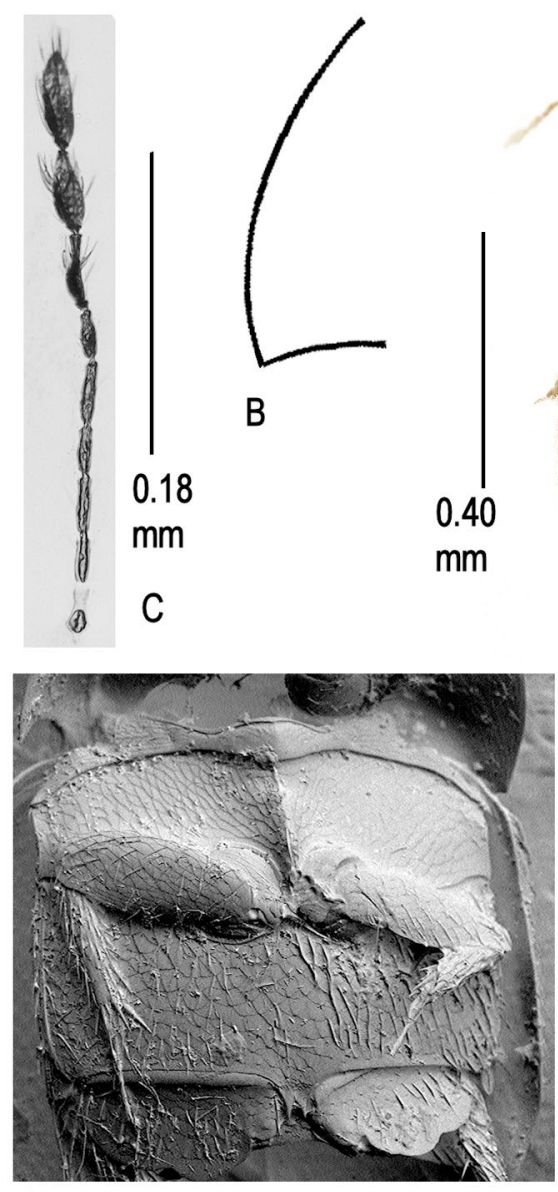

G
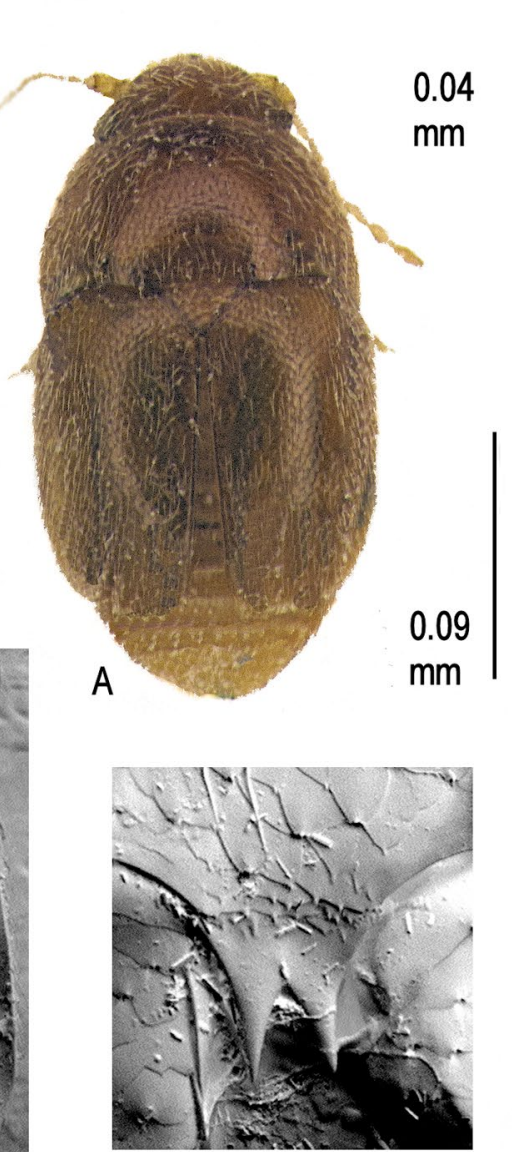

$\mathrm{H}$
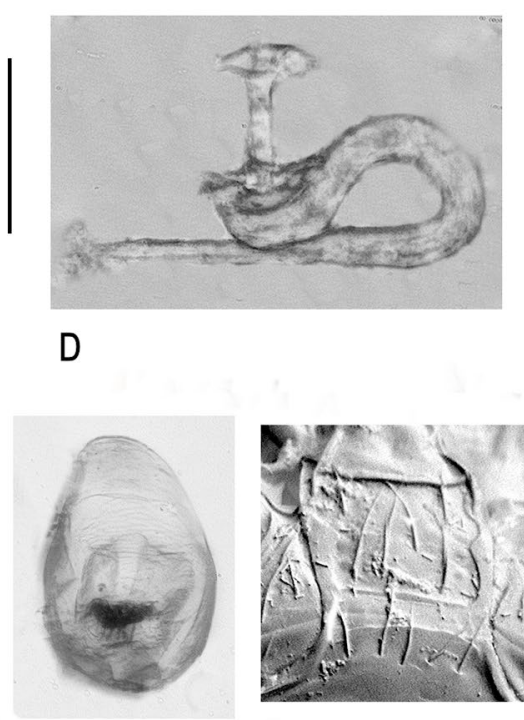

$E$
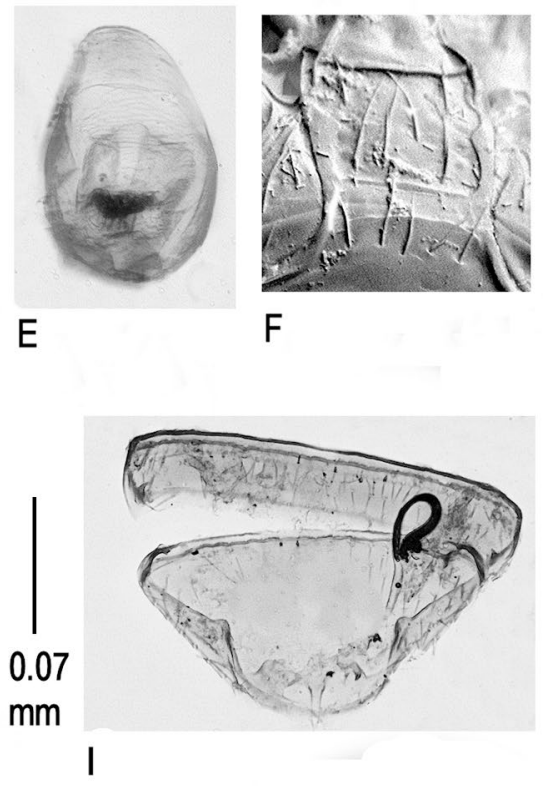

Fig. 23. Storicricha resticula sp. nov. A. Habitus. B. Hind angle of pronotum viewed at $45^{\circ}$. C. Antennomeres III-XI. D. Spermatheca. E. Aedeagus. F. Mentum and submentum $\times 1000$. G. Mesoand metaventra $\times 320$. H. Bifid process between metacoxae $\times 1700$. I. Pygidium. 


\section{Note}

Many further examples from the Gunung Mulu National Park determined by association, not classed as paratypes, retained in alcohol.

\section{Description}

SizE. Habitus (Fig. 23A), length $0.81 \mathrm{~mm}$.

CoLour. Yellow brown, head darker, antennae, and legs yellow, dorsal surface covered with overlapping yellow pubescence.

HeAd. Distance across eyes $0.27 \mathrm{~mm}$; antennomeres III-XI, length $0.36 \mathrm{~mm}$; mentum and submentum chaetotaxy (Fig. 23G).

Pronotum. Length $0.23 \mathrm{~mm}$, width $0.46 \mathrm{~mm}$, hind angles right angled (Fig. 23B).

ELYTRA. Length $0.47 \mathrm{~mm}$, width $0.46 \mathrm{~mm}$.

Ventrum. Mesoventrum reticulate, without pubescence, keel obliterated anteriorly before meeting collar, narrowing to a point between the mesocoxae (Fig. 23F). Metaventrum reticulate and pubescent throughout, posterior margin between metacoxae reduced to two sharp points, adjacent cells with microtrichiae (Fig. 23G).

AвDomen. Pygidium lateral teeth obscured, apical point extended forwards, anterior border with row of setae (Fig. 23H).

Female genitalia. Spermatheca (Fig. 23D).

Male genitalia. Aedeagus (Fig. 23E).

Storicricha umbella sp. nov.

urn:1sid:zoobank.org:act:A1094C0A-72D5-4048-9ACE-926CF1D0F21C

Fig. 24

\section{Diagnosis}

The fan-shaped form of the spermathecal pump distinguishes this species and is unique amongst Ptiliidae.

\section{Etymology}

Refers to the form of the spermathecal pump.

\section{Type material}

\section{Holotype}

MALAYSIA-BORNEO • đ̧; Sarawak, 4th division, Gunung Mulu National Park; 800-1700 m a.s.1.; 29 Apr. 1978; I. Hanski leg., BM 1978-524; pitfall trap fish bait, LMR forest slope 4-6; BMNH.

\section{Paratypes}

MALAYSIA-BORNEO -5 specs (two mounted disarticulated on the slides); same data as for holotype; $\mathrm{BMNH} \bullet 4$ specs; same data as for holotype; Mar.-Aug. 1978; traps 1-6; BMNH.

\section{Description}

Size. Habitus (Fig. 24A), length $0.67 \mathrm{~mm}$. 
CoLour. Dark brown, covered with fine overlapping pale pubescence.

HEAD. Distance across eyes $0.29 \mathrm{~mm}$; antennomeres III-XI, length $0.34 \mathrm{~mm}$; mentum and submentum chaetotaxy (Fig. 24G).

Pronotum. Length $0.21 \mathrm{~mm}, 0.45 \mathrm{~mm}$ hind angles acute (Fig. 24B).

ELYTRA. Length $0.49 \mathrm{~mm}$, width $0.48 \mathrm{~mm}$.

VENTRUM. Mesoventrum reticulate, without pubescence, lateral margins short, slightly concave, keel obliterated before meeting collar and terminating posteriorly in a fine point between the mesocoxae (Fig. 24F). Metaventrum reticulate, pubescent, posterior margin reduced to two sharp points between the metacoxae (Fig. 24F).

ABdomen. Pygidium lateral teeth and apical point obscured, anterior border with row of setae (Fig. 24H).
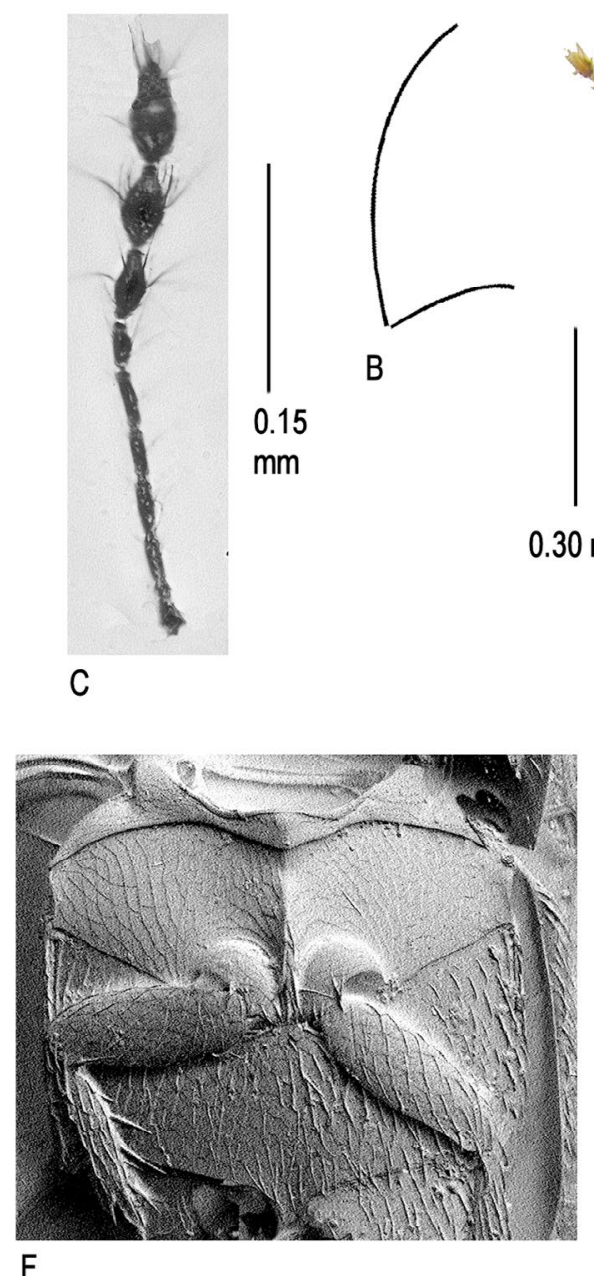

$\mathrm{F}$
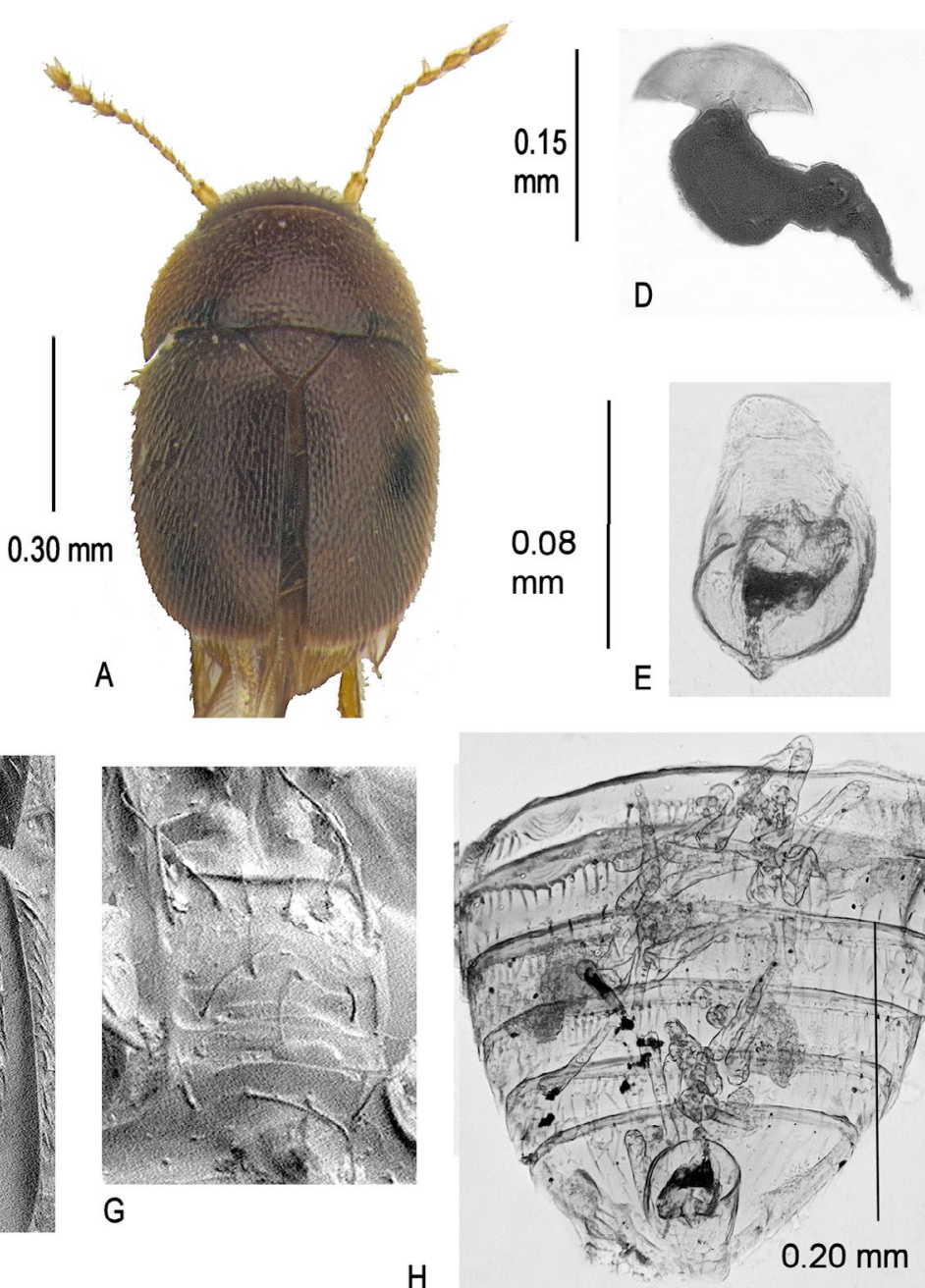

Fig. 24. Storicricha umbella sp. nov. A. Habitus. B. Hind angle of pronotum viewed at $45^{\circ}$. C. Antennomeres III-XI. D. Spermatheca. E. Aedeagus. F. Meso- and metaventra $\times 340$. G. Mentum and submentum $\times 1300$. H. Abdominal ventrites. 
Female genitalia. Spermatheca (Fig. 24D).

Male genitalia. Aedeagus (Fig. 24E).

\section{Discussion}

These collections involved \pm 1900 specimens of 20 species in 19 genera trapped in fish baited pitfalls and 110 specimens of 18 species in 8 genera collected from litter samples. Of the pitfall trapped specimens, the vast majority, \pm 1640 , are in the genera Acrotrichis, Storicricha, Bambara and Ptiliola. It is interesting to note that the morphological differences between the species of Acrotrichis and Storicricha in particular, compared with those of the same genera in other regions, appear to be much less pronounced. The wide range of pygidial, elytral, abdominal and other features recorded in Nearctic species is not present in the specimens from both Sarawak and Sabah most of which are smaller and paler. Furthermore, their overall similarity to species of Ptiliola, and Bambara is such that a careful microscopic study is required to separate them. As a result, many have been determined on the basis of association and not designated as paratypes. The few examples of adventive species such as A. cursitans and A. cognata however immediately stand out as being clearly alien to the fauna.

The six new species of Cissidium add further evidence to this being a highly speciose genus throughout the tropical regions in contrast to Ptenidium, which is speciose in regions to the north and west, and has also been recorded from neotropical countries, which might have been expected to occur in the material, but no specimens have been found from either Sarawak or Sabah.

\section{Acknowledgements}

I am most grateful to Dr Alfred Newton for his continuing help and support, and for checking the names and making various changes and corrections. I also owe a debt of gratitude to my colleagues Maxwell Barclay and Dr Robert Angus for making the material available and for reading through the manuscript.

\section{References}

Chung A.Y.C., Eggleton P., Speight M.R., Hammond P.M. \& Chey V.K. 2000. The diversity of the Mulu National Park. Research 90: 475-496.

Darby M. 2014a. Studies of Madagascan Ptiliidae (Coleoptera) 3: the genus Acrotrichis including twenty five new species. Zootaxa 3866 (2): 151-201. https://doi.org/10.11646/zootaxa.3866.2.1014b

Darby M. 2014b. Studies of Madagascan Ptiliidae (Coleoptera) 4: the genus Bambara including eight new species and the first account of blindness and aptery in the genus. Zootaxa 3895 (2): 151-169. https://doi.org/10.11646/zootaxa.3895.2.1

Darby M. 2017a. Erro gen. nov. a new genus of featherwing beetles from Angola and Madagascar. Zootaxa 4299 (1): 137-140. https://doi.org/10.11646/zootaxa.4299.1.10

Darby M. 2017b. Studies of Peruvian Ptiliidae (Coleoptera) 6: new species and records of Acrotrichini. Entomologist's Monthly Magazine 153: 179-203.

Darby M. 2018. Studies of Ptiliidae (Coleoptera) in the spirit collection of the Natural History Museum, London, 3: new species and records from the expedition to SW Africa in 1971-1972, Entomologist's Monthly Magazine 154: 179-196. https/doi.org/10.311084/M00138908.1544.3959

Darby M. 2019. Studies of Ptiliidae (Coleoptera) in the spirit collection of the Natural History Museum, London, 4: new records and species collected by M.E. Bacchus in Sabah (Borneo) in 1977. Entomologist's Monthly Magazine 155: 43-58. https://doi.org/10.31184/M00138908.1551.3964 
Dybas H.S. 1966. Evidence for parthenogenesis in the Featherwing Beetles, with a taxonomic review of a new genus and eight new species (Coleoptera: Ptiliidae). Fieldiana, Zoology 51: 11-52. https://doi.org/10.5962/bhl.title.2999

Hall W.E. 2000. 11.2 Ptiliidae Erichson 1845. In: Beutel R.G. \& Leschen R.A.B. (eds) Handbook of Zoology, Volume 4. Arthropoda: Insecta: Part 38. Coleoptera, Beetles. Volume 1: Morphology and Systematics: 251-261. W. De Gruyter, Berlin/New York.

Johnson C. 1971. Some Ptiliidae from the Philippines, Bismarck and Solomon Islands (Insecta Coleoptera). Steenstrupia 2: 39-47.

Johnson C. 1982. An introduction to the Ptiliidae of New Zealand. New Zealand Journal of Zoology 9: 333-376.

Johnson C. 1985. Revision of Ptiliidae (Coleoptera) occurring in the Mascarenes, Seychelles and neighbouring islands. Entomologica Basiliensia 10: 159-237.

Johnson C. 1988. Revision of Sri Lankan Acrotrichines (Coleoptera: Ptiliidae). Revue Suisse de Zoologie 95: 257-275. https://doi.org/10.5962/bhl.part.79651

Johnson C. 2007. Studies on Ptiliidae (Col.) from the Solomon Islands, 1. Entomologist's Monthly Magazine 143: 213-226.

Sawada Y. \& Hirowatari T. 2002. Systematic position of the genus Kuschelidium Johnson (Coleoptera, Ptiliidae) with description of a new species from Japan. Elytra (Tokyo) 30 (2): 431-438.

Vorst O. 2007. Ptiliola flammifera (Mlynarski) reinstated as a species distinct from P. kunzei (Coleoptera: Ptiliidae). Zootaxa 1546: 63-68.

Manuscript received: 12 November 2018

Manuscript accepted: 4 February 2019

Published on: 4 April 2019

Topic editor: Gavin Broad

Section editor: Max Barclay

Desk editor: Pepe Fernández

Printed versions of all papers are also deposited in the libraries of the institutes that are members of the EJT consortium: Muséum national d'Histoire naturelle, Paris, France; Meise Botanic Garden, Belgium; Royal Museum for Central Africa, Tervuren, Belgium; Royal Belgian Institute of Natural Sciences, Brussels, Belgium; Natural History Museum of Denmark, Copenhagen, Denmark; Naturalis Biodiversity Center, Leiden, the Netherlands; Museo Nacional de Ciencias Naturales-CSIC, Madrid, Spain; Real Jardín Botánico de Madrid CSIC, Spain; Zoological Research Museum Alexander Koenig, Bonn, Germany. 